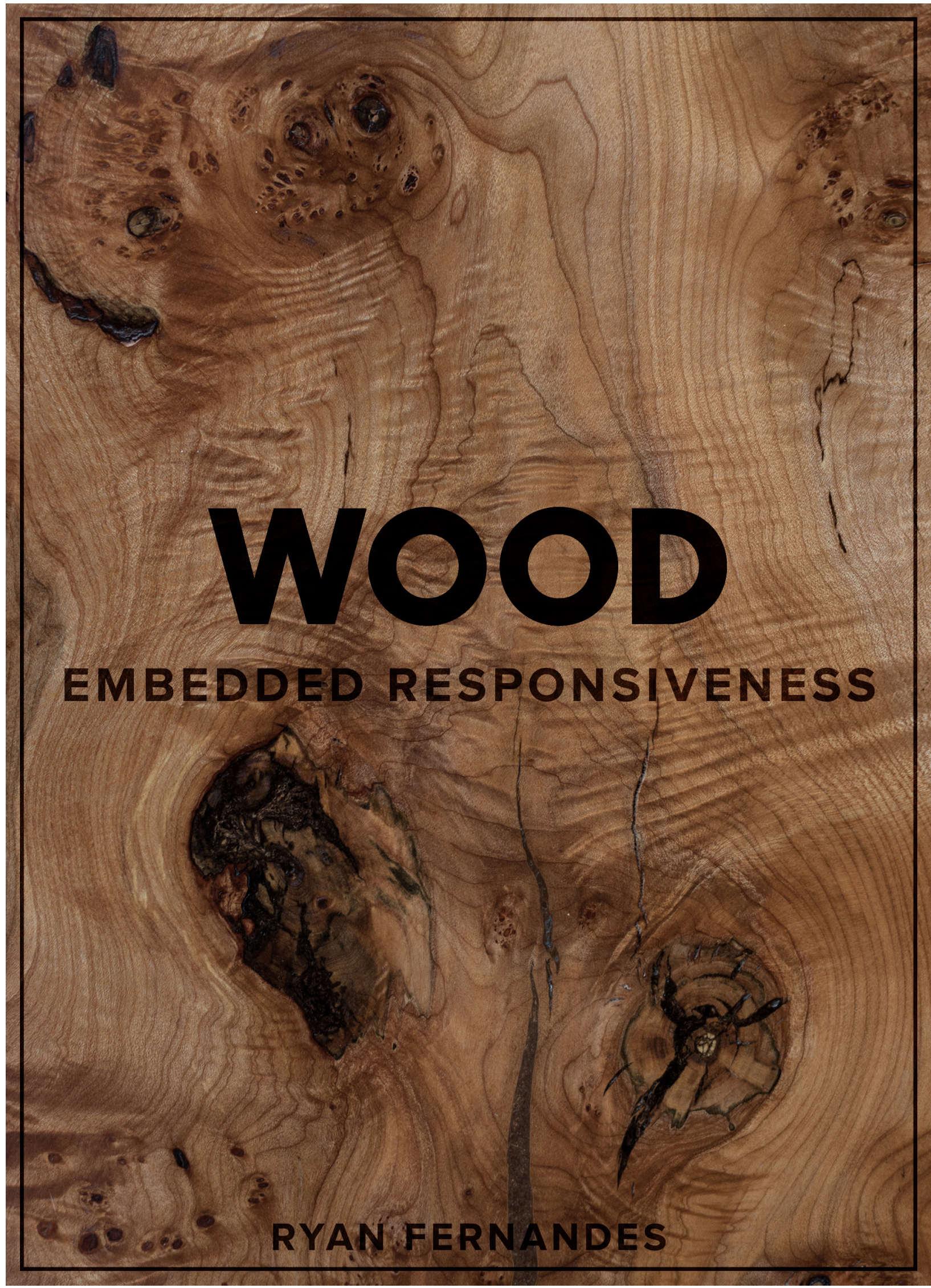





\title{
WOOD: EMBEDDED RESPONSIVENESS
}

\author{
by \\ Ryan Michael Fernandes \\ Bachelor of Architectural Science, Ryerson University, 2017 \\ A thesis \\ presented to Ryerson University \\ in partial fulfillment of the \\ requirements for the degree of \\ Master of Architecture \\ in the Program of \\ Architecture \\ Toronto, Ontario, Canada, 2019 \\ (C) Ryan Fernandes 2019
}





\section{AUTHOR'S DECLARATION}

I hereby declare that I am the sole author of this thesis. This is a true copy of the thesis, including any required final revisions, as accepted by my examiners.

I authorize Ryerson University to lend this thesis project to other institutions or individuals for the purpose of scholarly research.

I further authorize Ryerson University to reproduce this thesis project by photocopying or by other means, in total or in part, at the request of other institutions or individuals for the purpose of scholarly research.

I understand that my thesis may be made electronically available to the public.

Ryan Fernandes 



\section{WOOD: EMBEDDED RESPONSIVENESS}

Ryan Fernandes

Master of Architecture 2019

Architecture Program, Ryerson University

\section{ABSTRACT}

Architecture provides the material context in which everyday life unfolds. As a material practice, architecture is constantly in flux, responding dynamically to changes in the surrounding environment. The emergence of New Materialism, stemming from Modernist ideas, marks a shift in architecture from a discourse of symbolism and metaphors, towards one of performance and material behaviour. This thesis studies material performance in the context of wood architecture. Wood is a heterogeneous material with unique performative capacities as a result of its biological makeup. This heterogeneity is often viewed as a disadvantage when compared to more uniform materials that behave more predictably. However, when reconsidered, the unique qualities of wood can be used to inform design. This thesis investigates these qualities with a focus on the material's responsiveness to moisture. In doing so, it attempts to unravel the potential of wood in the advancement of a new wood architecture. 



\section{ACKNOWLEDGMENTS}

PAUL FLOERKE For your honest and inspiring criticism. And for your genuine interest in my work.

MARCO POLO For your valuable insights and questions that challenged me and TERRI PETERS propelled this thesis forward.

MARCO CASAGRANDE For opening up my mind to new perspectives. And for daring me ESPEN FOLGER $\varnothing$ to be hardcore.

DAS WORKSHOP For helping me bring my ideas to life. And for sharing your extensive STAFF knowledge with me.

MY FAMILY For your unconditional love and support throughout my life and education. Without you I would not be here writing these words. A special thanks to my father for bringing woodworking into my life.

MY FRIENDS AT HOME, For the laughs and distractions that kept me balanced. And for SCHOOL \& ABROAD rooting for me every step of the way.

MARIAH For encouraging me to always strive further. And for bringing me joy always. 

To the forests that sustain us. 


\section{TABLE OF CONTENTS}

$\begin{array}{ll}\text { iii } & \text { Author's Declaration } \\ \text { v } & \text { Abstract } \\ \text { vii } & \text { Acknowledgments } \\ \text { ix } & \text { Dedication } \\ \text { x } & \text { Table of Contents } \\ \text { xii } & \text { List of Figures } \\ \text { xvi } & \text { List of Appendix Figures } \\ \text { xxi } & \text { Preface }\end{array}$

$01 \quad 1$ I INTRODUCTION

052 I RESPONSIVE ARCHITECTURE

Defining Responsive Architecture

The Evolution of Responsiveness in Architecture

High-Tech vs Low-Tech

A Low-Tech Materials Approach

$13 \quad 3$ । ACTIVE MATTER

Philisophical Underpinnings

Defining Active Matter

234 I WOOD

Material Overview

Changing Attitudes Towards Wood

Wood as an Active Material

Physical and Mechanical Properties of Wood

Wood as a Humanizing Material

\section{5 | MOISTURE RESPONSIVENESS}

Reconsidering Moisture in Wood Architecture

Hygroexpansion: Microscale Analysis

Characteristics Affecting Wood's Response to Moisture 
Program

Bathing and Bathhouses

Location

History of the Portlands

The Future Port Lands \& Villiers Island

A Catalyst for Creating Community

Establishing Bathing Culture in Canada

557 | DESIGNING WITH WOOD, WATER, AND HEAT

Studies

Structural Studies

Environmental Studies

The Expression of Hygroscopicity in Architecture

73

\section{I BATHHOUSE}

Design

Conclusion

9199 | POSTSCRIPT

95 APPENDIX A I PROPERTIES OF VARIOUS WOOD SPECIES

117 APPENDIX B । MISCELLANEOUS DRAWINGS

135 BIBLIOGRAPHY 


\section{LIST OF FIGURES}

Figure 0-1: Borgund Stave Church

Image Source: Author

Figure 1-1: Programmable materials

Image Source: https://bit.ly/2Ki2nP4 (accessed January 2019).

Figure 2-1: Al Bahr Towers responsive facade

Image Source: https://bit.ly/2D4ASm1 (accessed January 2019).

Figure 2-2: A Walking City

Image Source: https://bit.ly/2GaNXMv (accessed January 2019).

Figure 2-3: Institut du Monde Arabe dynamic facade

Image Source: https://bit.ly/2GOIOR9 (accessed January 2019).

Figure 2-4: Traditional Japanese home

Image Source: https://bit.ly/2DgKMkT (accessed January 2019).

Figure 2-5: Schroder House

Image Source: https://bit.ly/2D7HFeH (accessed January 2019).

Figure 2-6: HygroSkin Meteorosensitive Pavilion

Image Source: https://bit.ly/2Kodvds (accessed January 2019).

Figure 3-1: 3D printed wood

Image Source: https://bit.ly/2UsbvFm (accessed January 2019).

Figure 3-2: Column at The Allen Memorial Art Museum (1977) in Oberlin, Ohio by Robert Venturi, Denise Scott Brown, and Associates

Image Source: https://bit.ly/2Knr3py (accessed January 2019).

Figure 3-3: Antoni Gaudi hanging string model

Image Source: https://bit.ly/2Gdpm9Z (accessed January 2019).

Figure 3-4: Frei Otto soap bubble model

Image Source: https://bit.ly/2UDvnF2 (accessed January 2019).

Figure 3-5: Josef Albers material experimentation with folded paper

Image Source: https://bit.ly/2Ut6NqU (accessed January 2019).

Figure 3-6: Bloom pavilion (2012) in Los Angeles, California by DOISU Studio Architecture

Image Source: https://bit.ly/2lqzZHZ (accessed January 2019).

Figure 3-7: Thermobimetal panel for the Bloom pavilion

Image Source: https://bit.ly/2VwGqgs (accessed January 2019).

Figure 4-1: Wood microstructure

Image Source: https://bit.ly/2UOUa9m (accessed January 2019).

Figure 4-2: Japanese craftsman working with wood in pre-industrial times Image Source: https://bit.ly/2VzmkIL (accessed January 2019).

Figure 4-3: The rise of iron during the industrial revolution 
Image Source: https://bit.ly/2WXZRyU (accessed January 2019).

Figure 4-4: Robotic fabication in the $21^{\text {st }}$ century

Image Source: https://bit.ly/2OXDF5c (accessed January 2019).

Figure 4-5: Tree section

Image Source: Author

Figure 5-1: Hygroscopic nature of pine cones

Image Source: https://bit.ly/2D6PMIB (accessed January 2019).

Figure 5-2: Types of wood cuts

Image Source: Author

Figure 6-1: Stacked wood logs

Image Source: https://bit.ly/2UpUJHh (accessed January 2019).

Figure 6-2: Grotto Sauna, Ontario, Canada, 2014, PARTISANS

Image Source: https://bit.ly/2VjlOax

Figure 6-3: Löyly, Helsinki, Findalnd, 2016, Avanto Architects. As the wood greys, the building will appear like a rock on the shoreline

Image Source: https://bit.ly/2JwyJUv

Figure 6-4: Therme Vals, Graubünden, Switzerland , 1996, Peter Zumthor

Image Source: https://bit.ly/2M2HwP2 (accessed January 2019).

Figure 6-5: Toronto Port Lands

Image Source: https://bit.ly/2I8HbJE (accessed January 2019).

Figure 6-6: The future Villiers Island

Image Source: https://bit.ly/2D5X53g (accessed January 2019).

Figure 6-7: Villiers Island

Image Source: https://bit.ly/2GaZ6gD (accessed January 2019).

Figure 6-8: Villiers Island plan

Image Source: Author

Figure 6-9: Raumlabor's Gothenburg sauna (2015), placed in a Gothenburg's port area, acts as an agent to seed the area's regeneration into a new urban quarter

Image Source: https://bit.ly/2Bi3RTj (accessed January 2019).

Figure 6-10: Indigenous sweat lodge

Image Source: https://bit.ly/2CltjrR (accessed January 2019).

Figure 6-11: Sompasauna

Image Source: https://bit.ly/2WxtSpl (accessed January 2019).

Figure 7-1: Ginzan Onsen Fujiya, Yamagata, Japan, 2008, Kengo Kuma \& Associates Image Source: https://bit.ly/2E2TcyR (accessed January 2019).

Figure 7-2: Wood-moisture studies

Image Source: Author 
Figure 7-3: Michael Thonet Chair No 14., 1881

Image Source: https://mo.ma/2HinuMH (accessed January 2019).

Figure 7-4: Eames Lounge Chair, 1956, Charles and Ray Eames

Image Source: https://bit.ly/2DV2HOC (accessed January 2019).

Figure 7-5: Twisted white oak

Image Source: Author

Figure 7-6: Wood joinery study 1

Image Source: Author

Figure 7-7: Wood joinery study 2

Image Source: Author

Figure 7-8: Wood joinery study 3

Image Source: Author

Figure 7-9: Moisture buffering studies

Image Source: Author

Figure 7-10: Bilayer composite

Image Source: Author

Figure 7-11: Impact of veneer cut on response Image Source: Author

Figure 7-12: Impact of grain direction on response Image Source: Author

Figure 7-13: Impact of aspect ratio on response Image Source: Author

Figure 7-14: Pre-programming hygromorph response Image Source: Author

Figure 7-15: Shou Sugi Ban study Image Source: Author

Figure 8-1: Bathhouse west elevation Image Source: Author

Figure 8-2: Site location Image Source: Author

Figure 8-3: Site plan Image Source: Author

Figure 8-4: Bathhouse approach Image Source: Author

Figure 8-5: Wall assembly Image Source: Author 
Figure 8-6: Twisted wood shading screen

Image Source: Author

Figure 8-7: North-western corner

Image Source: Author

Figure 8-8: Bathhouse plan

Image Source: Author

Figure 8-9: Birch bark roof

Image Source: Author

Figure 8-10: Hall

Image Source: Author

Figure 8-11: Skylight shading system

Image Source: Author

Figure 8-12: Shower room

Image Source: Author

Figure 8-13: Change room

Image Source: Author

Figure 8-14: Sauna

Image Source: Author

Figure 8-15: Lounge

Image Source: Author

Figure 8-16: Outdoor bath

Image Source: Author

Figure 8-17: Bath section

Image Source: Author

Figure 9-1: Wood veneer system

Image Source: https://bit.ly/2WWtwsj (accessed January 2019). 


\section{LIST OF APPENDIX FIGURES}

\section{APPENDIX A I PROPERTIES OF VARIOUS WOOD SPECIES}

Figure A-1: Western red cedar

Image Source: https://bit.ly/2D8rDBI (accessed January 2019).

Figure A-2: Northern white cedar

Image Source: https://bit.ly/2GOWkcl (accessed January 2019).

Figure A-3: Douglas fir

Image Source: https://bit.ly/2WYVaVv (accessed January 2019).

Figure A-4: Eastern hemlock

Image Source: https://bit.ly/2I9bZK3 (accessed January 2019).

Figure A-5: Jack pine

Image Source: https://bit.ly/2uSEONw (accessed January 2019).

Figure A-6: Red pine

Image Source: https://bit.ly/2Z3PRGu (accessed January 2019).

Figure A-7: Black spruce

Image Source: https://bit.ly/2ULQZ1Y (accessed January 2019).

Figure A-8: Hard maple

Image Source: https://bit.ly/2Z11rmT (accessed January 2019).

Figure A-9: White oak

Image Source: https://bit.ly/2U34KFb (accessed January 2019).

Figure A-10: Red oak

Image Source: https://bit.ly/2D5EbJH (accessed January 2019).

Figure A-11: Black cherry

Image Source: https://bit.ly/2UQ17JO (accessed January 2019).

Figure A-12: Black walnut

Image Source: https://bit.ly/2uYGdqs (accessed January 2019).

Figure A-13: Ipe

Image Source: https://bit.ly/2GbRFWv (accessed January 2019).

Figure A-14: Teak

Image Source: https://bit.ly/2GOnikq (accessed January 2019).

Figure A-15: American beech

Image Source: https://bit.ly/2ImtExj (accessed January 2019).

Figure A-16: European beech

Image Source: https://bit.ly/2uYcyOG (accessed January 2019).

Figure A-17: Modulus of rupture Image Source: Author

Figure A-18: Crushing strength 
Image Source: Author

Figure A-19: Janka hardness

Image Source: Author

Figure A-20: Elastic modulus Image Source: Author

Figure A-21: Shrinkage Image Source: Author

Figure A-22: Rot resistance Image Source: Author

Figure A-23: Pricing

Image Source: Author 



\section{APPENDIX B I MISCELLANEOUS DRAWINGS}

Figure B-1: North elevation

Image Source: Author

Figure B-2: East elevation

Image Source: Author

Figure B-3: South elevation

Image Source: Author

Figure B-4: West elevation

Image Source: Author

Figure B-5: Plumbing diagram

Image Source: Author

Figure B-6: Wood selection matrix

Image Source: Author

Figure B-7: Construction sequence

Image Source: Author

Figure B-8: Model looking east

Image Source: Author

Figure B-9: Model looking north

Image Source: Author

Figure B-10: Model looking south Image Source: Author

Figure B-11: Aerial model photo

Image Source: Author

Figure B-12: Joinery study

Image Source: Author

Figure B-13: Joinery study

Image Source: Author

Figure B-14: Joinery study

Image Source: Author

Figure B-15: Joinery study

Image Source: Author

Figure B-16: Envelope study

Image Source: Author 


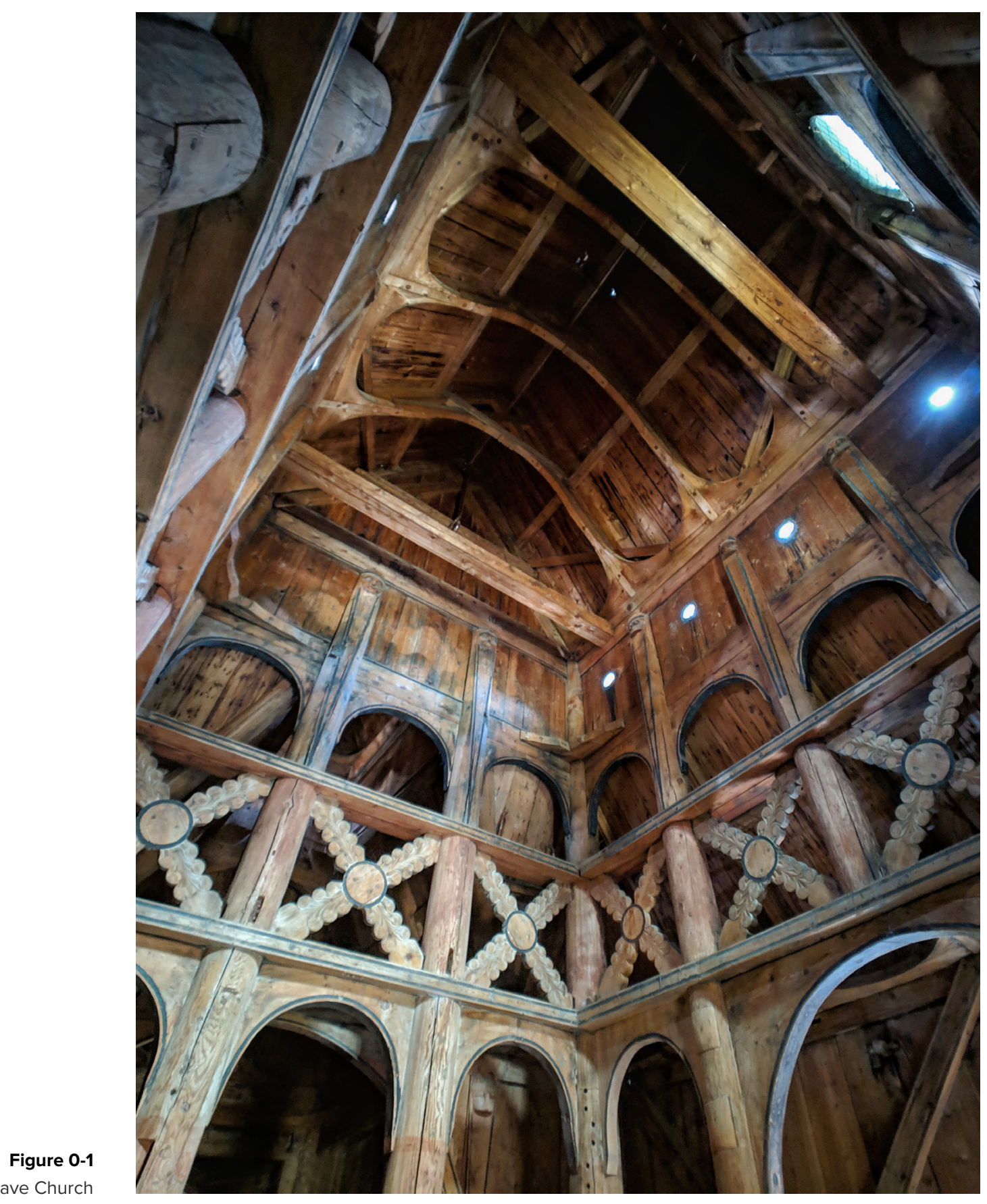

Borgund Stave Church 


\section{PREFACE}

Over the last 12 months, I have had the opportunity to participate in a New Wood Architecture initiative between Ryerson University's Department of Architectural Science and the Bergen School of Architecture. The goal of this initiative was to advance the way architects think about wood in the $21^{\text {st }}$ century. Four students from Toronto (including myself) and 5 students from Bergen took part in the initiative, along with two professors from each institution. Over the 12 month period, workshops were held to investigate new wood architecture using a hands-on approach. While the workshops in Toronto focused on the current use of wood in architecture, the workshops in Bergen looked to the past. Together these workshops provided perspectives for future wood architecture and informed much of the work presented in this thesis. 
Figure 1-1

Programmable materials

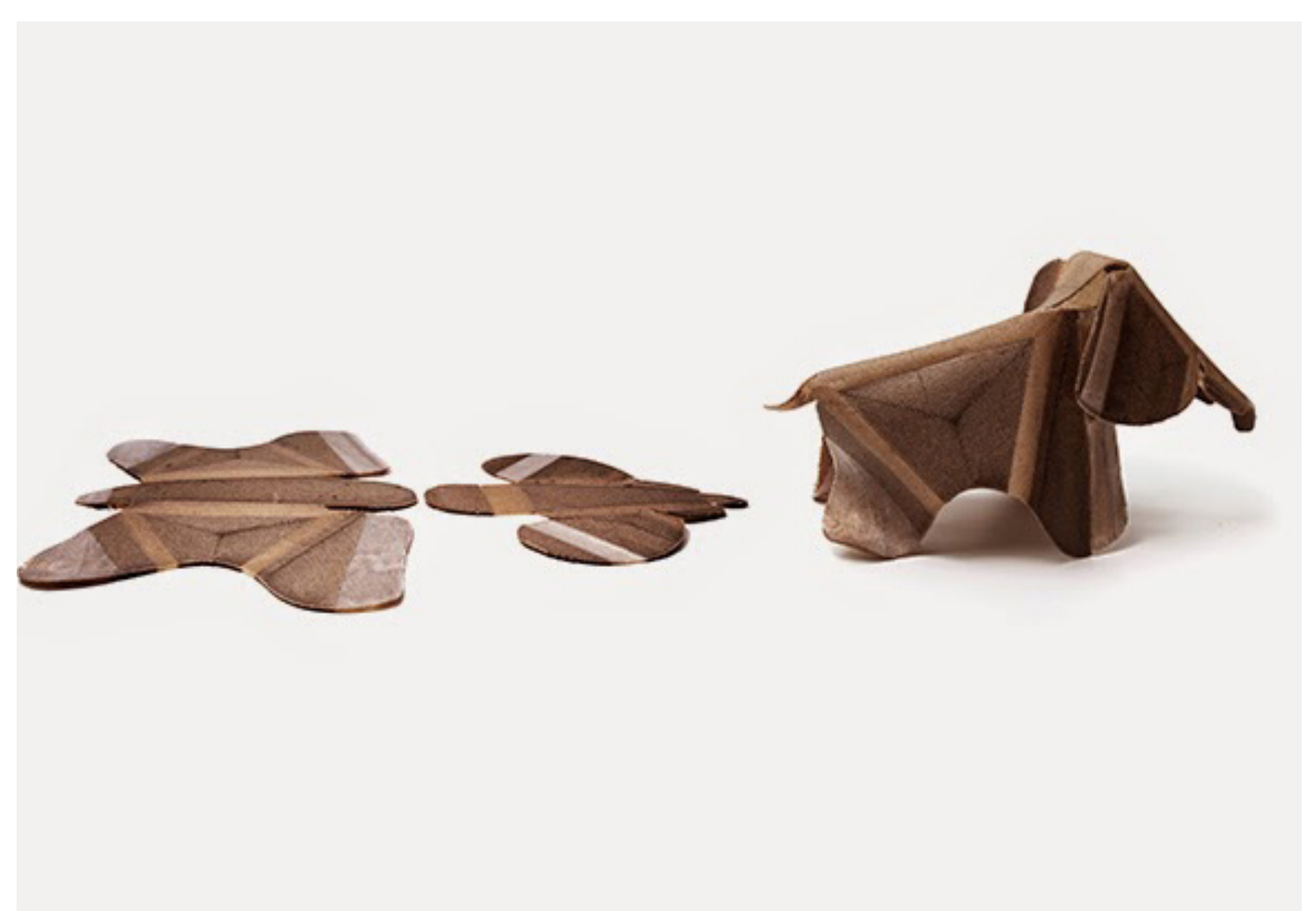




\section{1 | INTRODUCTION}

"No man ever steps in the same river twice, for it's not the same river and he's not the same man."

- Heraclitus $^{1}$

Through his famous quote, Heraclitus illustrates a world of eternal flux-a world that is constantly interacting and transforming. Though architecture has often been associated with ideas of timelessness, it is really a formation of matter and energy that is constantly transforming. That said, as Branko Kolarevic and Vera Parla argue, the impact of transformation and responsiveness in architecture has largely been neglected and insufficiently explored. ${ }^{2}$

Within the context of wood design, this thesis explores architecture as a material practice that is in constant interaction with the surrounding environment. While wood is a material that has been used in buildings for thousands of years, architects have rarely taken full advantage of its ability to facilitate and accommodate changes in the surrounding environment. In investigating the unique characteristics and capacities of wood, this thesis attempts to uncover an ecologically embedded responsive architecture capable of enhancing human experience. 



\section{NOTES}

01 Plato, Cratylus. 402a.

02 Branko Kolarevic \& Vera Parlac. Building Dynamics: Exploring Architecture of Change. (Routledge Taylor \& Francis Group, 2015), $v$. 

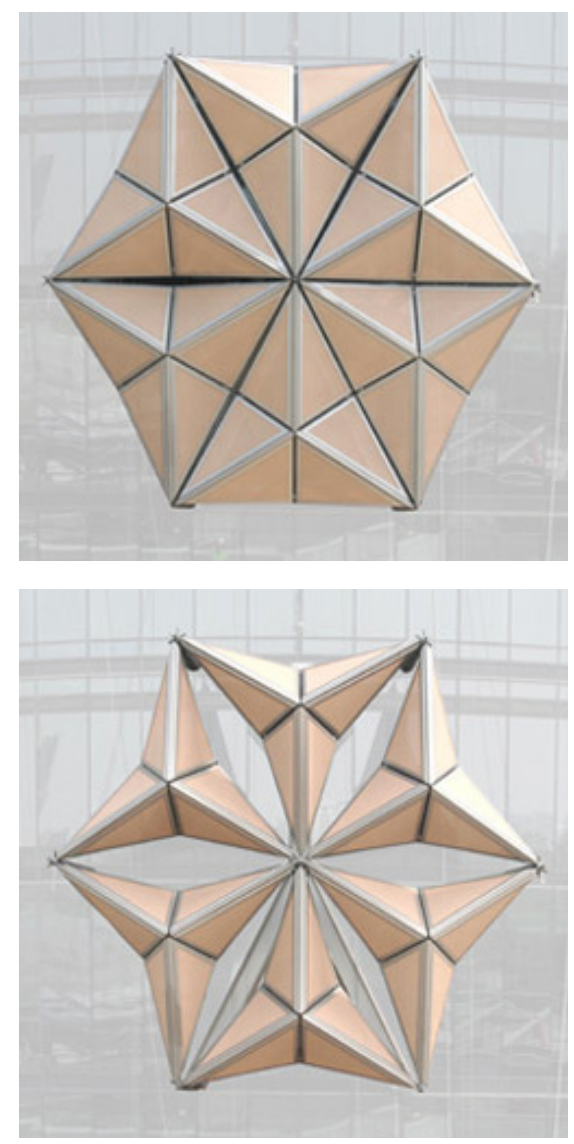

Figure 2-1

Al Bahr Towers responsive facade

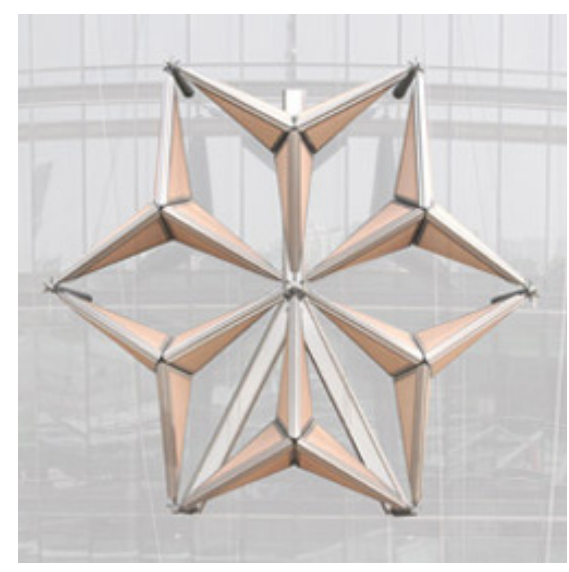




\section{2 | RESPONSIVE ARCHITECTURE}

\section{DEFINING RESPONSIVE ARCHITECTURE}

Throughout history, architects have been interested in creating spaces that have a capacity to respond to changes in the surrounding environment. In the book Building Dynamics: Exploring Architecture of Change, Branko Kolarevic and Vera Parlac assemble essays from various writers that discuss ideas of responsiveness in architecture. In general, responsive architecture can be defined as architecture that seeks to facilitate and/or accommodate change. Kolarevic and Parlac explain that responsive architecture establishes symbiotic relationships between architecture, its inhabitants, and the environment. ${ }^{1}$

\section{THE EVOLUTION OF RESPONSIVENESS IN ARCHITECTURE}

In the late 1960s and early 1970s, developments in cybernetics, artificial intelligence and information technologies led to the first concepts of responsive architecture as it is known today. ${ }^{2}$ These concepts were first envisioned in science fiction in work such as J.G. Ballard's Psychotropic House-a machine-like house that could sense and mirror the psychological state of its owners-and Ron Herron's Walking City-a hypothetical project that envisioned cities as giant robotic structures that could traverse water and land, and move to wherever they were required. ${ }^{3}$

While Ballard and Herron were among the first to imagine changeable buildings and interactive cities, it is commonly accepted that Gordan Pask set the foundations for interactive environments in the 1960s with his concept of Conversation Theory. ${ }^{4} \mathrm{His}$ 
Figure 2-2 A Walking City

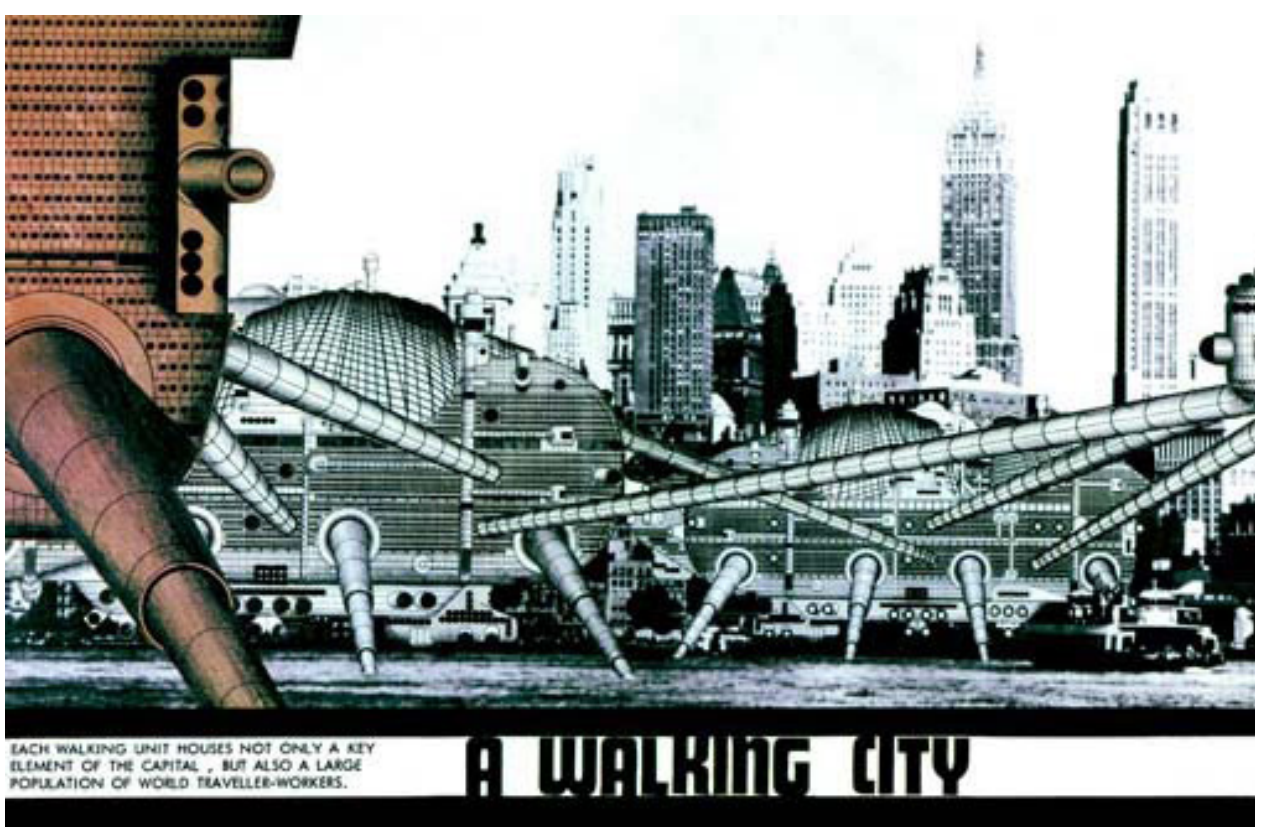

work influenced the work of Cedric Price, Nicholas Negroponte and others. ${ }^{5}$ Price went on to develop the concept of "anticipatory architecture" ${ }^{6}$, and Negroponte advocated for the integration of computers in buildings, turning buildings into "architecture machines". 7 Negroponte believed it was possible to create intelligent environments that responded to their users, suggesting "maybe a house is a home only once it can appreciate your jokes". ${ }^{8}$ Around the same time, Charles Eastman developed the concept of "adaptive-conditional architecture" which used automated systems to self-adjust based on environmental conditions and user feedback. ${ }^{9}$
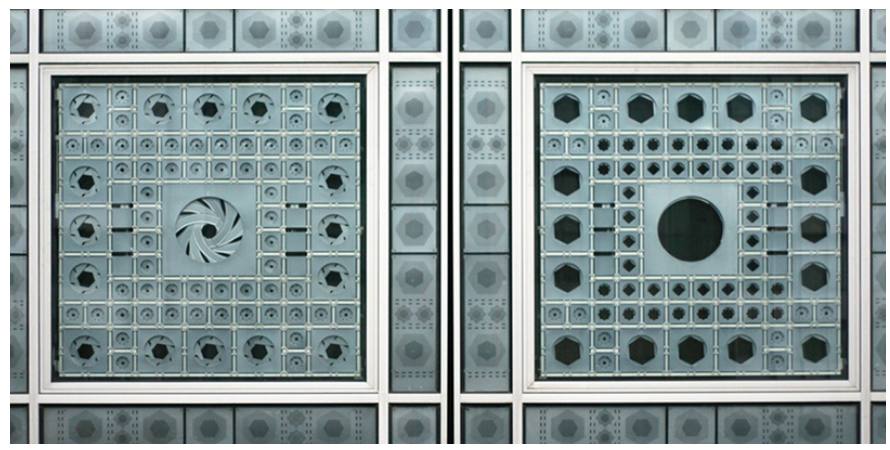

Between 1970 and 1990 there was little development in the field of responsive architecture with the exception of Jean Nouvel's Institut du Monde Arabe in Paris. Completed in 1989, it was the first large scale building to have an adaptive facade that responded to environmental changes. ${ }^{10}$ Inspired by traditional Arab lattice 
screens called "mashrabiyas", the facade is composed of photosensitive mobile apertures that open and close to control light infiltration. ${ }^{11}$

Following the completion of Nouvel's Institut du Monde Arabe, more attention was paid to building energy use within the architectural community. ${ }^{12}$ Soon, much more emphasis was placed on the building envelope, and many projects were developed that focused on dynamic, responsive facades, as well as some that focused on creating dynamic structures that could change their overall shape. ${ }^{13}$

Today the field of adaptive, responsive architecture is vast, with designs that range from the highly technical and pragmatic, to the speculative and conceptual.

\section{HIGH-TECH VS LOW-TECH}

The idea of adaptable, responsive architecture is not new. While today adaptability and responsiveness is often achieved through high-tech means, in the past it was achieved through simple technologies. For example, traditional Japanese homes can be transformed to serve various programmatic functions through the use of lightweight furniture and sliding partitions. Similarly, Gerrit Rietveld's Schroder House, built in 1924 in Utrecht can be considered an example of adaptable architecture as it features a large adaptive space on the upper floor that can be left open or subdivided into four separate rooms using sliding and revolving partitions. ${ }^{14}$

Kolarevic and Parlac suggest that active systems should not be blindly implemented without consideration of a low or no-tech alternative, as these solutions are often all that is necessary for some designs to be effective. ${ }^{15}$ They also remind us that "any cutting-edge technological system of today becomes obsolete technology rather quickly [and] [o]ne way of addressing this challenge is to design with technologies that are already 'obsolete', but which can be deployed in an innovative way". ${ }^{6}$

Figure 2-4

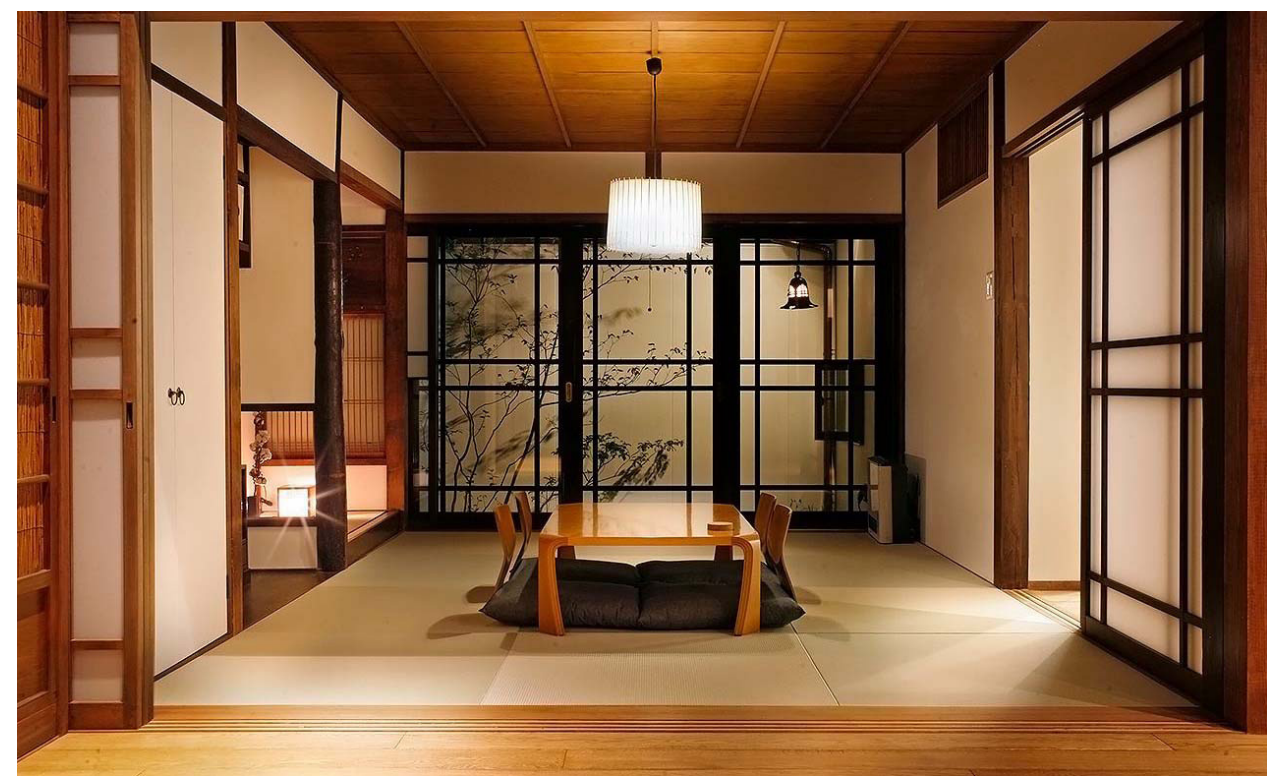


Figure 2-5

Schroder House

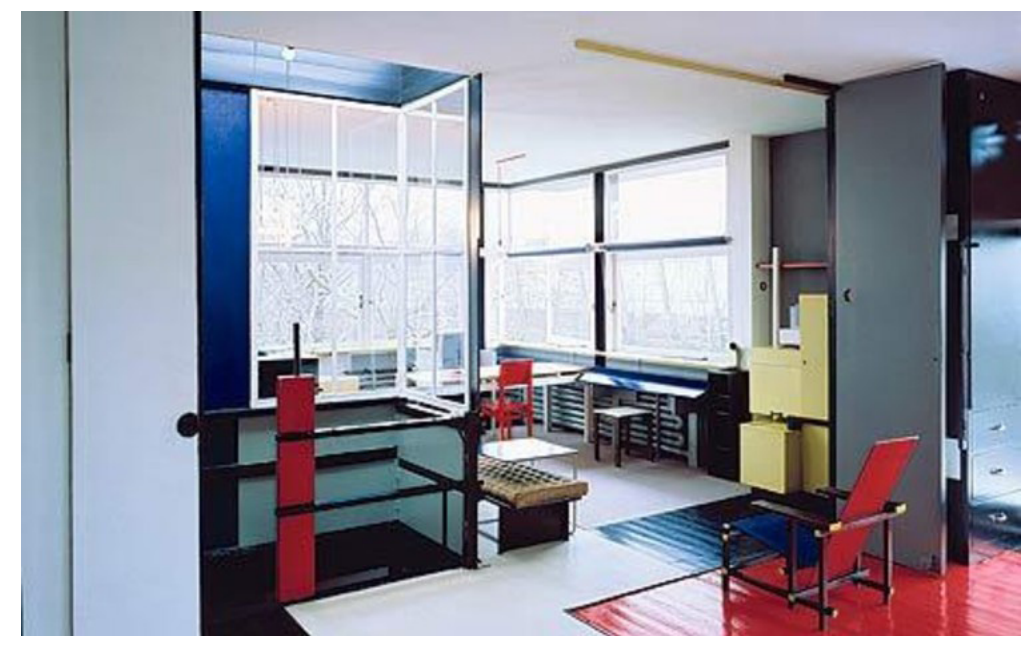

A LOW-TECH MATERIALS APPROACH

One promising approach to low-tech responsive design involves the use of materials that transform in response to external stimuli based on their inherent characteristics. This kind of an approach is especially beneficial today as minimizing building energy use is becoming a top priority for building owners and architects. That said, it requires a tremendous understanding of materiality that most designers currently do not possess.

Achim Menges argues that architecture as a material practice is still predominantly based on design approaches that struggle to take advantage of the performative capacities and richness of materials: "Materiality is usually conceptualised as a mere passive property assigned to geometrically defined elements, and materialisation is implicitly conceived as a secondary process of facilitating a scheme's realization within the physical world. Consequently, material information is understood as facilitative rather than generative". ${ }^{17}$ Menges goes on to explain how contemporary methods of digital design have reinforced this notion by placing emphasis on form generation without taking into account the specific characteristics of materials. ${ }^{18}$ Today, aspects of materiality are commonly dealt with in later phases of projects when the design needs to be adapted for fabrication and construction.

Tapping into the complexity of materials to unleash their potential in design requires a reconceptualization of materiality as a whole. This reconceptualization of materiality is happening within the field of Active Matter, where designers have been investigating the ability of materials to respond to changes in the environment based on their inherent characteristics. Likewise, this thesis presents an experimental approach of employing the innate material capacities of wood to inform design in an open-ended creative process. It aims to inject the notion of the materiality of architecture as no longer a static property and passive receptor of digitally derived form, but rather an active participant in design. 


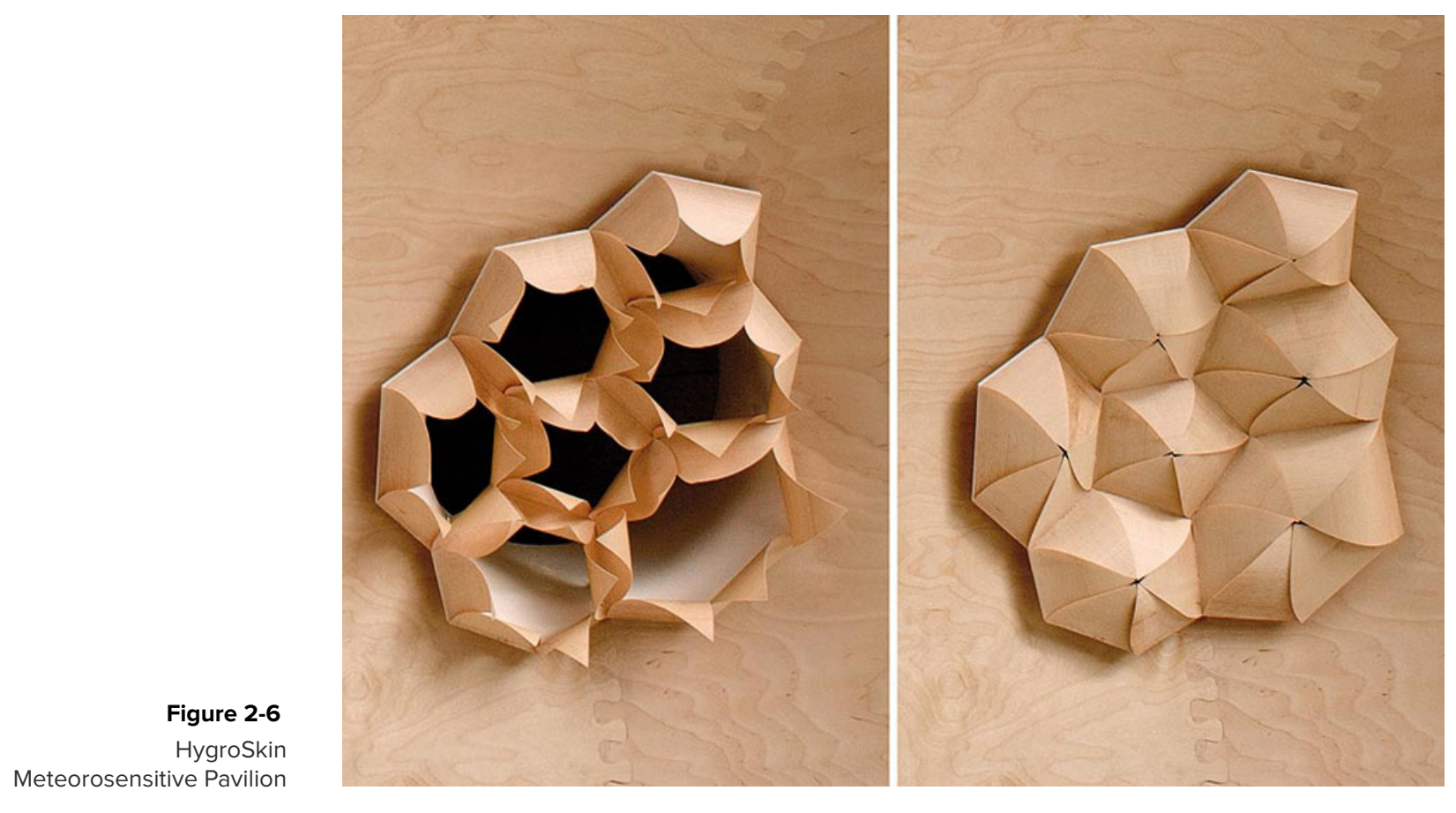




\section{NOTES}

01 Branko Kolarevic. "Towards Architecture of Change," in Building Dynamics: Exploring Architecture of Change eds. Branko Kolarevic \& Vera Parlac. (Routledge Taylor \& Francis Group, 2015), 2.

02 Ibid., 2.

03 Ibid., 2.

04 Gordon Pask, “Architectural Relevance of Cybernetics," Architectural Design (1969).

05 Kolarevic, Op. cit., 3.

06 Ibid., 3.

07 Nicholas Negroponte. Soft Architecture Machines. (MIT Press, 1975).

08 Ibid., 133.

09 Charles Eastman. "Adaptive Conditional Architecture," in Design Participation: Proceedings of the Design Research Society Conference ed. N. Cross. (Academy Editions, 1972), 51-57.

10 Kolarevic, Op. cit., 4.

11 Tim Winstanley, "AD Classics: Institut du Monde Arabe," Archdaily, accessed November 2018, https://goo.gl/VpPriF

12 Kolarevic, Op. cit., 4.

13 Ibid., 5.

14 Ibid., 11.

15 Ibid., 12.

16 Ibid., 12.

17 Achim Menges, "Material computation: Higher integration in morphogenetic design," Architectural Design 82, 2 (2012): 17.

18 Ibid., 17. 
Figure 3-1

3D printed wood

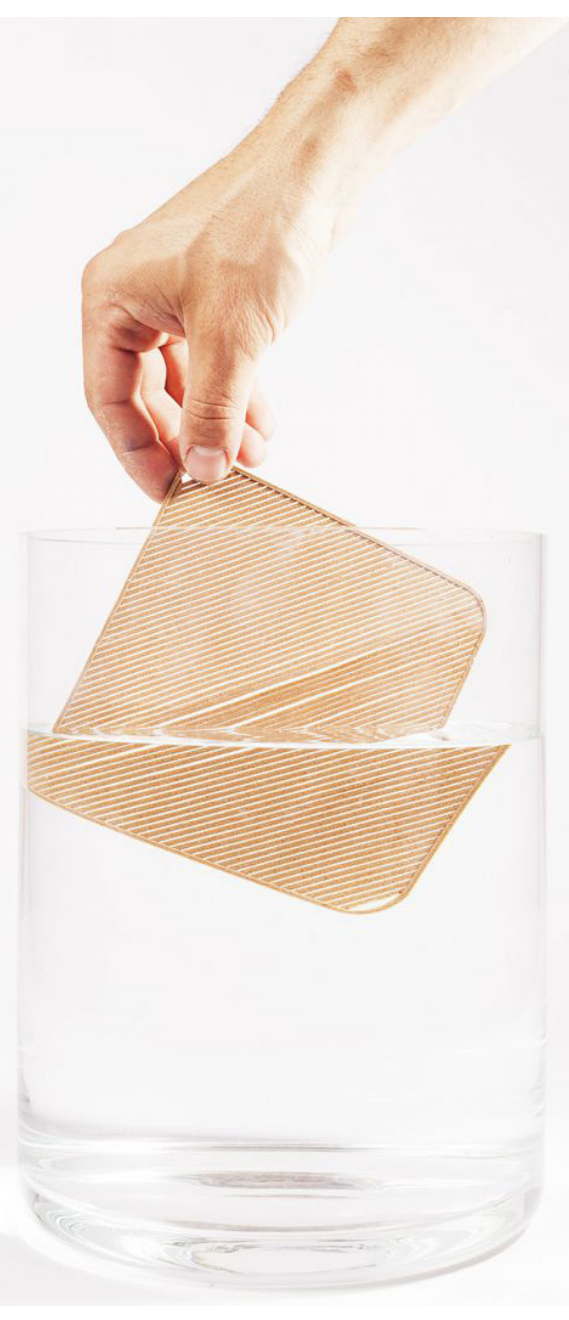




\section{3 | ACTIVE MATTER}

"We are beginning to recover a certain philosophical respect for the inherent morphogenetic potential of all materials. And we may now be in a position to think about the origin of form and structure, not as something imposed from the outside on an inert matter, not as a hierarchical command from above as in an assembly line, but as something that may come from within the materials, a form that we tease out of those materials as we allow them to have their say in the structures we create."

-Manuel DeLanda'

\section{PHILISOPHICAL UNDERPINNINGS}

In the preface to the book Active Matter, Neil Leach suggests that the emerging field of Active Matter can be linked to the shift from the representational logic of Postmodernism toward a more process-based way of thinking that is emerging in design today. ${ }^{2}$ He explains that this shift from a discourse of symbolism and metaphors to one of performance and material behaviour stems from the philosophy of New Materialism. ${ }^{3}$

Backed by philosopher Manuel DeLanda, New Materialism provides a philosophical framework for understanding the move away from emphasizing the subject, representation, and interpretation, towards focusing instead on the object, material processes, and expression in architecture. ${ }^{4}$ It is important to note that these are not entirely new ideas, but rather stem from the key tenets of Modernism. New 
Materialism rejects the Aristotelian view that "matter is an inert receptacle for forms that come from the outside", as well as the Newtonian idea of an "obedient materiality that simply follows general laws". ${ }^{5}$ Instead, New Materialism presents a new conceptualization of an active matter empowered by its own tendencies and capacities. $^{6}$

Neil Leach describes New Materialism as a drastic shift in thinking from Postmodernism. While Robert Venturi and Denise Scott Brown's 1972 book, Learning from Las Vegas: The Forgotten Symbolism of Architectural Form was a manifesto for Postmodernism, Manuel DeLanda's book, A Thousand Years of Nonlinear History, published nearly 30 years later can be read as a manifesto for New Materialism. ${ }^{7}$ While Learning from Las Vegas focuses on representation, A Thousand Years of Nonlinear History focuses on processes. Leach argues that the key to understanding New Materialism is to recognize that the emphasis today should not be on symbols but on material expressions. ${ }^{8}$ Today, building performance and behaviour is becoming more important than what a building might mean. ${ }^{9}$ In the same way that DeLanda believes we need to understand our cities in terms of the forces that shape them, Leach suggests that we need to understand architectural design in terms of material processes. ${ }^{10}$ Rather than imposing form on the built environment in a top-down manner without regard for inherent material capacities, architects operating within the arena of New Materialism are more interested in how various processes determine architectural form.

Figure 3-2

Column at The Allen Memorial Art Museum (1977) in Oberlin, Ohio by Robert Venturi, Denise Scott Brown, and Associates

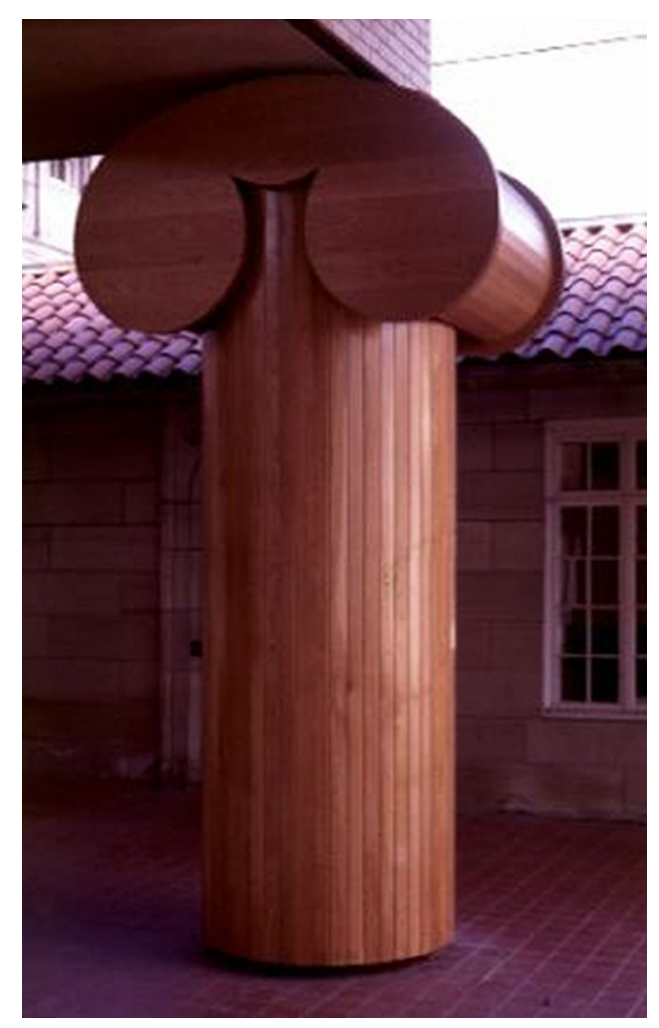


In A Thousand Plateaus, Deleuze and Guattari offer another instance of a radical shift to process-oriented thinking. ${ }^{11}$ In fact, Deleuze's distinction between the Romanesque and the Gothic highlights the key difference between Postmodernism and New Materialism that Leach describes. Whereas Postmodernism privileged the Romanesque logic of representation and symbolism, New Materialism focuses on the Gothic logic of process and material performance. In A Thousand Plateaus, Deleuze and Guattari write:

Gothic architecture is indeed inseparable from a will to build churches longer and taller than Romanesque churches. Even further, even higher. ... But this difference is not simply quantitative; it marks a qualitative change: the static relation, form-matter, tends to fade into the background in favor of a dynamic relation, material-force. It is the cutting of stone that turns it into material capable of holding and coordinating forces of thrust, and of constructing ever higher and longer vaults. The vault is no longer a form but the line of continuous variation of the stones. It is as if Gothic conquered a smooth space, while Romanesque remained partially within a striated space (in which the vault depends on the juxtaposition of parallel pillars). ${ }^{12}$

This is one example that demonstrates that the Romanesque logic in general was based on following visual rules, such as rules of proportions. ${ }^{13}$ As such it was more concerned with meaning and symbolism, versus the Gothic tradition which embodied ideas of experimentation, performance, expression, and material behaviour. ${ }^{14}$

Using the distinction between hylomorphic and morphogenetic form-making, Leach offers another way to think through the distinction between the Gothic and the Romanesque..$^{15}$ He explains that the hylomorphic approach imposes form from above regardless of the actual properties of the material, whereas a morphogenetic approach teases the form out of the material in a bottom-up process. ${ }^{16}$ Leach laments the fact that to date the dominant approach in architecture has been a hylomorphic one, with little attempt to take into account the morphogenetic capacities of materials themselves. ${ }^{17}$ Exceptions to this include the work of Antoni Gaudi, Frei Otto, Josef Albers, and more recently Achim Menges and Neri Oxman. The work of these practitioners can be described as generative material explorations. In the case of Gaudi, Otto, and Albers, the design methods that they developed enabled them to interact and explore alternate forms that could not be easily designed and visualized with the conventional tools of the time.

When designing the Sagrada Famila for example, Gaudi used weighted string models to explore possible forms of vaults, based on gravitational forces..$^{18}$ Using this method, the curves for the vaults were derived automatically since gravity was an actual constraint. ${ }^{19}$

In the late 1920s Josef Albers taught at the Bauhaus in Dessau and developed an approach to design driven by material experimentation. ${ }^{20}$ He later conducted similar material studies at the Black Mountain College in North Carolina where he continued 
Antoni Gaudi hanging string model

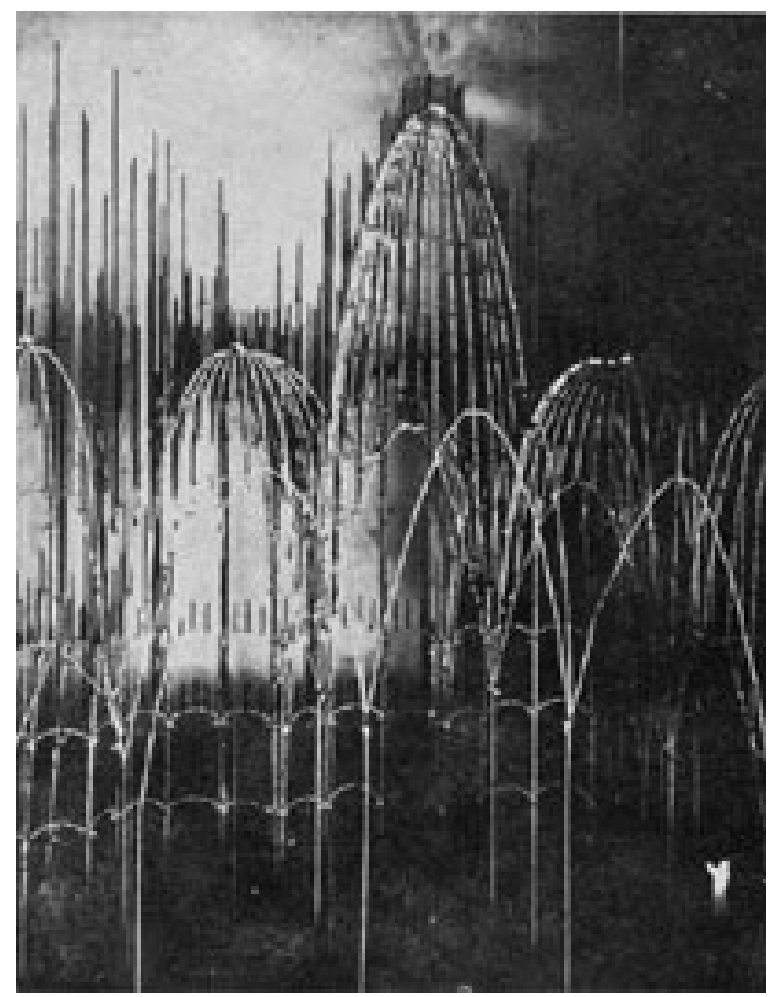

Figure 3-4

Frei Otto soap bubble model

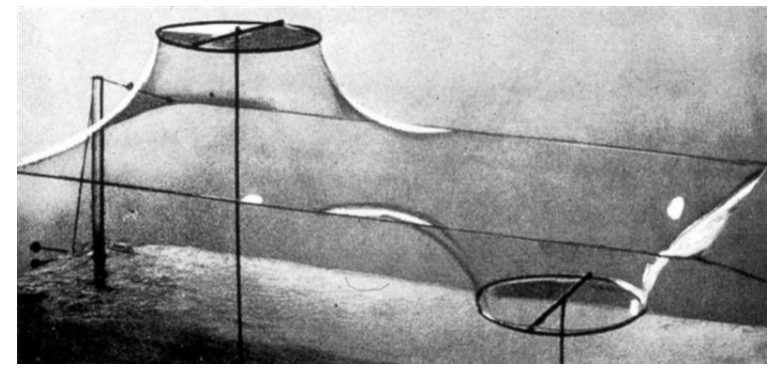

Figure 3-5

Josef Albers material experimentation with

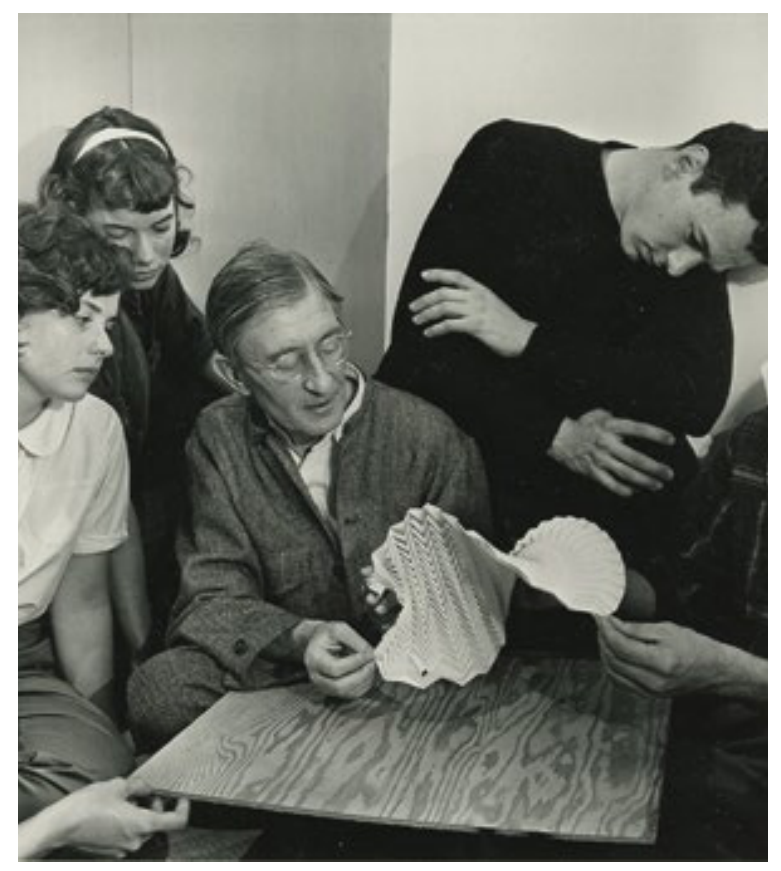

folded paper 
to emphasize open-ended experimentation. ${ }^{21}$ He believed employing established processes of materialization based on existing knowledge stifled innovation. ${ }^{22}$ Instead, Albers challenged his students to investigate the internal properties of materials through experimentation, exploiting their structural possibilities and limitations. ${ }^{23}$ In this way, the specific behaviour of materials became drivers of design. His students worked with a wide range of materials-paper, wire mesh, corrugated cardboard, glass, plastic, sheet metal, tin foil and others- ultimately unravelling new possibilities for these substances. ${ }^{24}$

Another important precedent of morphogenetic design is Frei Otto's work at the University of Stuttgart from the 1960s to the 1980s. Through experimentation, Frei Otto developed form-finding methods using various material systems, ranging from soap bubbles and sand, to grid-shells and cable-nets. ${ }^{25}$ Form-finding refers to a design technique that utilizes the self-organization of material systems that have been subjected to external forces. As such, Otto's studies enabled him to develop structures based on the inherent capacity of materials to physically compute form. ${ }^{26}$ They also served as models for developing architectural designs based on material behaviour rather than top-down determination of form and space. ${ }^{27}$ The Multihalle constructed in Mannheim, Germany in 1975 embodies Otto's experimental approach and provides an interesting example of how his form-finding method could take place at a one to one scale. It is an example of a highly material-efficient, structurally stable, double-curved form based on the elastic behaviour of wood elements. ${ }^{28}$

A contemporary example of a morphogenetic design approach comes from Neri Oxman, whose research proposes computational form-finding paired with a deep understanding of materials as heterogeneous entities. She builds her research stating: "As in Nature, when creation begins with matter, morphogenesis, or the generation of form, is a process engendered by the physical forces of Nature... Material behaviour in Nature appears to be a prerequisite for the emergence of form and yet in design, shape eternally comes first." ${ }^{29}$

As an alternative she proposes "material-based design computation", emphasizing a "non-hierarchical association between form, structure, and material". ${ }^{30}$ Oxman believes that natural forms, "which [are] directly informed by the materials from which they are made", are more efficient and less wasteful than any of mankind's own material strategies, and are thus inherently sustainable. ${ }^{31}$

Similarly, Achim Menges and his team at the Institute for Computational Design and Construction (ICD) in Stuttgart, Germany have been investigating ways to integrate and combine the fundamental material properties of wood through computational design, simulation, and fabrication processes. Menges advocates for a bottom-up morphogenetic approach, in which a material's inherent characteristics are utilized as morphogenetic drivers for form generation. He argues: "In contrast to the integral processes of material formation in nature, architecture as a material practice is still predominantly based on design approaches that struggle to fully explore the materials' richness of performative capacity and resourcefulness for design." ${ }^{32}$ 
Menges recommends an "exploratory design process of unfolding material-specific gestalt and related performative capacity". ${ }^{33}$ In other words, we must understand the microstructure of materials in relation to their external appearance and use the inherent qualities of materials to inform design. His approach attempts to unleash the performative capacity of materials without differentiating between formation and materialization processes. This approach to design requires the integration of form, material, structure and environment as one. Stemming from this, Menges embraces the idea that materials have the ability to physically compute form. He explains that in the simplest terms, computation refers to the processing of information. ${ }^{34}$ While digital computation has given architects access to new facets of the material world that were inaccessible in the past, it is important to note that computation is not limited to the digital domain. Approaching design with this understanding will have significant implications for the future built environment. In this mode of designing, materiality becomes an active participant in design rather than a passive receptor of digitally derived form.

The approach of both Menges and Oxman represent bottom-up material approaches to architecture, and distinguish morphogenetic approaches from hylomorphic ones, just as they distinguish New Materialism from Postmodernism, or the logic of process from the logic of representation. When architecture is informed by performative considerations, it becomes less about form in and of itself, and more about material formations. It is in this arena that the richness and performative capacities of materials can be unleashed to their fullest potential.

\section{DEFINING ACTIVE MATTER}

The integration of active materials with the capacity to compute behavioural responses based on environmental conditions represents a growing field in architecture and construction. Championed by Skylar Tibbits, Active Matter is a field in which digitally controlled mechanisms are replaced by material systems that are based on the inherent capacities of the materials themselves. It is focused on material processes and performance, and thus directly aligns with the ideas of New Materialism. Skylar Tibbits describes the newly emerging field of Active Matter as one that is "focused on physical materials that can assemble themselves, transform autonomously, and sense, react, or compute based on internal and external information". ${ }^{35}$ Tibbits believes we are in the midst of a true material revolution in which we can sense, compute, and actuate with materials alone. ${ }^{36}$ This materials revolution that he speaks of is not separate from the digital revolution, but rather has been enabled by it. Digital technologies have now enabled a deeper understanding of materials that can in turn be used to create smart systems.

Within the field of Active Matter, there is potential for a future world in which material assemblies at various scales can be designed to dynamically respond to changes over time. Materials will be able to transform, triggered by external stimuli such as heat, pressure, and moisture. Thus, material transformations can be triggered by 
environmental changes allowing for smart, energy-saving, and sustainable solutions in architecture and other industries.

An example of work that exists within the field of Active Matter is the work of DOISU Studio Architects, led by Doris Sung. Her studio's work focuses on the use of thermobimetal-a material that curls when heated or cooled. ${ }^{37}$ The firm is using the material to develop systems that perform in various ways in response to changes in temperature. In the case of the Bloom pavilion, thermobimetal is used to regulate lighting and ventilation. ${ }^{38}$ The pavilion consists of several panels that form a selfsupporting shell. Each panel consists of thermobimetal tiles that curl when heated, and thus filter sunlight while simultaneously flushing out hot air from within the pavilion.

This thesis focuses on one specific active material-wood. As will be seen in the following chapters, wood has the capacity to respond to various activation energies based on its inherent material characteristics. This capacity will ultimately be used to inform the design of an ecologically embedded new wood project.

Figure 3-6

Bloom pavilion (2012) in Los Angeles, California by DOISU Studio Architecture

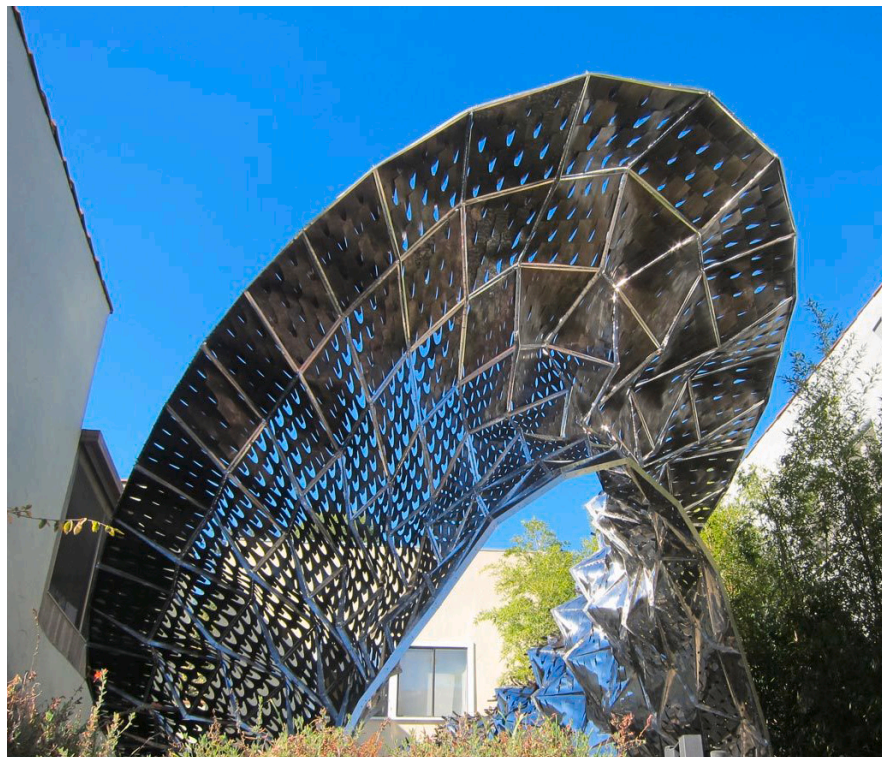

Figure 3-7

Thermobimetal panel for the Bloom pavilion

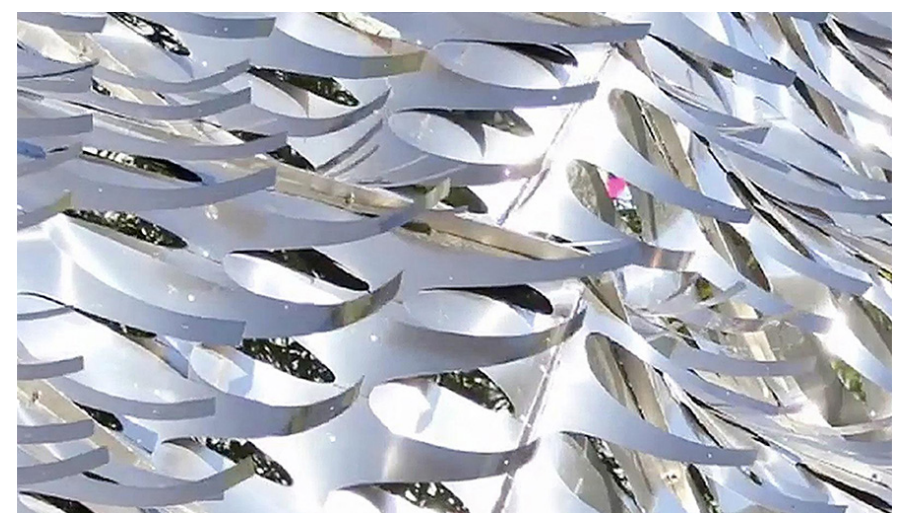


NOTES

01 Manuel DeLanda, "Uniformity and Variation: An Essay in the Philosophy of Matter."

02 Neil Leach. "Matter Matters: A Philosophical Preface," in Active Matter eds. Skylar Tibbits. (The MIT Press, 2017$), 18$.

03 Ibid., 18.

04 Ibid., 18.

05 Manuel DeLanda, “The new materiality," Architectural Design 85, 5 (2015):16.

06 Ibid., 16.

07 Leach, Op. cit., 18.

08 Neil Leach. "New Materialism in Architecture," in De-signing Design: Cartographies of Theory and Practice eds. Elizabeth Grierson, Harriet Edquist \& Hélène Fricho. (Lexington Books, 2016), 214.

09 Ibid., 214.

10 Ibid., 214.

11 Gilles Deleuze, Félix Guattari, A thousand plateaus: Capitalism and schizophrenia, (University of Minnesota Press, 1987).

12 Ibid., 364.

13 Leach (2017), Op. cit., 20.

14 Ibid., 20.

15 Ibid., 20.

16 Ibid., 21.

17 Ibid., 21.

18 Mania Aghaei Meibodi, "Generative Design Exploration: Computation and Material Practice," (Doctoral Thesis, KTH Royal Institute of Technology, 2016), 16.

19 Ibid., 17.

20 Achim Menges, "Fusing the computational and the physical: Towards a novel material culture," Architectural Design 85, 5 (2015):10.

21 Oliver Barker, “Experimentation, Not Replication,” Bauhaus, 1 (2012). https://goo.gl/uFW755

22 Menges, Op. cit., 12.

23 Oliver Barker, “Experimentation, Not Replication," Bauhaus, 1 (2012). https://goo.gl/uFW755

24 Ibid.

25 Menges, Op. cit., 10.

26 Ibid., 10.

27 Ibid., 10.

28 Ibid., 11.

29 Neri Oxman, "Material-based design computation," (PhD diss., Massachusetts Institute of Technology, 2010), 70-71.

30 Ibid., 72.

31 Ibid., 145.

32 Achim Menges, "Material computation: Higher integration in morphogenetic design," Architectural Design 82, 2 (2012): 17.

33 Achim Menges, "Material Resourcefulness: Activating Material Information in Computational Design," Architectural Design 82, 2 (2012): 37.

34 Menges, "Material computation: Higher integration in morphogenetic design," (2012), Op. cit., 16.

35 Skylar Tibbits, Active Matter. (The MIT Press, 2017), 11.

36 Ibid., 12.

37 Doris Sung, "Smart Geometries for Smart Materials: Taming Thermobimetals to Behave," Journal of Architectural Education 70, 2 (2016): 97

38 Ibid., 98 


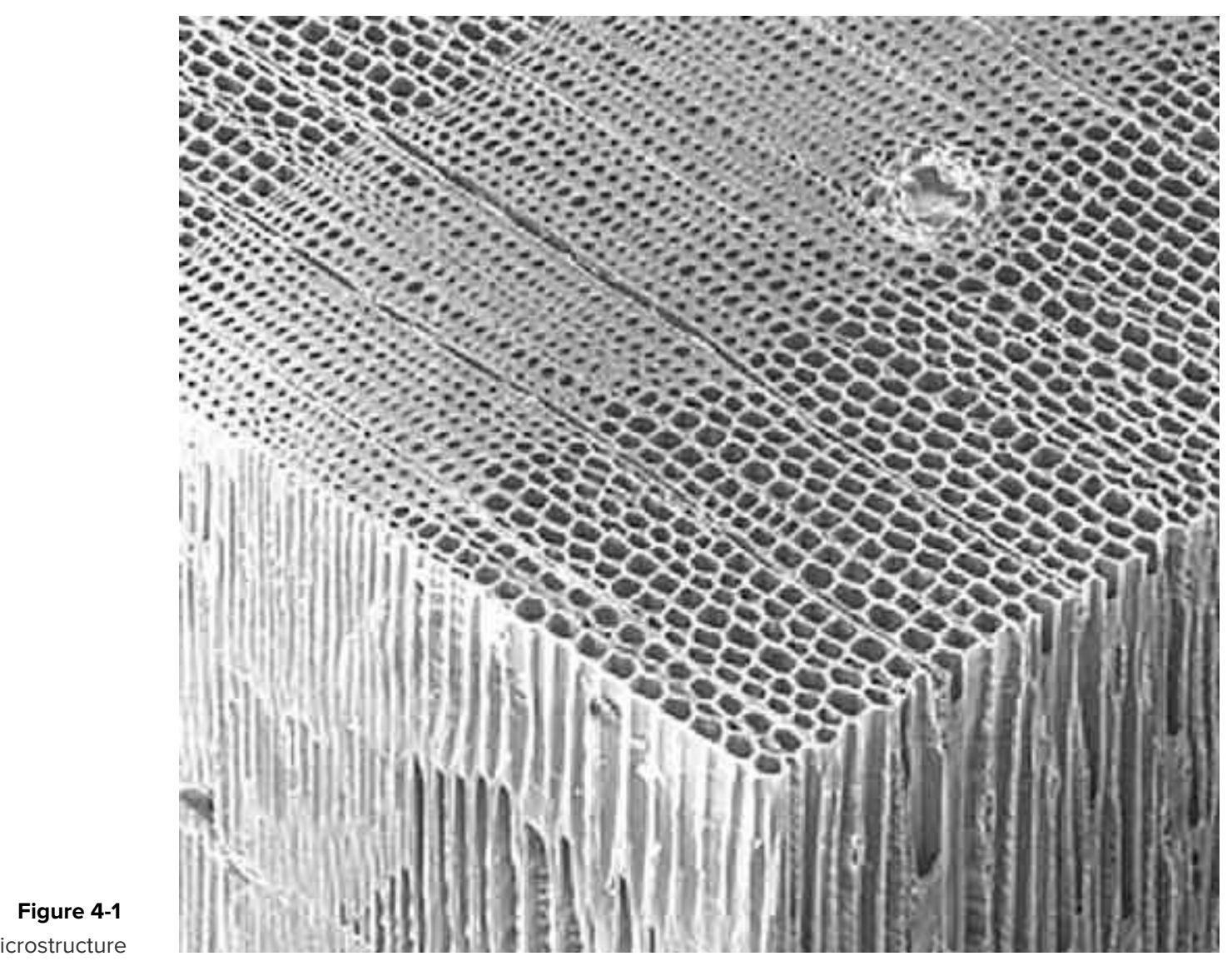

Wood microstructure 


\section{4 |WOOD}

"To use wood with intelligence, we must first understand wood."

Frank Lloyd Wright ${ }^{1}$

\section{MATERIAL OVERVIEW}

For thousands of years, humans have been building with wood. Not only does the material embody a rich history and deep cultural roots, but it also provides a remarkable synergy of structural and environmental performance. Today in light of environmental challenges and advancements in technology, wood is regarded as one of the most promising building materials for the future. Furthermore, unlike any other building material, wood has the capacity to bring warmth and comfort to a space. Through its surfaces and lines, wood communicates the history and origin of a tree, and through tectonics wood buildings convey the craft of architecture.

Wood is a fascinating example of the complexity and performative capacities of biological materials. Every piece of wood is unique and has been optimized to suit the complex biological and mechanical requirements of a tree. As part of the functional tissue of a tree, every piece of wood has a differentiated cellular anatomy that determines its material characteristics. ${ }^{2}$ When architects choose to build with wood, they must understand the origin of the wood, its unique characteristics, as well as its remarkable potential for the built environment. 


\section{CHANGING ATTITUDES TOWARDS WOOD}

In the book Advancing Wood Architecture, Achim Menges, Tobias Schwinn \& Oliver David Krieg remind us how the perception of wood in the building industry has changed considerably across different eras of technological and cultural development. ${ }^{3}$

Up until the nineteenth century, over $80 \%$ of all buildings were made of wood. ${ }^{4}$ Wood was readily available, easy to work with, and there was already a tradition of craftsmanship that was deeply rooted in society. ${ }^{5}$ These factors led to wood being one of the most commonly used building materials. ${ }^{6}$ Since materials were not standardized at this time, designers were forced to rely on a general understanding of their properties and performance, which was gained through experience and observation. The heterogeneity of wood was accepted by craftsmen, and they developed techniques to work with the peculiarities of the raw material. For example, Japanese master craftsmen had a tremendous understanding of variations in the growth patterns of trees planted at different orientations and elevations. ${ }^{7}$ This enabled them to select specific trees for specific applications. When superior strength was required, they selected tight-grained, slow-growing trees from northfacing slopes. ${ }^{8}$ When members were required to carry vertical loads, logs were split to form members with straight grain, whereas members with curved grain were selected when bending stresses had to be resisted. ${ }^{9}$

With the dawn of industrialization, the predominance of wood as a building material was challenged by materials like iron, steel, concrete, and others that had precisely defined properties. These materials were thought to be better suited to new modes of production and the changing nature of work as a result of the industrialized process. ${ }^{10}$ In addition, near the end of the $19^{\text {th }}$ century, several European and North American cities burned to the ground, which resulted in new strict regulations that limited the size and type of structures that could be built in wood. ${ }^{11}$ At the same time, advancements in reinforced concrete and steel made it possible to build taller and taller. For these reasons, wood was relegated mainly to residential and small commercial construction. ${ }^{12}$ Though wood was still considered to be an important building material, innovation slowed significantly. ${ }^{13}$

Today, the perception of wood as a building material changes yet again. One of the driving forces propelling this shift is a general rise in environmental consciousness within the global architectural community. ${ }^{14}$ We now know that the building industry is a significant contributor to greenhouse gas emissions, and we are slowly beginning to realize that wood is one of the very few environmentally sound building materials that we have. In fact, the Intergovernmental Panel on Climate Change has concluded that sustainable forest management, complemented by increased wood use, is the most effective long-term measure to mitigate the effects of global warming..$^{15}$

Another critical reason for the renewed interest in wood stems from advancements in technology that have enabled us to understand the material more fully, and work 
Figure 4-2

Japanese craftsman working with wood in pre-industrial times

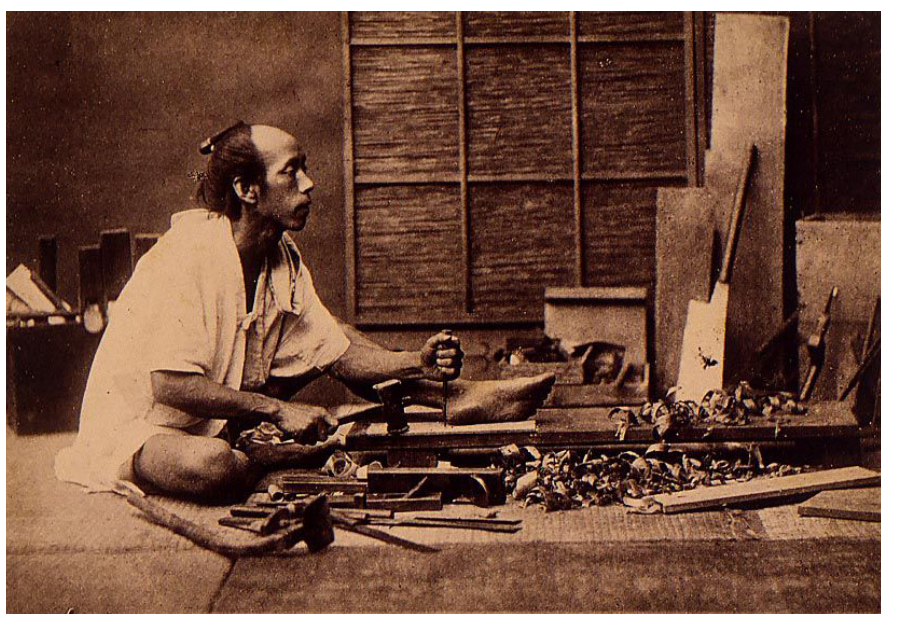

Figure 4-3

The rise of iron during the industrial revolution
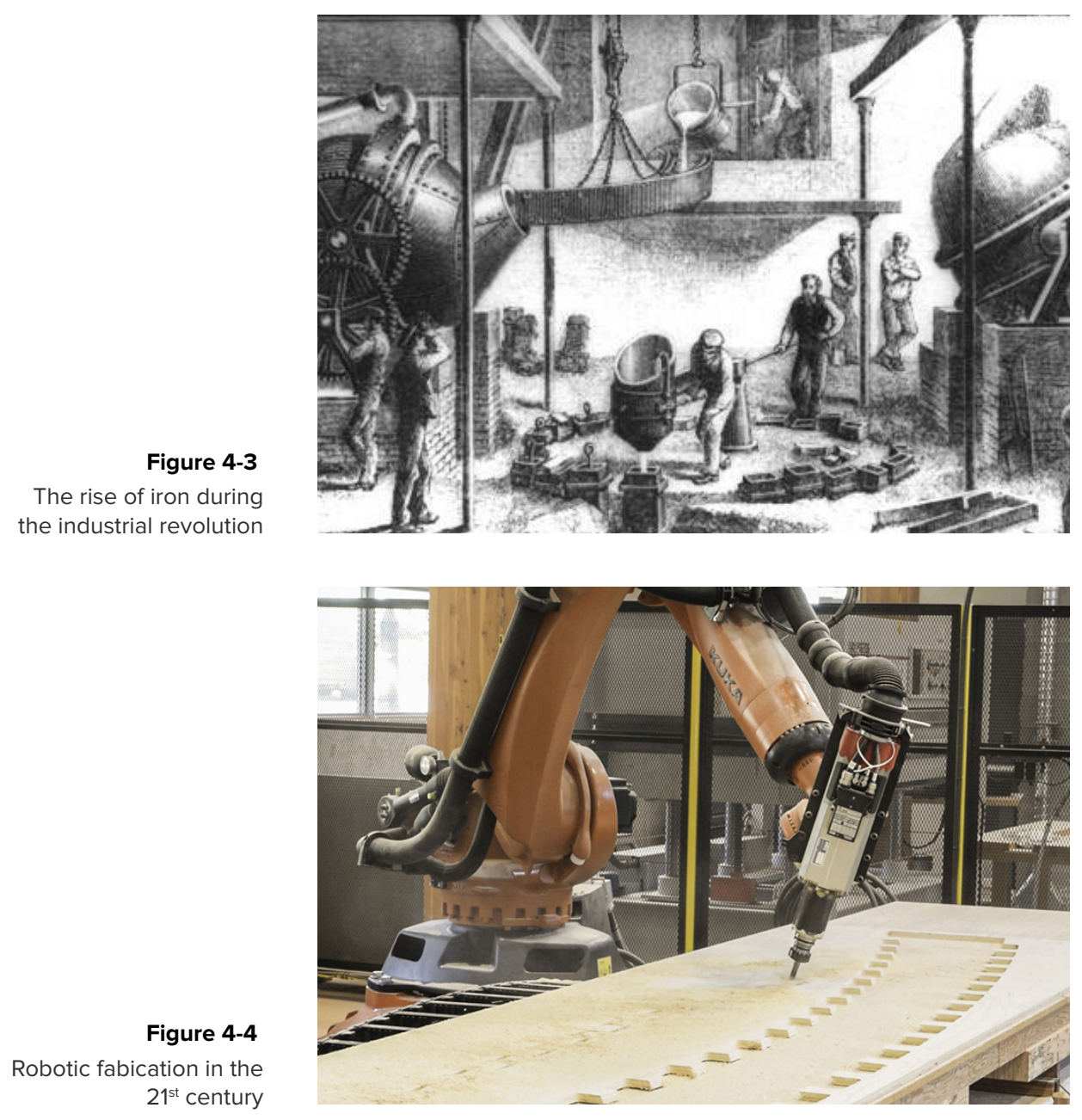
with it more easily. ${ }^{16}$ Recent advancements in technology are enabling a reconnecting of the material's inherent capacities to design and construction processes. Achim Menges argues that "[i]n this development computation plays a key role... because it equips both the designer and the maker with integrative modalities to revisit wood's intricate structure and related complex properties. ${ }^{17}$ Designers now have the ability to reconsider aspects of the material that have been largely overlooked and use them to inform design in an open-ended creative process. In the book Advancing Wood Architecture, Menges, Schwinn \& Krieg present research from Europe that focuses on using cutting edge digital technologies to integrate material, form, and structure. They also discuss completely new fabrication and assembly methods that are enabling the creation of an architecture that simply could not have emerged in the past.

With this renewed interest in wood, and technology as an enabler, designers now have the ability to reconsider aspects of wood such as its elasticity, hygroscopicity and responsiveness to heat and other stimuli that have been largely overlooked and use them to inform design.

\section{WOOD AS AN ACTIVE MATERIAL}

Wood is one of the most well-known active materials used in architecture and other crafts. In wood, material transformations are triggered by different activation energies such as heat, light, and moisture. The transformations are dependent on the material itself and its unique response to external activation energies. Therefore three aspects that must be considered when studying wood as an active material are: the material itself, its activation energies, and its transformation mechanics. A thorough understanding of these three aspects can guide a design approach that allows the innate characteristics, behaviour and capacities of the material to play a more active role in the formation of architecture.

\section{PHYSICAL AND MECHANICAL PROPERTIES OF WOOD}

Unlike most other building materials, wood is not industrially produced according to pre-specified requirements. Rather, wood is a material that grows from the earth in response to the biological requirements of trees; therefore most properties of wood are directly rooted in the microscopic make-up of the material. ${ }^{18}$

All wood is made from cellulose fibres with a high percentage of cavities. ${ }^{19}$ These fibres have a distinct alignment to the direction of tree growth, which is for the most part the longitudinal direction of the trunk..$^{20}$ As a result, many characteristics of wood are directionally dependent, making it an anisotropic material. Generally speaking, the characteristics of any given piece of wood depend greatly on the tree species, where the tree was grown, when the tree was cut, and what part of the tree the wood comes from.

The following sections provide an overview of the physical and mechanical properties of wood and the relationships that exist between them. A breakdown 
of these properties for various species of wood can be found in Appendix A. The appendix also includes graphs that compare the various species of wood based on specific properties. This mapping exercise will later be used as a tool to reliably specify woods for specific architectural applications in the context of a design project. The selection of wood species to be studied was largely based on local availability in relation to the site of the design project.

Figure 4-5 Tree section

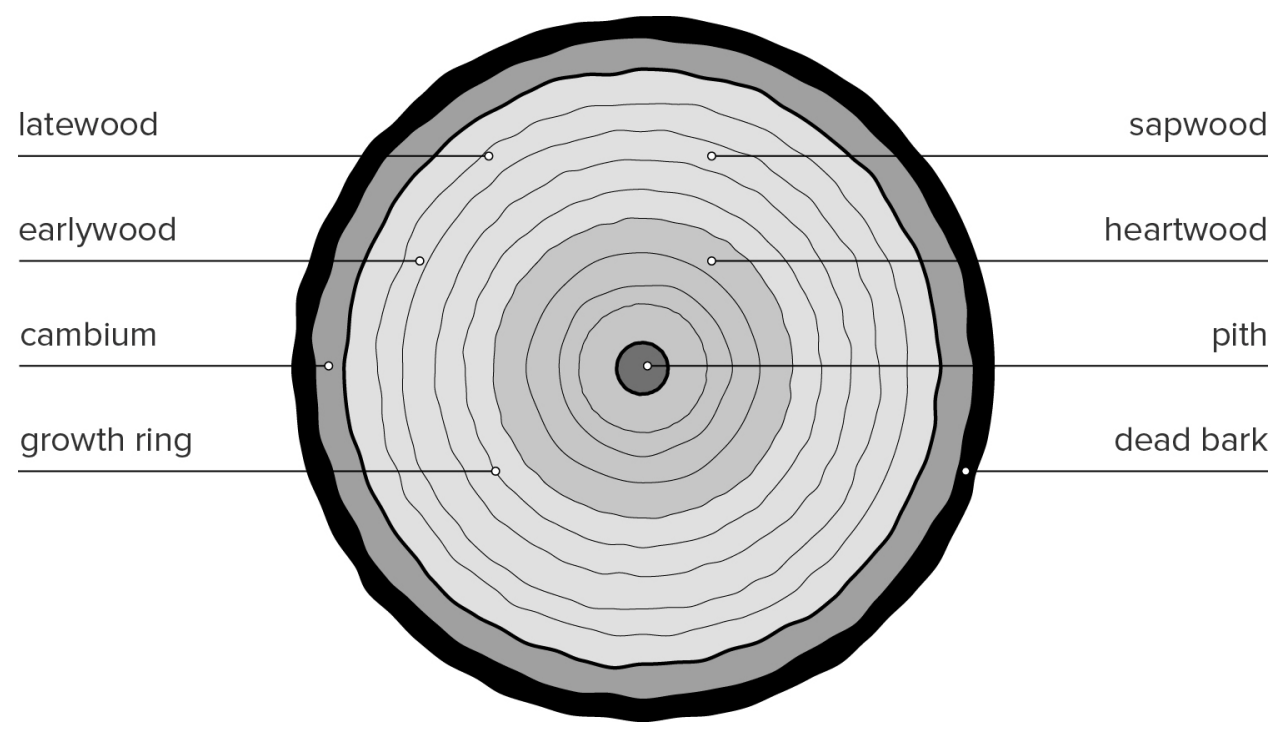

\section{Appearance}

Though we have come to appreciate wood for all of its sensual qualities such as its texture and smell, the appearance of wood is often central to our experience of the material. The appearance of wood varies significantly from species to species, and depends on the biological and physical processes that have occurred within the wood. Therefore through its appearance, every piece of wood communicates its own unique history.

\section{Density}

Compared to other building materials, wood possesses tremendous strength at a relatively low density, making it a very efficient and lightweight material. ${ }^{21}$ With that said, each species of wood possesses a different density based on its microstructure. Knowing how different species of wood compare in density is useful when selecting woods for specific applications. For example, spruce is a relatively light but strong species of wood, and it is therefore often used for structural beams and columns. On the other hand, beech is a hard and abrasion-resistant wood, often used for stair treads. ${ }^{22}$ 


\section{Strength}

Since wood is a building material with a distinct alignment of its fibers in the direction of growth, its strength characteristics vary significantly in each axis. ${ }^{23}$ As cited by Menges, Schwinn \& Krieg in the book Advancing Wood Architecture, parallel to the grain wood has almost the same compressive strength as concrete, and has a greater tensile loading capacity than steel for the same weight, but perpendicular to the grain, it is not nearly as strong. ${ }^{24}$

\section{Weathering Resistance}

The weathering resistance of wood varies significantly from species to species. ${ }^{25}$ In general, heartwood-the dense inner part of a tree trunk-is much more resistant to moisture and decay, when compared to sapwood-the soft outer layer of a tree trunk between the heartwood and bark. ${ }^{26}$ In addition, wood will decay at a very slow rate if it is kept consistently dry. ${ }^{27}$ The reverse is also true. If kept submerged in water, wood decays very slowly due to a lack of oxygen in the water. ${ }^{28}$

\section{Elasticity}

Wood is composed of a multitude of flexible cellulose fibres that allow elastic bending while maintaining structural capacity. ${ }^{29}$ The elasticity of wood is dependent on wood type, which part of the tree the wood came from, the wood's current moisture content, and the thickness of the wood. Although wood's elasticity is well suited for the construction of complex curvature from initially simple planar elements, it has rarely been employed in architecture.

\section{Hygroscopicity}

Wood is a hygroscopic material, meaning it absorbs moisture from the atmosphere when dry and releases it when wet, thereby maintaining a moisture content in equilibrium with the surrounding relative humidity. ${ }^{30}$ As wood absorbs and releases moisture, it exhibits anisotropic dimensional change. The magnitude, strength, and actuation range of these changes are remarkable when compared to those of synthetic materials. These changes vary significantly along the three orthogonal directions-tangential, radial, and longitudinal. Across a range of common species with wood moisture content between $6 \%$ and $30 \%$, dimensional changes occur on average $7.95 \%$ tangentially, $4.39 \%$ radially, and a negligible amount longitudinally. ${ }^{31}$ As cited by Wood et al..$^{32}$, the extremely high forces resulting from the dimensional changes that occur at the cellular level (measured as the swelling pressure of wood) have a measured value of $91 \mathrm{MPa}$ and a theoretical value of $158 \mathrm{MPa}$. Anecdotally, this force is exemplified by the known use of hygroscopic expansion in wooden wedges as a method for splitting granite stone from quarries in ancient Egypt. ${ }^{33}$

\section{Thermal Properties}

The inherent thermal properties of wood make it an excellent building material for architecture. Four important thermal properties of wood are thermal conductivity, specific heat, thermal diffusivity, and thermal expansion. ${ }^{34}$ 
Thermal conductivity is a measure of the rate of heat flow through materials. ${ }^{35}$ As a result of its porosity, the thermal conductivity of wood is a fraction of the conductivity of most metals, making it a good insulating material. ${ }^{36}$

The specific heat of a material is the ratio of the heat capacity of the material to the heat capacity of water. ${ }^{37}$ The specific heat of wood is an important physical property that affects wood drying, the fire performance of wood, and other characteristics related to thermal performance. The specific heat of wood depends on the temperature and moisture content of the wood but is practically independent of density or species. ${ }^{38}$

Thermal diffusivity is a measure of how quickly a material can absorb heat from its surroundings; it is the ratio of thermal conductivity to the product of density and specific heat. ${ }^{39}$ Because of the small thermal conductivity and moderate density and specific heat of wood, the thermal diffusivity of wood is much smaller than that of other structural materials such as metals, brick, and stone. ${ }^{40}$ For this reason, wood does not feel extremely hot or cold to the touch as some other materials do.

The coefficient of thermal expansion is a measure of the change of dimension caused by temperature change. ${ }^{41}$ For completely dry wood, the coefficient of thermal expansion is always positive, meaning that the wood will expand when heated and contract when cooled. ${ }^{42}$ However, wood that contains moisture reacts to varying temperature differently than dry wood. ${ }^{43}$ When moist wood is heated, it will expand due to normal thermal expansion, but it will shrink to a volume smaller than the initial volume due to a loss in moisture content. ${ }^{44}$ Therefore, unless wood is very dry, the shrinkage due to moisture loss as a result of heating will be greater than the thermal expansion, so the net dimensional change from heating will be negative. ${ }^{45}$

\section{Aroma}

The aroma of most species of wood is perceived as natural and pleasant, and it is often associated with a positive impact on health. In fact, in their research, Ikei, Song \& Miyazaki cite studies that have found the aroma of wood to have a positive impact on human physiological responses. ${ }^{46}$

The aroma of wood varies greatly between different wood species. For example cedar has a distinct lingering aroma, whereas jack pine has a faint, resinous aroma. Often, the aromatic potency of woods will subside over time. In fact, in fully seasoned wood there may be little to no detectable aroma. ${ }^{47}$ On the other hand, some woods such as sandalwood and hinoki retain their scent for very long periods of time. In addition, moistening and/or heating wood often helps to enhance the natural aroma of the wood. ${ }^{48}$

\section{Acoustic Properties}

The acoustic properties of a material are determined by its sound absorption and sound insulation abilities. ${ }^{49}$ Wood is a naturally sound-dampening material. 
Its network of small interlocking cells converts sound energy into heat energy by frictional resistance within these cells and by vibrations within their sub-structure. ${ }^{50}$ Because of this internal friction, wood has a stronger sound dampening capacity than most structural materials. ${ }^{51}$ For example, while a concrete wall also reflects sound, it does so in a much harsher way, resulting in stronger echoes. The natural acoustic properties of timber control this excessive reverberation by reducing the transmission of sound vibrations. ${ }^{52}$ Sound absorption values for wood vary with moisture content, grain direction, and density. ${ }^{53}$

\section{WOOD AS A HUMANIZING MATERIAL}

It is often said that wood has the ability to humanize the spaces we inhabit. In the book Sustainable Timber Design, the authors suggest that our preference for wood over other materials may be hardwired into our genes, through the legacy of our ancestors who turned to wood for shelter and warmth. ${ }^{54}$ Due to the fact that wood is grown from the earth and is widely available and easily worked, it is only natural that our ancestors would develop an affinity for the material. However, this is surely not the only reason that humans are attracted to wood.

In addition to being readily available and easy to work with, wood provides an extension of life that we appreciate, since every piece of wood comes from a tree that was once living. As such, every piece of wood is unique and communicates the history of a tree. Using wood in the built environment helps to satisfy our need to situate ourselves in nature-a need that has persisted ever since we started spending the majority of our time in highly developed environments. Satisfying this need by living and working in spaces made of wood, or by immersing ourselves in lush greenery is important for our health and wellbeing. In fact, in Japan it is common to practice shinrin-yoku or "forest bathing", which refers to the act of spending time in forests practicing mindfulness, in order to obtain rejuvenating benefits to the mind, body and spirit.

In studying the human attraction to wood, it is important to consider that in some nations such as Japan and Norway, wood is tied to national heritage. In Japan wood is regarded as a precious resource, and the people have been using the material for hundreds of years. It is therefore likely that the Japanese have developed a greater appreciation for the material than most other nations. The same can be said for Canada-a nation with some of the world's largest forests, and one that has been built on the foundation of forestry.

Though there are many reasons why humans are drawn to wood, the fact remains that we do have an affinity for the material. With this in mind, and knowing the

environmental virtues of wood, we must begin to ask more of its potential, and attempt to find a fresh expression for the material. 


\section{NOTES}

01 Frank Lloyd Wright, "In the Cause of Architecture: Wood," Architectural Record (1928).

02 Achim Menges, Tobias Schwinn \& Oliver David Krieg, Advancing Wood Architecture, (Routledge, Taylor \& Francis Group, 2017$), 3$.

03 Ibid., 97.

04 ibid., 3.

05 Ibid., 97.

06 Ibid., 97.

07 Jim Taggart, Toward a culture of wood architecture, (Abacus Editions, 2011), 13.

08 Ibid., 13.

09 Ibid., 13.

10 Menges, Schwinn \& Krieg, Op. cit., 97.

11 Taggart, Op. cit., 40.

12 Ibid., 40.

13 Ibid., 40.

14 Menges, Schwinn \& Krieg, Op. cit., 98.

15 Intergovernmental Panel on Climate Change, "Climate Change 2007: Working Group III: Mitigation of Climate Change," IPCC.

16 Menges, Schwinn \& Krieg, Op. cit., 98.

17 Ibid., 98.

18 Achim Menges, "Material Resourcefulness: Activating Material Information in Computational Design," Architectural Design 82, 2 (2012):37.

19 Menges, Schwinn \& Krieg, Op. cit., 2.

20 Menges, Op. cit., 40.

21 Josef Kolb. Systems in timber engineering: Loadbearing structures and component layers, (Birkhäuser, 2008$), 32$.

22 Ibid., 32.

23 Ibid., 32.

24 Menges, Schwinn \& Krieg, Op. cit., 2.

25 Kolb, Op. cit., 32.

26 Artem Holstov, Ben Bridgens \& Graham Farmer, "Hygromorphic materials for sustainable responsive architecture," Construction and Building Materials 98 (2015): 575.

27 Laboratory, Building News Inc. \& Forest Products. Wood Engineering Handbook (2 ${ }^{\text {nd }}$ Edition), (BNI Publications Inc., 2000$), 322$.

28 Ibid., 322.

29 Menges, Op. cit., 40.

30 Achim Menges \& Steffen Reichert, "Material capacity: Embedded responsiveness," Architectural Design 82, 2 (2012): 54.

31 R. Bruce Hoadley. Understanding Wood: A Craftsman's Guide to Wood Technology. (Taunton Press, 1980).

32 Dylan Wood et al., "Material computation-4D timber construction: Towards building-scale hygroscopic actuated, selfconstructing timber surfaces," International Journal of Architectural Computing 14, 1 (2016): 51.

33 Ibid., 51

34 Laboratory, Building News Inc. \& Forest Products. Wood Engineering Handbook (2 ${ }^{\text {nd }}$ Edition), (BNI Publications Inc., 2000$), 324$.

35 Ibid., 324.

36 Ibid., 324.

37 Ibid., 324

38 Ibid., 325 .

39 Ibid., 324.

40 Ibid., 325.

41 Ibid., 324.

42 Ibid., 325.

43 Ibid., 326. 
44 Ibid., 326.

45 Ibid., 326.

46 Harumi Ikei, Chorong Song \& Yoshifumi Miyazaki, "Physiological Effects of Wood on Humans: A Review," Journal of Wood Science 60, 1 (2017).

47 "Wood Odor," The Wood Database, accessed November 2018, https://goo.gl/uu1msR

48 Ibid.

49 American Institute of Timber Construction, Timber Construction Manual, (John Wiley \& Sons, Inc., 2012 ), 55.

50 "Acoustic Performance," Wood Solutions, accessed November 2018, https://goo.gl/Ddm1wr

51 Ibid.

52 Ibid.

53 American Institute of Timber Construction, Op. cit., 55.

54 Michael Dickson \& Dave Parker. Sustainable Timber Design, (Routledge, 2015), xviii. 


\section{Figure 5-1}

Hygroscopic nature of

pine cones
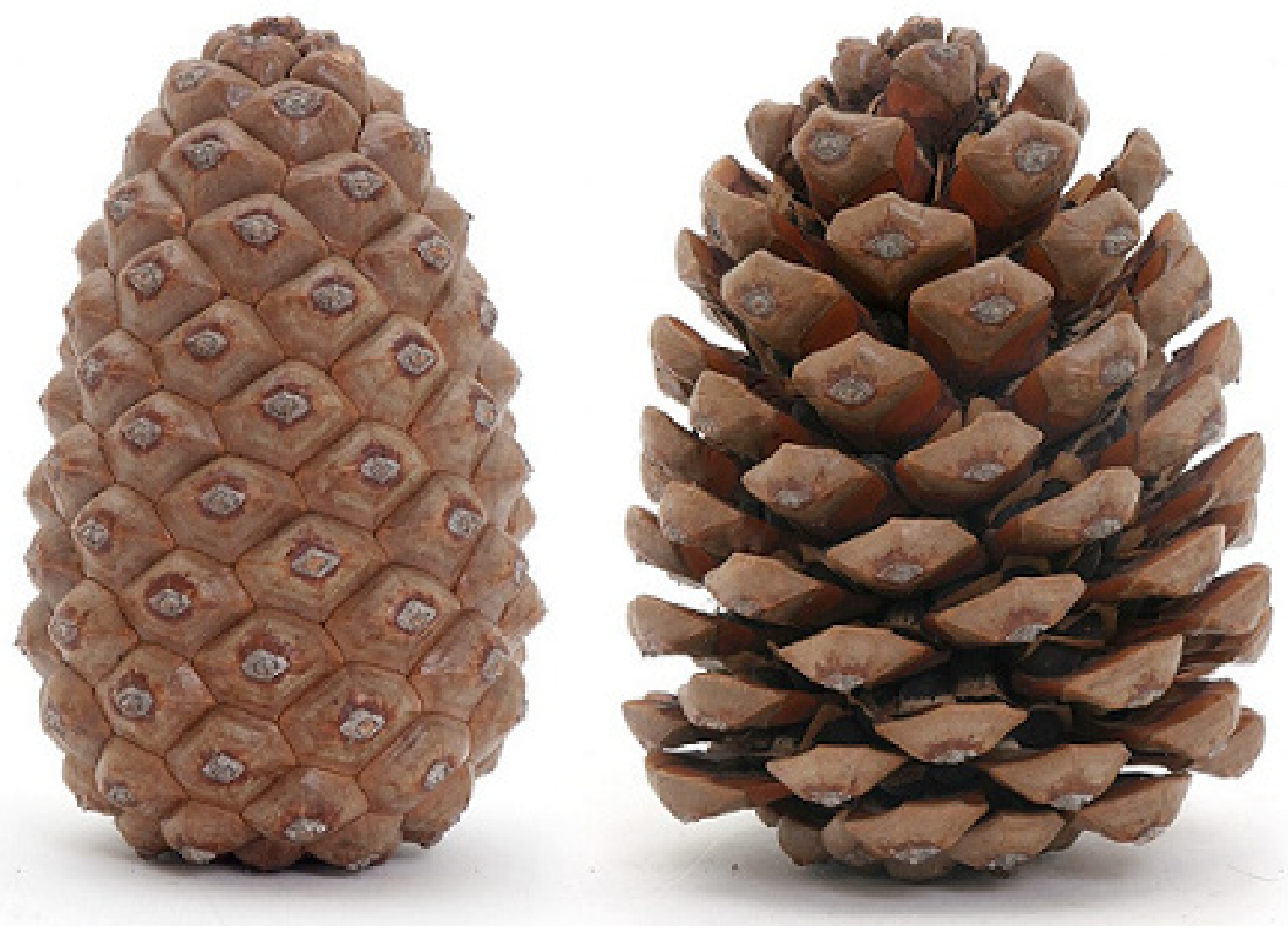


\section{5 | MOISTURE RESPONSIVENESS}

"In light of both the rapid technological advances we are experiencing and the severe environmental challenges architecture is facing, wood can no longer be understood as an outdated material with inferior properties and idiosyncratic characteristics as compared to industrially produced building materials. Instead, it is increasingly regarded as a most promising building material for the future with unrivalled environmental advantages."

Achim Menges, Tobias Schwinn, Oliver David Krieg1

\section{RECONSIDERING MOISTURE IN WOOD ARCHITECTURE}

After studying wood in great depth, it became clear that one of the most overlooked capacities of the material is its ability to respond dynamically to moisture. Often, the hygroscopic behaviour of wood and its related transformations are considered to be a deficiency of the material. ${ }^{2}$ Michael Hensel attributes this to the increase in standardization, tight tolerances, and stringent liability in the building industry. ${ }^{3}$ Rather than embracing wood's responsiveness to moisture, the current approach is to try and eliminate it in order to apply the material to designs in a top-down manner. As cited by Reichert, Menges \& Correa, the vast majority of energy expended in the processing of wood is invested in suppressing the innate characteristics of the material. ${ }^{4}$ Rather than suppressing wood's innate ability to respond dynamically to moisture, this thesis embraces the behaviour of the material in the pursuit of a new wood architecture based on material performance. 
Studying how wood reacts to moisture and applying the findings in an architectural context is not a trivial undertaking. The information in the following sections establishes a body of knowledge on the hygroscopicity of wood. The first section describes the mechanisms of hygroexpansion at a microscale. Following this is an overview of the various characteristics of wood that affect its responsiveness to moisture. Finally, ways of treating wood that alter its responsiveness to moisture are discussed. Ultimately, the information presented in these three sections will go on to inform the design project in this thesis.

\section{HYGROEXPANSION: MICROSCALE ANALYSIS}

It has already been stated that wood absorbs moisture from the atmosphere when dry and yields it back to the atmosphere when wet, thereby maintaining a moisture content in equilibrium with the surrounding relative humidity. A direct result of this absorption and release of moisture is anisotropic dimensional change. While this macroscale understanding of wood's responsiveness to moisture is useful, understanding the behaviour at a microscopic level is crucial to the development of new and innovative applications.

Wood contains two types of moisture in liquid form; free moisture and bound moisture. ${ }^{5}$ In the book Tall Wood Buildings, the authors describe the structure of wood fibre using the analogy of a cluster of drinking straws:

Bound moisture is the moisture that is naturally contained within the cell walls (or within the casing of the straw itself) and is chemically bonded to the wood. Free (or capillary) moisture is the moisture that is contained between the cell walls (or within the tubular centre of the straw) and is held in the wood only by capillary forces. It constitutes the greater part of the moisture present in 'green wood' from newly felled trees. ${ }^{6}$

As cited by Holstov, Bridgens \& Farmer, the dimensional changes caused by the presence of free water are usually negligible; hence, the main factor influencing hygroexpansion is the change in the amount of bound water. ${ }^{7}$

The moisture content at which the cell walls have reached their maximum capacity to hold bound water while there is no free water in the cell cavities is called the fibre saturation point (MCf). ${ }^{8}$ Beyond this point, the cell lumen begins to fill with free water.

The moisture content of wood is defined as the ratio between the weight of water in the wood and the weight of the dry wood. ${ }^{9}$ Typically, the fibre saturation point is around $27-30 \%$ moisture content. ${ }^{10}$ Below this point, any change to the bound water content within the cell walls will cause a dimensional change in the piece of wood. ${ }^{11}$ Adsorption of bound water results in swelling at the macro-scale, while removal of bound water results in shrinkage. ${ }^{12}$

The actual amount of bound water content is a function of the relative humidity and, to a much lesser degree, temperature of the surrounding air. $^{13}$ The temporal 
equilibrium condition reached when the wood neither loses nor gains moisture in exchange with the environment is referred to as the equilibrium moisture content (EMC). ${ }^{14}$ As wood always seeks to reach this equilibrium, it continuously responds to changes in the surrounding relative humidity by adjusting the bound water content, resulting in constant dimensional movement.

As cited by Holstov, Bridgens \& Farmer, a linear relationship, expressed as the coefficient of hygroexpansion, is commonly assumed between moisture content changes below the fibre saturation point and the resulting dimensional changes in each of the three grain directions. ${ }^{15}$ In living trees and freshly cut wood, the moisture content is always above the fibre saturation point, and thus only dried wood exhibits hygroexpansion.

It is important to note that wood's responsiveness to moisture is a passive material capacity resulting from innate material characteristics independent from biological cell activity. ${ }^{16}$ No additional energy, sensory and actuation systems are required to trigger these changes. As such, applying wood's responsiveness to moisture in an architectural context is a low-tech design approach with the potential for very interesting outcomes.

\section{CHARACTERISTICS AFFECTING WOOD'S RESPONSE TO MOISTURE}

The characteristics of wood that affect its responsiveness to moisture are outlined in the following subsections. Generally, they can be divided into two groups. One group consists of characteristics that are inherent to the material, such as density and rot resistance, and the other group consists of characteristics that are a result of processing. These characteristics define what part of the tree the wood had come from, its geometry, and the ways in which the wood has been treated.

\section{Wood Selection}

When investigating wood's responsiveness to moisture, the selection of wood species is a key parameter to consider. Earlier in this thesis, a number of wood species were selected to be studied in greater detail. The findings reveal that when it comes to the hygroscopic behaviour of the selected wood species, Maple and European Beech have the highest shrinkage coefficients. In order to decide which of the two is most appropriate for a particular application that requires good hygroscopic behaviour, it would be wise to consider other factors. For example, although European Beech shows slightly better hygroscopic behaviour, Maple demonstrates better overall performance due to a number of other key factors such as a lower modulus of elasticity, marginally better resistance to decay, and greater homogeneity in grain. ${ }^{17}$

Wood's responsiveness to moisture also depends on which part of the tree the wood is harvested from. For example, while the majority of hygroexpansion in wood occurs tangentially and radially, certain atypical types of wood exhibit excessive longitudinal shrinkage. Reaction wood, whether compression wood in softwoods or 
tension wood in hardwoods, as well as wood from near the center of trees (juvenile wood) of some species, and wood with cross grain, tend to shrink excessively longitudinally. ${ }^{18}$ In addition, as cited by Holstov, Bridgens \& Farmer, in many wood species, the hygroscopicity of heartwood is somewhat smaller than that of sapwood due to the presence of toxic extractives deposited during its formation. ${ }^{19}$

\section{Shape and Material Thickness}

The thickness and overall geometric shape of a piece of wood affects the speed of moisture absorption and release. Thicker material samples require more time to balance their moisture level with the external environment, while thinner samples will react more quickly. In research conducted at the ICD, researchers tested the hygroscopic actuation of pieces of wood veneer that varied in shape. They found that longer pieces (cut across the grain) exhibit greater movement in terms of curvature when compared to shorter pieces. ${ }^{20}$ Ways to increase the rate of moisture content change in a piece of wood include increasing the surface area to volume ratio and shortening diffusion paths parallel to the fibre direction. ${ }^{21}$ This can be achieved by strategically milling grooves into the piece of wood.

\section{Wood Cut and Fibre Directionality}

Wood cut and fibre directionality affect the direction and the magnitude of shape change of a piece of wood as it responds to moisture. The hygroscopic behaviour of wood is directly related to the cellular structure and the angle of the micro-fibrils in relation to the cell's axial direction. ${ }^{22}$ Wood movement in response to moisture occurs perpendicular to the direction of the wood grain. Thus, the grain pattern of a piece of wood, which depends on how it was cut, can serve as a visual indicator for wood movement. ${ }^{23}$

Plain sawn wood has annular rings that are generally 30 degrees or less to the face of the board. The resulting wood displays a cathedral pattern on the face of the board. Plain sawn wood demonstrates a cupping distortion in the opposite direction of the growth rings. Plain sawn wood is generally more dimensionally stable than

Figure 5-2

Types of wood cuts

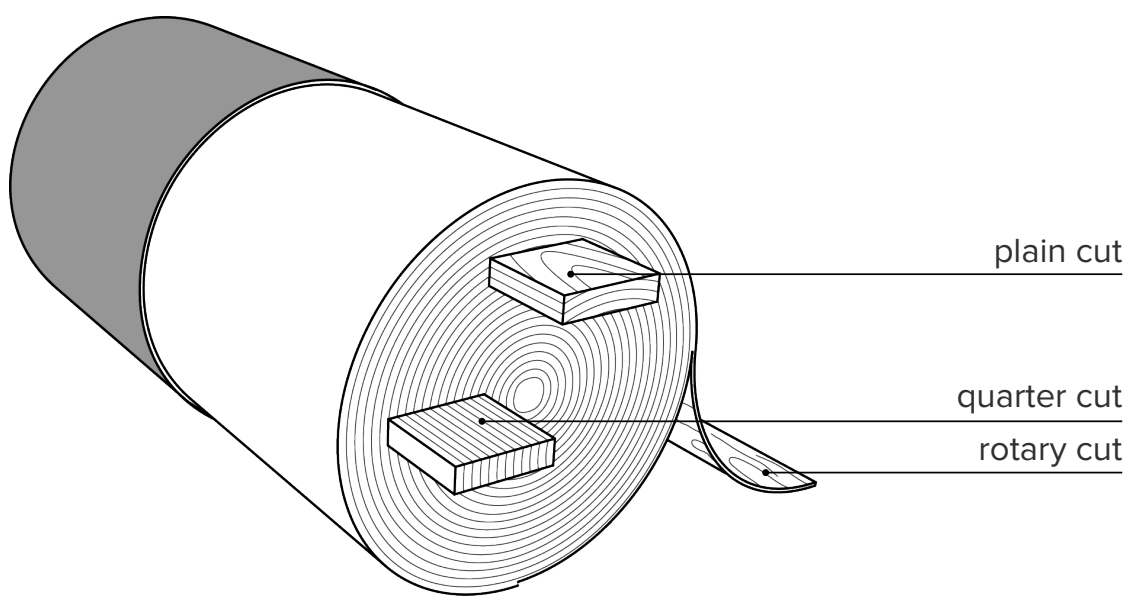


rotary cut wood but less stable that quarter or rift sawn wood. It is also the most commonly available type of wood cut.

Quarter and Rift sawn wood exhibits the least bending when exposed to moisture. ${ }^{24}$ However, wood cut in this manner has a homogeneous, linear grain pattern which results in uniform and predictable motion. ${ }^{25}$

When working with wood veneer, rotary-cut veneer exhibits the greatest hygroexpansion thanks to its near-exact alignment along the growth rings. ${ }^{26}$ Obtained through the peeling of cylindrical logs, it is also one of the cheapest veneer types and can be produced in larger sheets when compared to the other types. However, it is not always commercially available.

\section{The Application of Heat + Moisture}

When heat is combined with moisture in the form of steam, wood's elasticity can be enhanced. Steam bending wood can be used to maintain the integrity of the strongest axis of wood. However, steamed wood is less rigid, since adding moisture and heat to wood results in plasticization. ${ }^{27}$

\section{Other Treatments}

From the time humans began using wood in construction several techniques have been developed to treat wood in ways that make it more resistant to moisture related decay.

One particularly interesting example is the application of pine tar, used most notably as a water repellent barrier on the exterior of historic wooden stave churches in Norway. As the name suggests, the tar was not made from crude oil, but rather from the burning of pine wood in artificial mounds that produced a black molasses-like substance. ${ }^{28}$ The effectiveness of the tar in preserving wood from weathering and decay has been proven by the very survival of many Norwegian stave churches that date back hundreds of years.

Recently, the heat treatment of wood using various methods has emerged. Treating wood with heat in order to improve its quality involves raising the temperature in several stages up to a maximum of 250 degrees Celsius while excluding oxygen. ${ }^{29}$ This treatment, sometimes intensified by adding moisture and increasing the pressure, leads to a chemical change-mainly in those constituents in the wood that attract or repel moisture. ${ }^{30}$ As a result, the moisture absorption can be reduced by up to $50 \%$, leading to considerable reductions in shrinkage and swelling. ${ }^{31}$

Wood can also be modified through a process called acetylation in which the cell structure of the wood is altered, improving its technical properties and making it much stronger and more durable. In contrast to other wood preserving treatments, acetylation is non-toxic. Furthermore, unlike thermal modification which discolours and weakens wood, acetylation actually improves the strength of the wood.

Another technique used to protect wood from rot is Shou Sugi Ban. The technique 
which originates from Japan, involves charring the surface of wood in order to seal it with a layer of carbon that is highly resistant to mould, insects, water and even fire. The technique was traditionally used with cryptomeria japonica, a species of Japanese cedar. The wood is charred, cooled, cleaned, and then finished with natural oil, making it an effective method of preserving wooden structures without using chemicals. The pagoda at the Horyuji Temple in Japan which dates back to 711 AD employs the technique of Shou Sugi Ban and demonstrates its effectiveness. 


\section{NOTES}

01 Achim Menges, Tobias Schwinn \& Oliver David Krieg, Advancing Wood Architecture, (Routledge, Taylor \& Francis Group, 2017$), 1$.

02 Ibid., 105.

03 Michael Hensel, Performance-Oriented Architecture, (Wiley, 2013), 59.

04 Steffen Reichert, Achim Menges \& David Correa, "Meteorosensitive architecture: Biomimetic building skins based on materially embedded and hygroscopically enabled responsiveness," Computer-Aided Design 60 (2015): 51.

05 Michael Green \& Jim Taggart. Tall wood buildings: Design, construction and performance. (Birkhäuser, 2017$), 26$.

06 Ibid., 26.

07 Artem Holstov, Ben Bridgens \& Graham Farmer, "Hygromorphic materials for sustainable responsive architecture," Construction and Building Materials 98 (2015): 573.

08 Achim Menges \& Steffen Reichert, “Material capacity: Embedded responsiveness," Architectural Design 82, 2 (2012): 55.

09 Ibid., 55.

10 Ibid., 55.

11 Ibid., 55.

12 Ibid., 55.

13 Ibid., 55 .

14 Ibid., 55.

15 Artem Holstov, Ben Bridgens \& Graham Farmer, Op. cit., 573.

16 Achim Menges \& Steffen Reichert, Op. cit., 54.

17 Steffen Reichert, Achim Menges \& David Correa, Op. cit., 54.

18 Laboratory, Building News Inc. \& Forest Products. Wood Engineering Handbook (2nd Edition), (BNI Publications Inc., 2000$), 316$.

19 Artem Holstov, Ben Bridgens \& Graham Farmer, Op. cit., 575.

20 Steffen Reichert, Achim Menges \& David Correa, Op. cit., 55.

21 Chiara Vailati et al., "Upscaling of wood bilayers: Design principles for controlling shape change and increasing moisture change rate," Materials and Structures 50 (2017): 2.

22 Steffen Reichert, Achim Menges \& David Correa, Op. cit., 54.

23 Ibid., 55.

24 Artem Holstov, Ben Bridgens \& Graham Farmer, Op. cit., 575.

25 Steffen Reichert, Achim Menges \& David Correa, Op. cit., 67.

26 Artem Holstov, Ben Bridgens \& Graham Farmer, Op. cit., 574.

27 Laboratory, Building News Inc. \& Forest Products. Op. cit., 136.

28 Wolter, "Heavenly Design: The Stave Churches of Norway," Heritage Times, accessed March 2019, https://bit.ly/2NKPN93

29 Josef Kolb. Systems in timber engineering: Loadbearing structures and component layers, (Birkhäuser, 2008$), 295$.

30 Ibid., 295.

31 Ibid., 295. 
Figure 6-1

Stacked wood logs

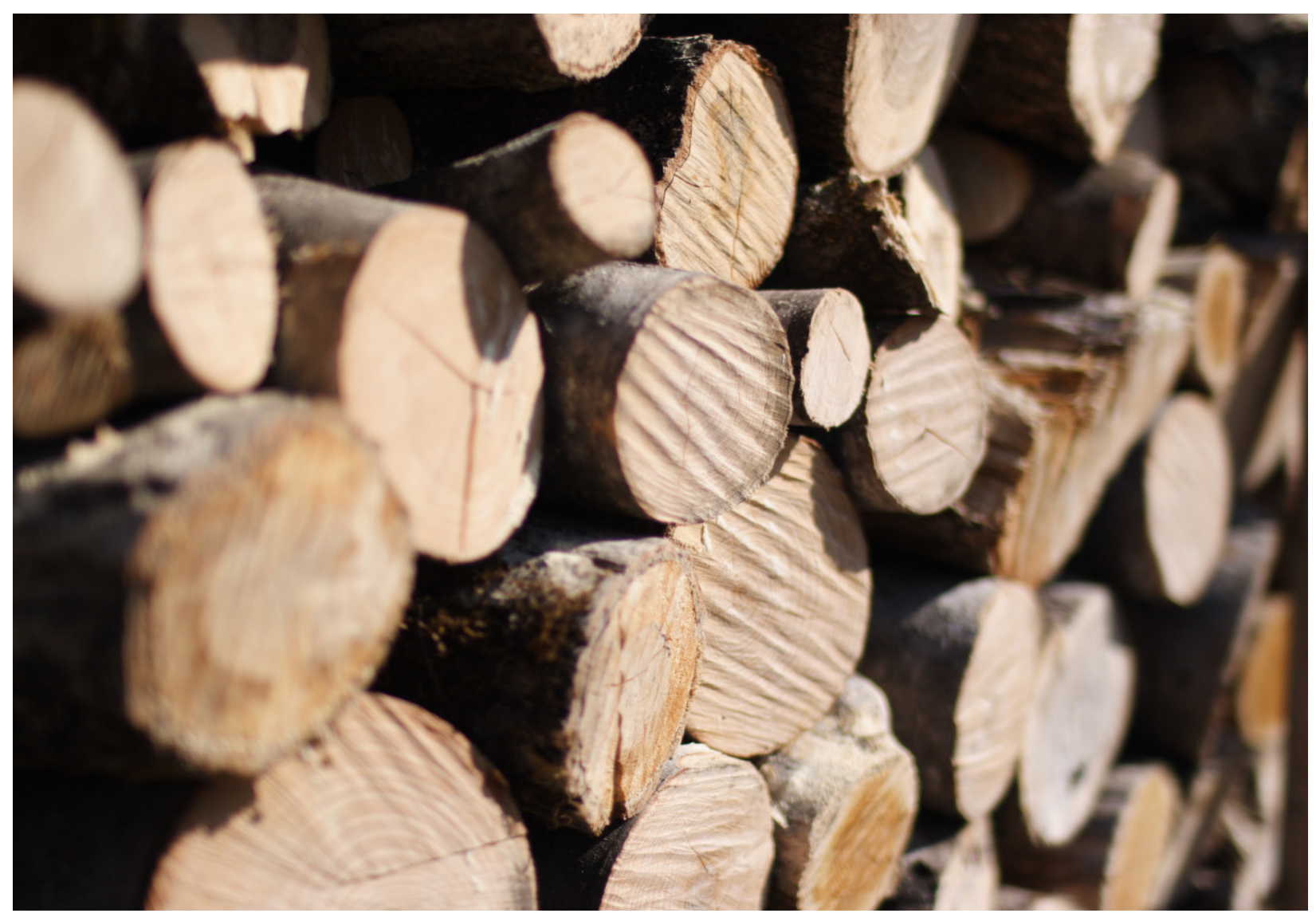




\section{6 | DESIGN PROPOSAL}

\section{PROGRAM}

The investigation of wood's responsiveness to moisture will be carried out in an architectural context through the design of a bathhouse on Lake Ontario. The variation in moisture and temperature conditions inherent to a waterfront location and bathhouse typology afford an excellent opportunity to test the ideas of this thesis.

Bathhouses and saunas have often served as a typology for architectural exploration. The often limited program and scale of a bathhouse enables architects to explore ideas in considerable depth. For example, over the course of his career, Alvar Aalto designed several saunas, continually striving to improve his understanding of what constitutes an "authentic" sauna experience. Architects Kengo Kuma and Peter Zumthor have used the bathhouse typology to explore ideas of materiality and sensory design. For Kuma, the material of choice is most often wood. In particular, he favours cedar for its aromatic and aesthetic qualities, as well as its durability. More recently, firms such as Partisans have used the modest scale of the sauna to explore the application of new technologies in an architectural context. Not unlike these projects, the design of a bathhouse informed by the inherent capacities of wood requires a very detail-oriented approach. As such, the bathhouse designed for this thesis will be limited in scale (less than $100 \mathrm{~m}^{2}$ ) with a program that includes a sauna, a bath, and a gathering space. Limiting the scale of the project was also important as the project is one of the first of its kind in Toronto, and its aim is to 
Figure 6-2

Grotto Sauna, Ontario, Canada, 2014, PARTISANS

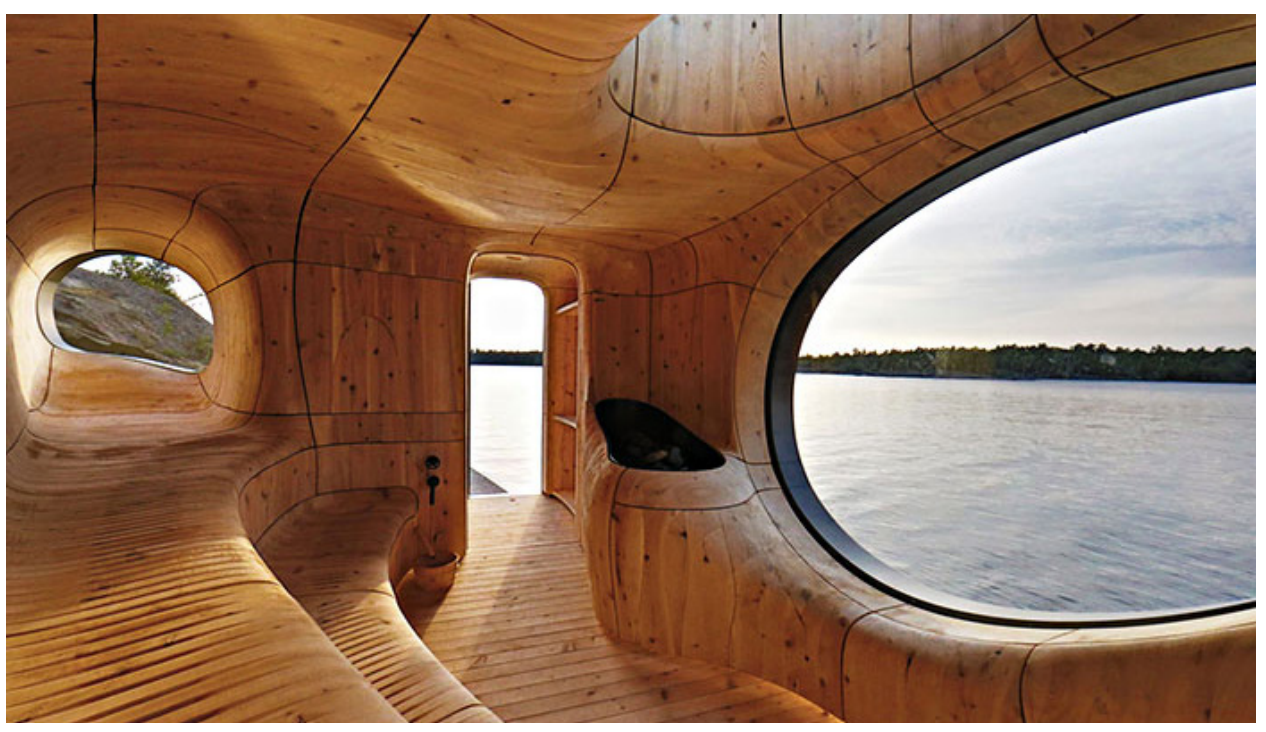

Figure 6-3

Löyly, Helsinki, Findalnd, 2016, Avanto Architects. As the wood greys, the building will appear like a rock on the shoreline

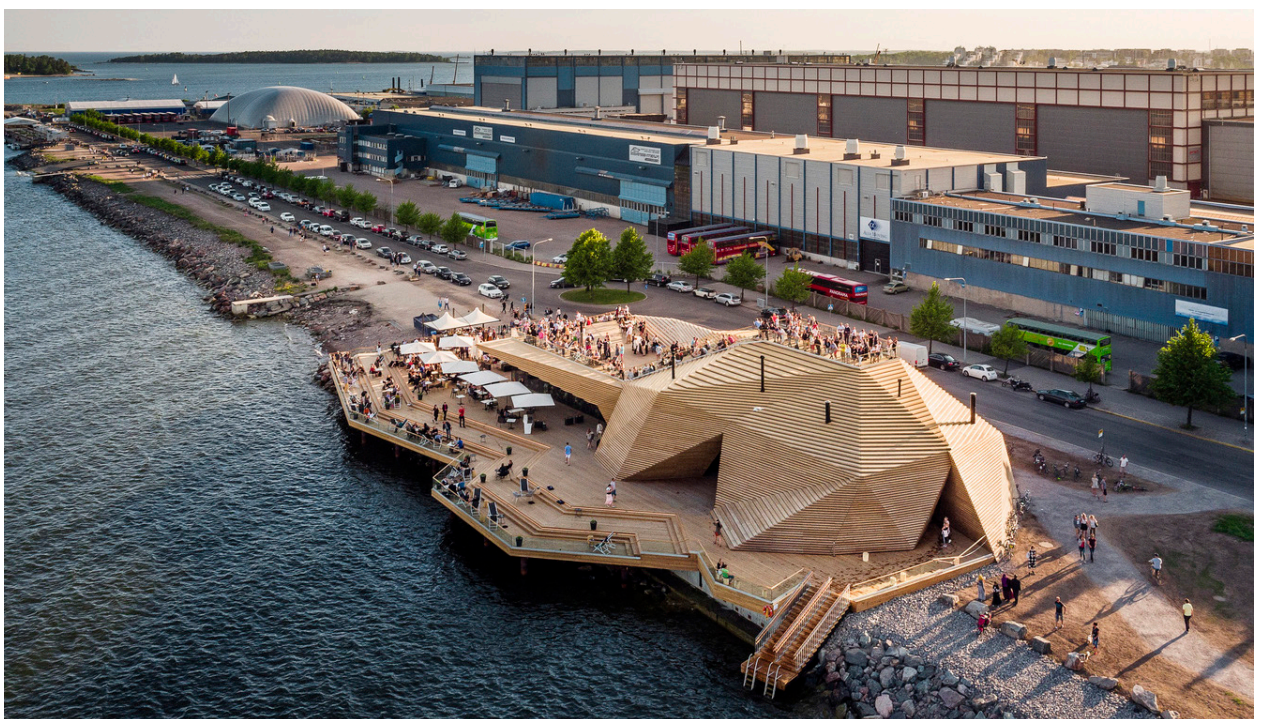

Figure 6-4

Therme Vals,

Graubünden, Switzerland,

1996, Peter Zumthor

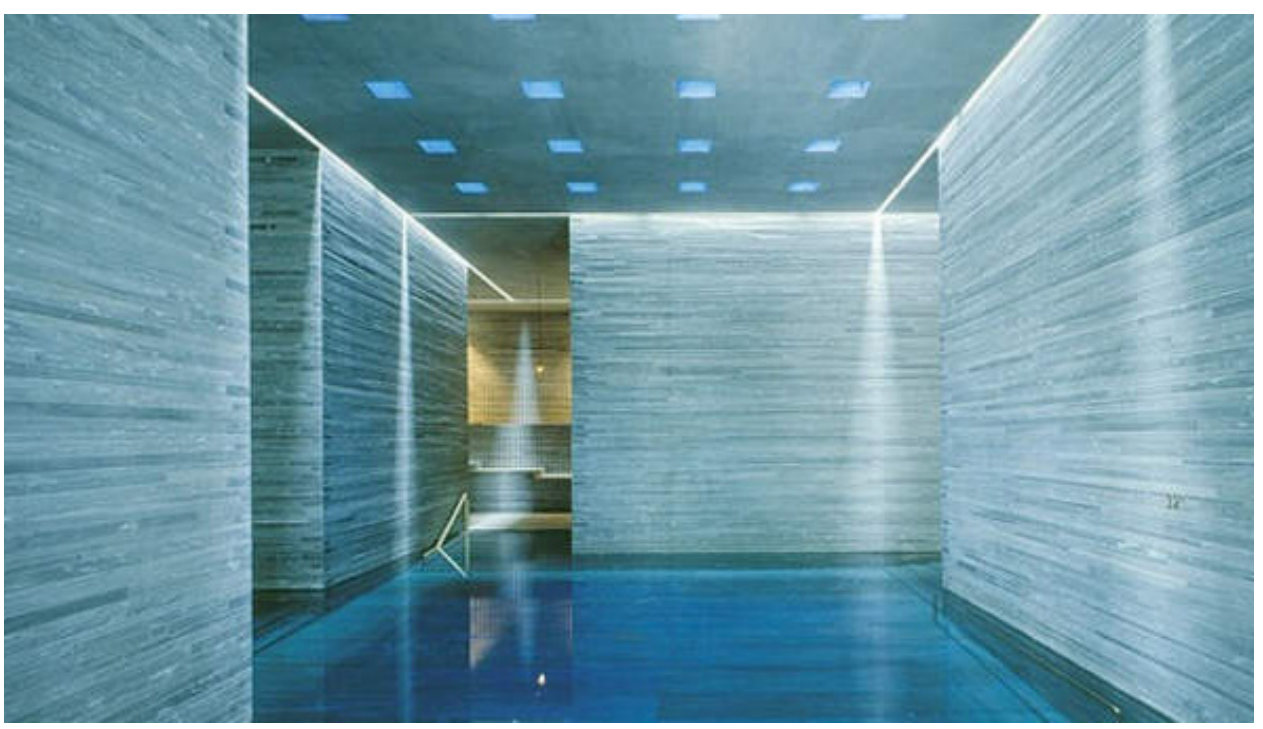


catalyze the growth of bathing culture across the city. Starting with a humble structure that provided an intimate bathing experience was therefore a seemingly appropriate first step.

\section{BATHING AND BATHHOUSES}

From the baths of Ancient Greece and Rome, to the Islamic hamam, the Japanese onsen, and the Nordic sauna, the bathhouse has found its place as an important institution in cultures around the world. In her 2016 exhibition titled Soak, Steam, Dream: Reinventing Bathing Culture, Jane Withers brings to light the connection between the physical and social aspects of bathing from ancient rituals to contemporary bathing projects. Accompanying the exhibition was an essay written by Withers on the history of bathing culture and its social, physical and meditative aspects. In the essay, Withers discusses the key roles that bathhouses once played in society. Firstly, bathhouses provided essential sanitation at a time when most people did not have access to private bathing facilities. ${ }^{1}$ Secondly, bathhouses were places of social, cultural and political exchange, where community members could fulfil their need to interact with each other. ${ }^{2}$ Finally, bathhouses served as places of relaxation and rejuvenation, where through physical immersion in water, prosaic anxieties could be dissolved, inducing a change of consciousness and enhancing one's well-being. ${ }^{3}$ Early bathing culture was based on an understanding that the bathhouse reconnected body to mind, and in turn could connect communities.

In her essay, Withers quotes artist Leonard Koren, who suggests that "bathing is as much a state of being as an act of cleansing". "Koren analyses the qualities of successful baths in his book Undesigning the Bath: "To bathe is to fall into step with your biological rhythms: in and out breathing, the speed of blood coursing through your veins, the slowness of tiredness...The mechanical world of objective time-seconds, minutes, hours-is irrelevant here. Taking a bath properly requires being able to guiltlessly linger, hang out, and/or do nothing whatsoever." ${ }^{5}$ Such an experience has been described my many cultures around the world. For instance, the Romans termed this mode of productive idleness "otium". ${ }^{6}$ Similarly, in Japanese bathing culture, there exists a belief that hot water transports the bather to a state of bliss called "yudedako", in which the mind floats freely into another dimension from everyday existence.?

In the $20^{\text {th }}$ century, bathing culture began to transform as a result of a more technological and clinical approach to sanitation. ${ }^{8}$ Bathing became more about hygiene and less about rejuvenation and communal gathering. ${ }^{9}$ In addition, moral standards that developed during the Victorian era instilled a sense of shame and embarrassment surrounding nakedness, and public bathing was regarded with disdain. As bathing culture transformed, so too did the architecture of bathingthe bathhouse became the private bathroom and its design was based solely on hygiene, ergonomic efficiency, and privacy. ${ }^{10}$ In Mechanization Takes Command, Sigfried Giedion bemoaned the arrival of the mean-spirited modern bathroom, 
lamenting that the great bathhouse had become a prison cell." In addition, Jane Withers believes that the loss of bathing culture also resulted in a denial of our ancient relationship with water. ${ }^{12}$

Today, there is a renewed interest in bathing culture that is helping to reimagine bathhouses as rejuvenating community spaces that can help reconnect us to water. One that stands out as having embraced the ancient tenets of bathing culture is Therme Vals, designed by Peter Zumthor over the hot springs at Graubünden in Switzerland. The bathhouse was constructed of local stone, and contains the thermal spring waters that bubble beneath the site. ${ }^{13}$ The architecture of the building sets up a framework for various bathing rituals to take place. Bathers experience different thermal sensations, as well as olfactory and aural water experiences, all the while taking in carefully curated views of the majestic surrounding landscape. ${ }^{14}$ The experience Therme Vals offers is truly an embodied experience that reconnects bathers to the ancient meaning of spa-salus per aqua or "healing through water". 15 In addition to extraordinary design, Therme Vals demonstrates how an exceptional architectural project, commissioned by a municipality can succeed in revitalizing its community and economy. ${ }^{16}$

Today, many bathhouses being built stem from an interest in catalyzing a sense of community in the surrounding area. This is especially prevalent in the design of bathhouses located in urban areas, where we are beginning to rethink how we live and interact with each other as living spaces begin to shrink. One example of this is Barking Bathhouse in London. Located in one of the city's poorer outer suburbs, the project references a local historic precedent of community-focused design in an attempt to serve the local community and make it stronger. ${ }^{17}$ The precedent dates back to the nineteenth century, when social activists in Britain established public baths for the poor based on traditional Ottoman Turkish baths. ${ }^{18}$ The goal of these new baths was not only hygiene and health, but also creating lasting social change. ${ }^{19}$

In describing the social aspect of bathhouses, Jane Withers quotes architect Tuomas Toivonen who explains the importance of the bathhouse as a public space: "More than creating a space for physical bathing, the architecture of the bath requires and creates - a space of anti-conflict, anti-competition and anti-hierarchy." ${ }^{20}$ She adds, "[u]nlike most other public spaces, the bathhouse is a place of synthesis and reconciliation, where the armour of daily life is discarded along with one's clothes, and usual codes of behaviour melt with the steam, helping make the bathhouse a powerful sanctuary as well as an agent of change." ${ }^{21}$

The bathhouse being designed for this thesis will take advantage of wood's inherent properties to create a rejuvenating experience for its occupants. It will highlight the interesting interactions between wood, water, and the human body. But perhaps more importantly, it will serve as a catalyst for social interaction. 


\section{LOCATION}

The bathhouse will be located in Toronto on the northwestern shore of the future Villiers Island precinct. Formerly referred to as Cousins Quay, the Villiers Island precinct is slated to become a new waterfront community in Toronto's Port Lands, just minutes away from the downtown core. The development of the island will be centred on principles of sustainability, resiliency and innovation.

\section{HISTORY OF THE PORTLANDS}

Two hundred years ago, the area in Toronto that is now called the Port Lands was one of the largest freshwater marshes on Lake Ontario. ${ }^{22}$ It was called Ashbridges Bay Marsh and was created by the lower Don River as it emptied into Toronto's inner harbour. Up until the late $18^{\text {th }}$ century, the marsh was home to many different species of wildlife including ducks, blackbirds, and salmon, but it soon began to deteriorate as mills were built along the river, and pollution and sewage from the Town of York emptied into the Lower Don River. ${ }^{23}$ By the end of the $19^{\text {th }}$ century, the rich ecosystem of the marsh had been completely devastated. ${ }^{24}$

Alterations to the city's shoreline and the marsh as a result of human interventions began in the 1870s. ${ }^{25}$ In the late 1890s, The Keating Channel was built along the northern edge of the marsh, redirecting the mouth of the Don River into the inner harbour by way of an unnatural 90-degree turn, which increased the risk of flooding in the Port Lands. ${ }^{26}$ From 1912 to 1922, Ashbridges Bay Marsh was filled in, transforming the area into a massive industrial district. ${ }^{27}$

A second wave of development began in the 1950s that included the construction of the Leslie Spit, the Hearn Generating Station, Commissioners Incinerator, and the Gardiner Expressway. ${ }^{28}$ When the St. Lawrence Seaway was opened, it ignited a renewed effort to turn the Port Lands into a major industrial district and shipping hub. ${ }^{29}$ Ultimately these aspirations were never realized, and instead the area became home primarily to civic and city-serving uses such as salt storage, as well as light industrial uses.

Today, the Port Lands area of Toronto is a 15-minute bike ride from the downtown core and is home to manufacturing, recreational, heavy industry, cultural, media and creative industry, retail and port uses. That said, most of the area is still largely underused. In fact, the area is considered one of the largest underdeveloped stretches of downtown waterfront in North America. The main reasons as to why the area has not become a thriving part of the city is because the soil is contaminated and several areas are at risk to flooding.

It was determined decades ago that the first step to unlocking the Port Lands was to re-naturalize the Don River mouth. Only now is the endeavour being pursued. The project is being referred to as the Port Lands Flood Protection Project, and it will be one of the most ambitious construction projects in Toronto's history. The project includes the construction of two new outlets for the existing river that will enable 
floodwaters to run off into the inner harbour instead of damaging the surrounding neighbourhoods. ${ }^{30}$ At the same time, polluted land will be cleaned up, aquatic habitats will be restored, water quality will be improved, and new roads, bridges, utilities and public trails will be built. ${ }^{31}$ The project will unlock more than one third of Toronto's waterfront for revitalization, and will create ample greenspace and parkland. ${ }^{32}$ It will bring thousands of new residents and jobs, and will grant more access to the waterfront for people to enjoy.

\section{THE FUTURE PORTLANDS \& VILLIERS ISLAND}

Once the Port Lands Flood Protection Project is complete in 2023, a new river valley home to diverse plants and wildlife will run through the Port Lands, creating a new island that will be referred to as Villiers Island. This project will transform an area that was once unusable and under the threat of flooding into a vibrant place where communities will thrive. It will help Toronto grow sustainably, reduce urban sprawl, and give the city's residents access to cleaner water and more greenspace.

Figure 6-5 Toronto Port Lands

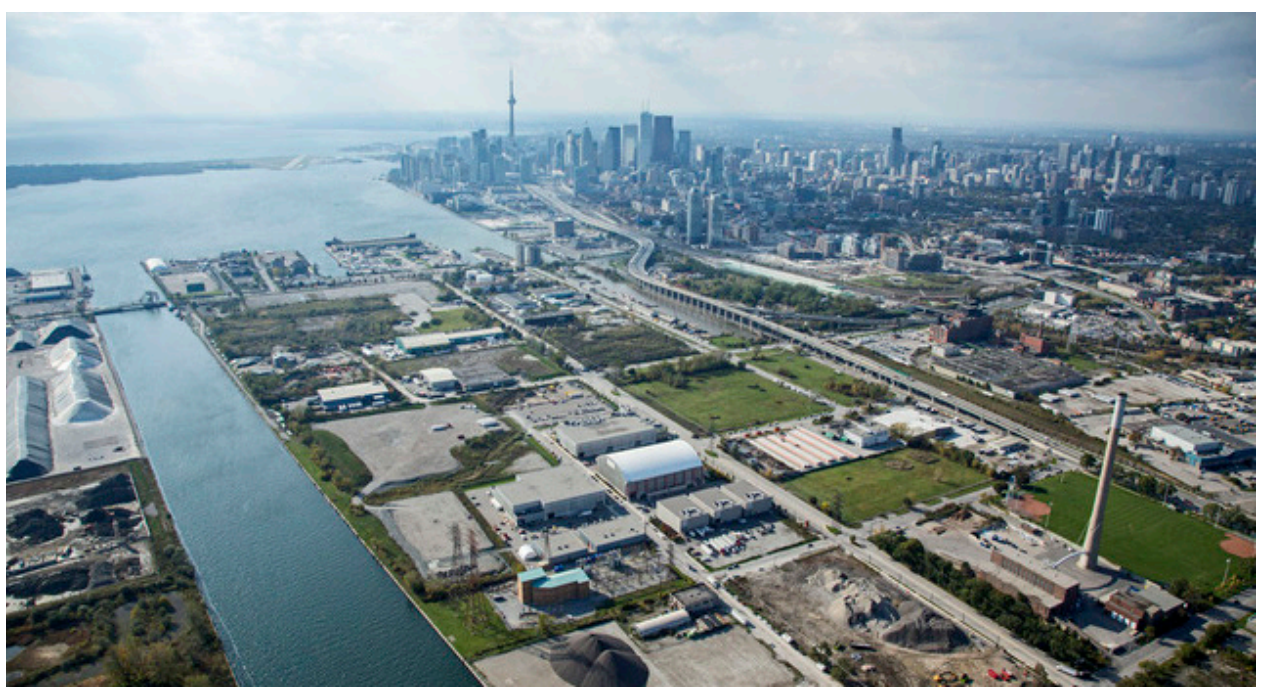

Figure 6-6

The Future Villiers Island

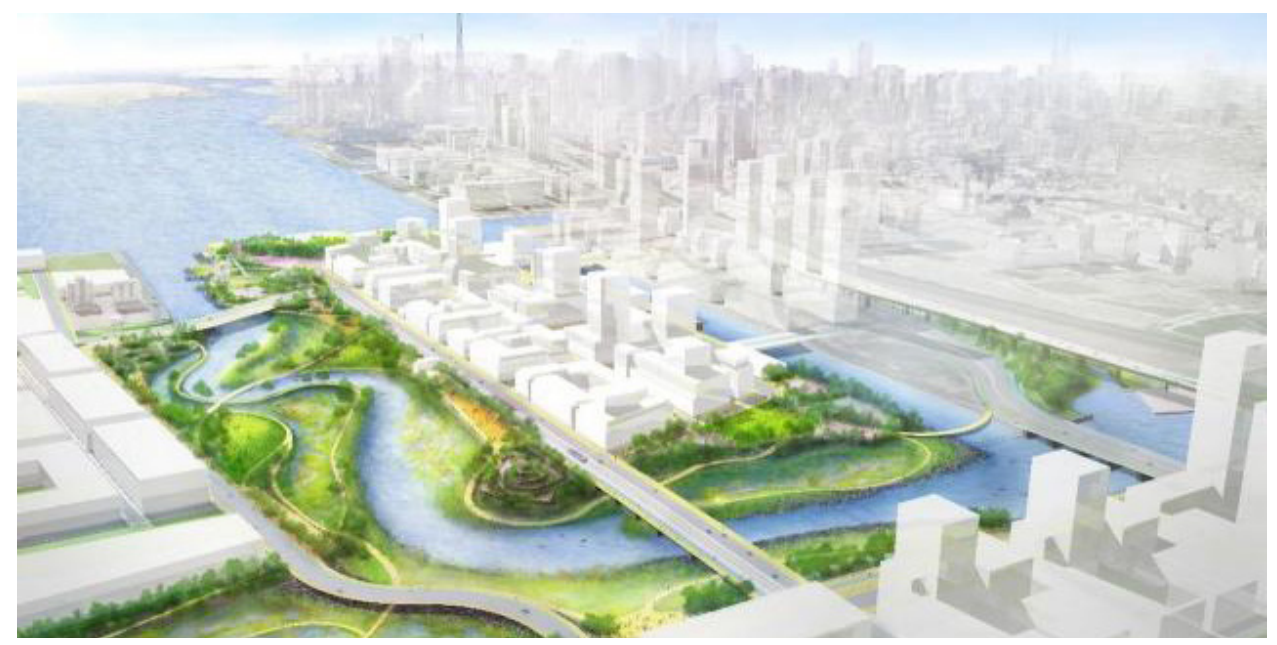


Villiers Island will be bordered by the Keating Channel to the north, the inner harbour to the west, and by the new river to the east and south. The 88 acre island will form a gateway from the West Don Lands and Keating Channel neighbourhoods to the rest of the Port Lands. It will predominately be a residential community, but will also contain a mix of retail, employment, recreational, and cultural uses. ${ }^{33}$ Some of these uses include a community centre, an elementary school, a local fire station, as well as two new parks-Promontory Park and River Park. ${ }^{34}$ In addition, the precinct plan suggests that there is the potential to expand Toronto's ferry service to connect the Port Lands to other waterfront destinations. Furthermore, the development of the island will be informed by the Villiers Island Climate Positive Assessment, and will produce more energy than it uses. ${ }^{35}$

Villiers Island will be a place where natural and urban environments interconnect. It will become an extension of the Central Waterfront, the Don Valley trail system and the Toronto Islands.

Figure 6-7

Villiers Island

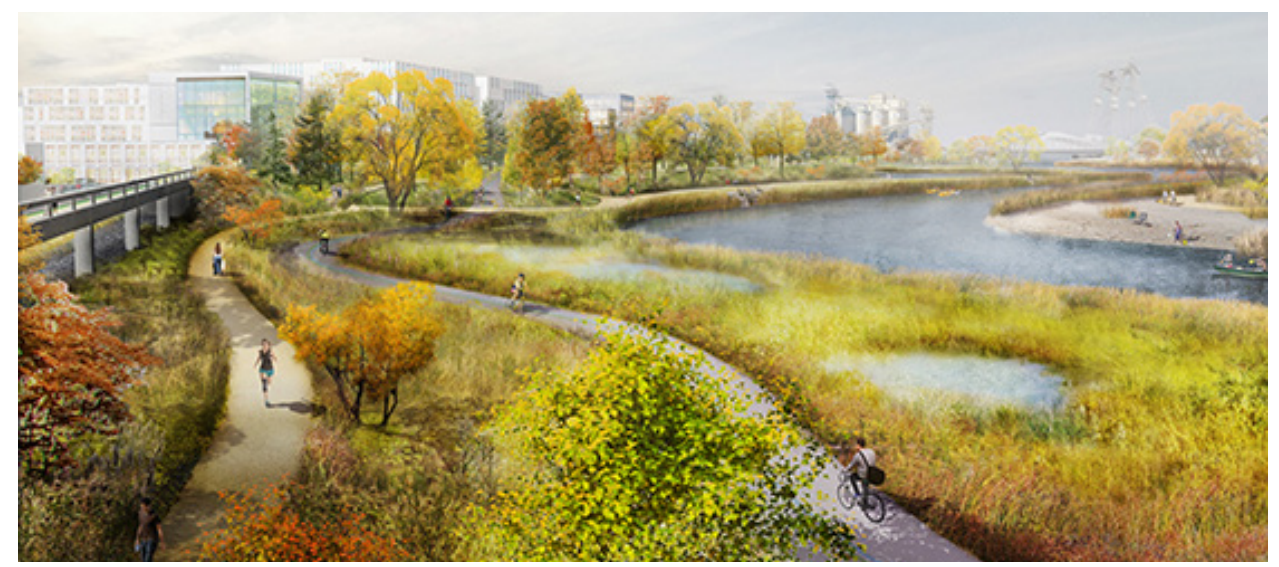

Figure 6-8

Villiers Island plan

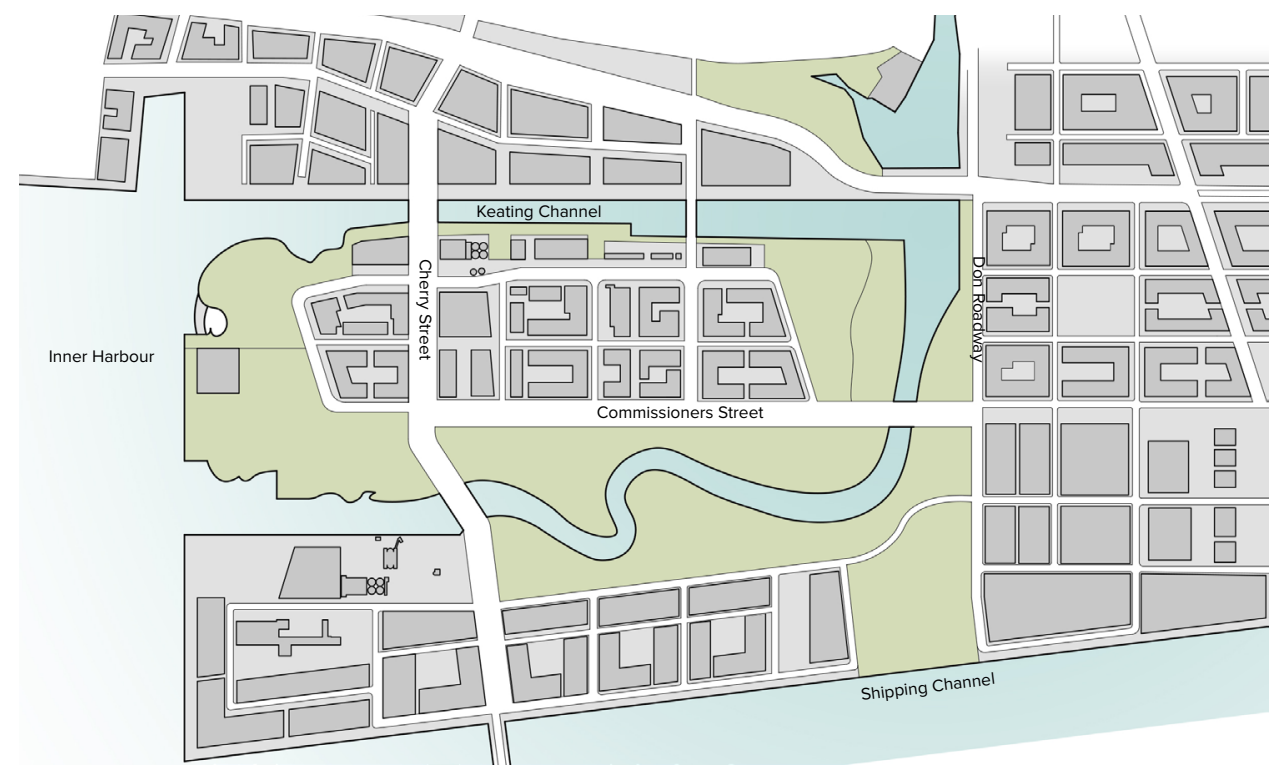




\section{A CATALYST FOR CREATING COMMUNITY}

Despite the growing trend of people living in close proximity to one another as a result of the densification of cities, issues of mental health and wellbeing are becoming more prevalent. As the population of Toronto continues to rise, the city is experiencing an increase in development, and a decrease in spaces for social interaction per capita. In order to have fulfilled citizens, architects must focus on facilitating opportunities for social interaction through the design of the built environment. Providing people with opportunities for interaction not only contributes to the health of individuals but it also contributes to the health and sustainability of cities.

The Port Lands of Toronto will soon lose its industrial character and become a new, central part of the city that will be adopted by its citizens. The development of Villiers Island and the links formed between the water, the land, and the community are crucial to the success of the whole area. Although the Port Lands area of Toronto is currently not an ideal location for a new bathhouse, in less than a decade, the newly developed area will need community spaces that provide an opportunity for different groups of people to meet, relax, and spend time together. The bathhouse on Villiers Island will provide the perfect context for exactly this. It will be a return to the traditional bathhouse-a place where there is no hierarchy or spectacle, but where the focus is solely on sharing spaces and thoughts, while enjoying the water.

Figure 6-9

Raumlabor's Gothenburg sauna (2015), placed in a Gothenburg's port area, acts as an agent to seed the area's regeneration into a new urban quarter

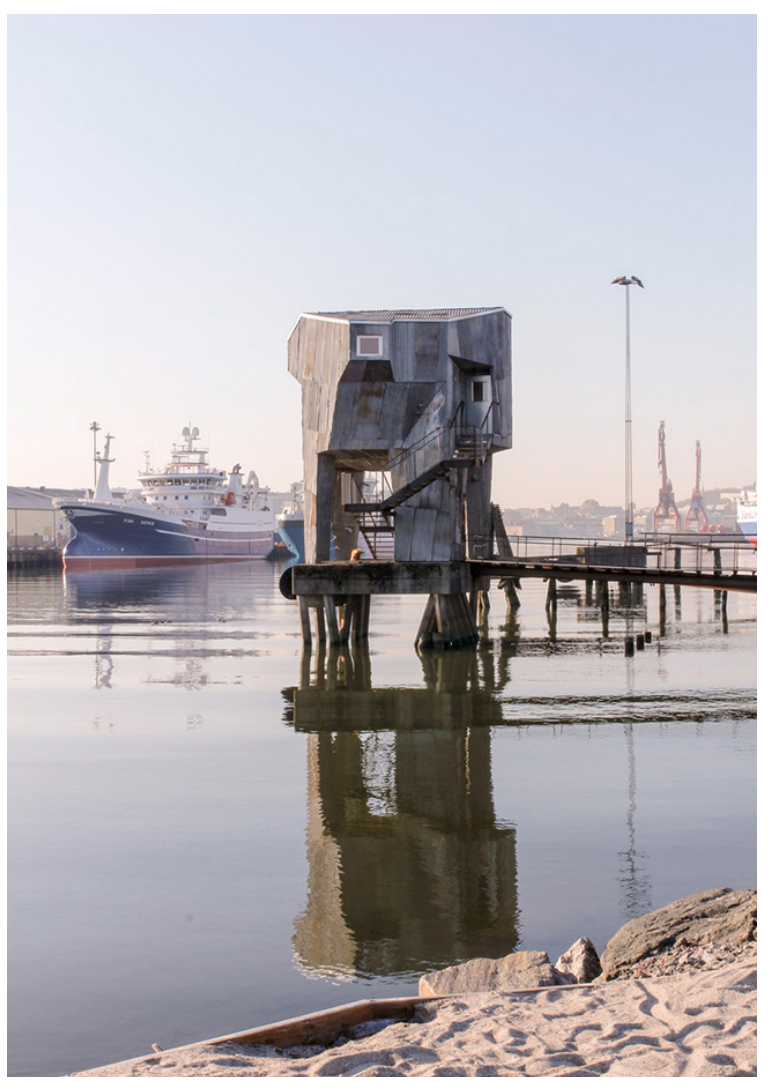




\section{ESTABLISHING BATHING CULTURE IN CANADA}

Over centuries, public bathing traditions have spread throughout the world, adapting to evolving cultures with differing customs and social norms. Interestingly enough, Canada is a large nation in the northern hemisphere that does not have a well-established bathing culture.

While Canada lacks a distinct and unified bathing culture, for decades, the nation's Indigenous people have used sweat lodges for various purification rituals. During these rituals, participants gather inside a dome-shaped structure containing a pile of heated rocks in the centre. A leader occasionally pours water on the rocks, filling the lodge with steam. ${ }^{36}$ It is believed that as participants sweat in response to the intense heat, the toxins and negative energy that create disorder and imbalance in life are released. ${ }^{37}$ As such, the sweat lodge ceremony is meant to purify the body, mind and soul. While the sweat lodge is an important aspect of Indigenous culture in Canada, it has not spread outside of Indigenous communities as the associated rituals are considered religious practice.

According to Jane Withers, the state of North American bathing culture is largely a result of western attitudes towards bathing. She explains how in Anglo Saxon cultures the bathhouse has often been the focus of debate on morality writing:

"Victorian prudery cemented a modern fear of promiscuity and depravity... Every culture has rules and taboos around hygiene and bathing, but in many culturesNordic or Japanese for instance-there is not the same dichotomy between pleasure and sin, and bathing is not moralized to the same extent." ${ }^{38}$

In Toronto, this moralizing was especially present in the 1970s and 1980s surrounding gay bathhouses. ${ }^{39}$ It led to the 1981 bathhouse raids by local police officers during which hundreds of gay men were mocked, humiliated and even arrested in institutions that they considered to be sanctuaries, free from hostility.

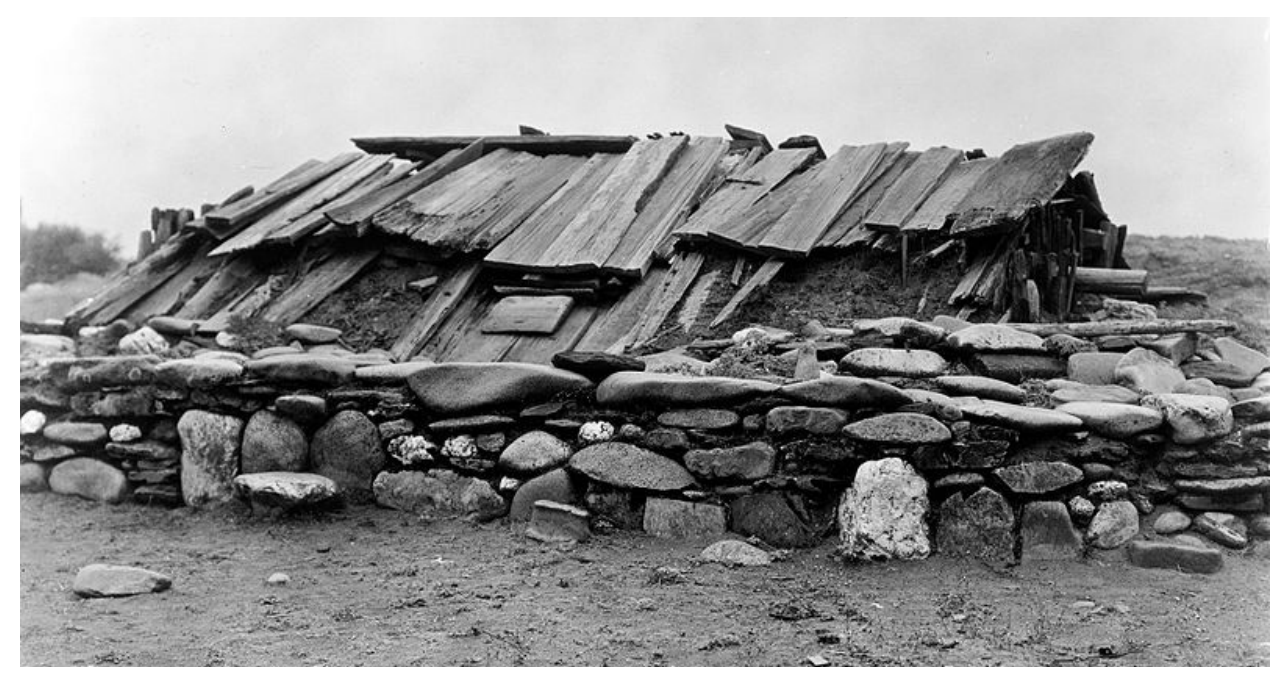


Following these raids, in the 1980's with the onset of the AIDS epidemic, many urban bathhouses in North America continued to be condemned for enabling promiscuity and helping spread the disease, and were eventually forced to close. ${ }^{40}$ To this day, the Victorian morality of the nineteenth century, which promoted sexual restraint and cemented a fear of promiscuity, is still engrained in societal attitudes across Canada.

If Canada is ever to develop a strong bathing culture, the nation must move beyond the moralizing associated with bathing and instead begin to view public bathing as an opportunity to develop stronger communities. Much can be learned from nations with already well-established bathing cultures. In Finland for instance, sauna culture is entwined in the country's national identity. The sauna first served as a place for people to wash, and it was also where they gave birth, did the laundry, treated the sick, and prepared the dead for burial. Today, friends and families visit saunas to reconnect and be rejuvenated. It is not uncommon for the space to be shared by men, women, and children, often nude, without any issue. The Finns view the sauna not a space of competition or consumption, but rather a space for oneself, where the focus is on enjoying and benefiting from the heat and water. Perhaps no sauna in Finland embodies this spirit more than Sompasauna-a self-service, volunteermaintained and free, public sauna revered for its distinct communal atmosphere. As a side note, the sauna was constructed without permission and was built mainly out of wood, since it was easy to work with, even for unskilled workers.

Though Canada lacks a well-established bathing culture today, it is quite possible that one might begin to emerge soon. In fact, as changing societal attitudes continue to evolve within Canadian culture, and there is an increased desire to escape the trappings of modern society, it can be argued that now more than ever there is a need for a newly established bathing culture that brings people together. That said, perhaps there is no better place for a bathhouse than on the up and coming Villiers Island-a place undergoing a tremendous rejuvenation.

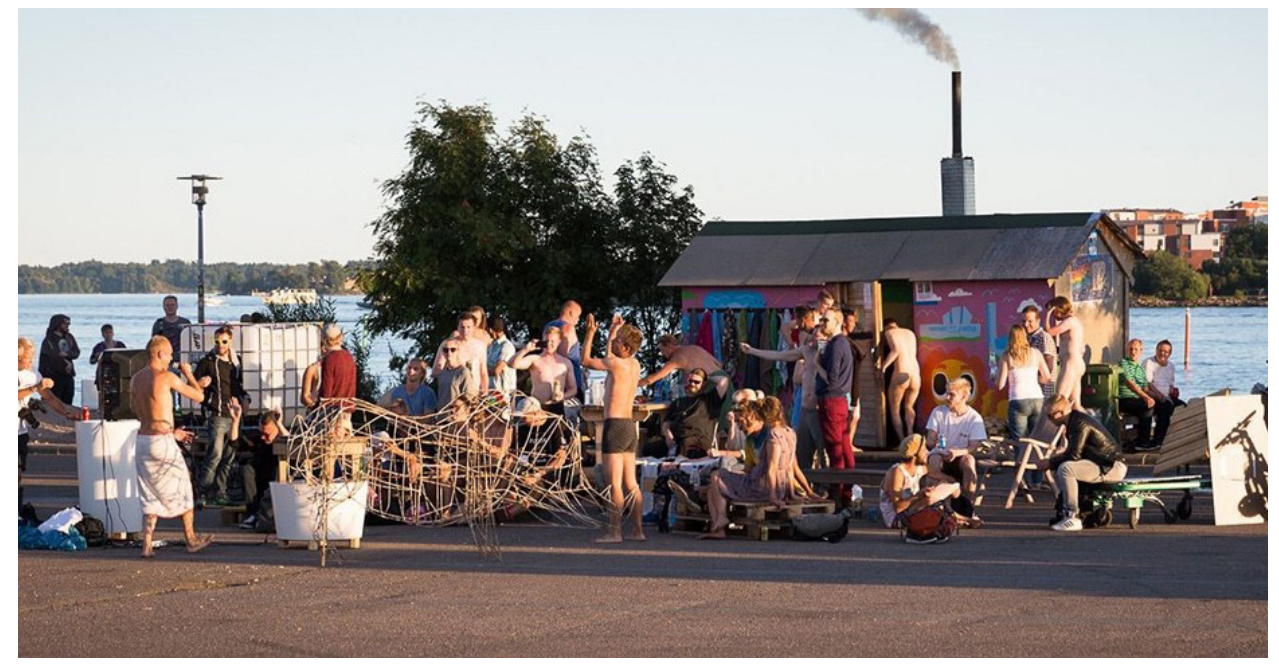




\section{NOTES}

01 Jane Withers, "Curators Essay by Jane Withers," Soak, Steam, Dream: Reinventing Bathing Culture, (2016). https://bit.ly/2LISvRz

02 Ibid.

03 Ibid.

04 Ibid.

05 Leonard Koren, Undesigning the Bath, (Stone Bridge Press, 1996), 29.

06 Withers, Op. cit.

07 Ibid.

08 Ibid.

09 Ibid.

10 Ibid.

11 Sigfried Giedion, Mechanization Takes Command, (University of Minnesota Press, 1948).

12 Withers, Op. cit.

13 Ibid.

14 Ibid.

15 Ibid.

16 Ibid.

17 Ibid.

18 Ibid.

19 Ibid.

20 Ibid.

21 Ibid.

22 Waterfront Toronto, "History of the Port Lands," accessed January 2019, https://goo.gl/Rk7yyp

23 Ibid.

24 Ibid.

25 Ibid.

26 Ibid.

27 Ibid.

28 Ibid.

29 Ibid.

30 Waterfront Toronto, "What is the Port Lands Floor Protection Project?," accessed January 2019, https://goo.gl/trMYQM

31 Ibid.

32 Ibid.

33 Urban Strategies Inc., "Villiers Island Precinct Plan," (Planning Report, 2017)

34 Ibid.

35 Ibid.

36 Rene Gadacz, “Sweat Lodge," The Canadian Encyclopedia, accessed March 2019, https://bit.ly/2CltjrR

37 Ibid.

38 Withers, Op. cit.

39 Ibid.

40 Ibid. 


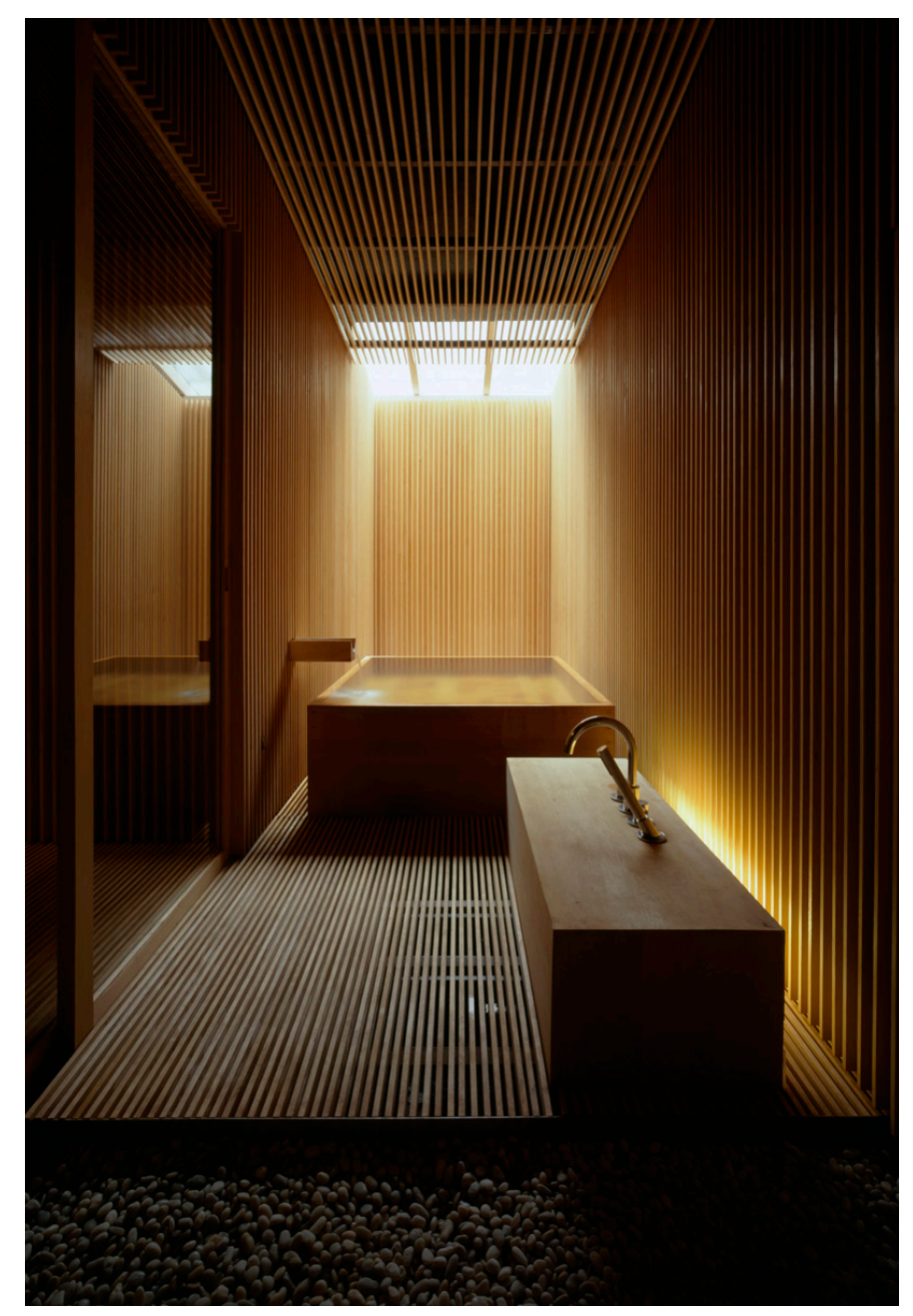




\section{7 | DESIGING WITH WOOD, WATER, AND HEAT}

"It is a question of surrendering to the wood, then following where it leads by connecting operations to a materiality, instead of imposing a form upon a matter: what one addresses is less a matter submitted to laws than a materiality possessing a nomos. One addresses less a form capable of imposing properties upon a matter than material traits of expression constituting affects."

-Deleuze \& Guattari'

\section{STUDIES}

In order to study the relationship between wood and moisture in an architectural context, a series of design explorations were carried out. These design explorations will be woven together to ultimately create the architectural basis for the thesis project. The studies have been broken down into two categories: structural studies and environmental studies. While there is no doubt that each of these affect the other, for the purpose of studying the various ways that wood's responsiveness to moisture can inform design, it is useful to first look at structure and environment separately.

The structural studies investigate how wood's responsiveness to moisture can inform form and joinery. In these studies, material and structure are not separate but one and the same. The environmental studies investigate how wood's responsiveness to moisture impacts the environment both directly and indirectly. Figure 7.2 provides a breakdown of the studies that were conducted. 


\section{WOOD-MOISTURE STUDIES}

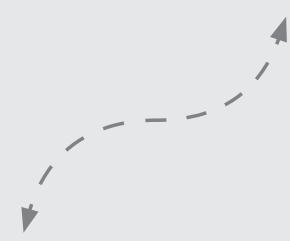

Structural Studies

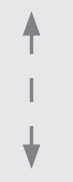

1. Form: Bending

2. Joinery

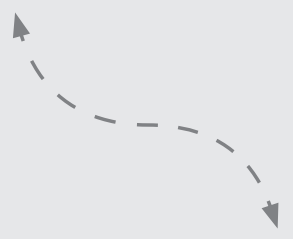

Environmental Studies

$\uparrow$

I

$\downarrow$

1. Moisture Buffering

2. Responsive Envelopes

\section{STRUCTURAL STUDIES}

\section{Form: Bending}

It is commonly known that wood can be bent quiet easily, especially if the piece is very thin. In making baskets and other products, thin veneers are bent by hand and held in place by weaving them together or attaching them to other parts. Such bending occurs within the elastic range of the material and can be achieved without treating the wood. As such, the individual elements will have a tendency to return to their unbent shape when separated.

This study investigates the inherent elasticity of wood, and how it is affected by moisture. The main factors to consider when bending wood are: wood type, wood thickness, and the wood's current moisture content. Each species of wood has a unique elastic range. In addition, thicker pieces of wood are generally less easily bent. Further, it is known that the moisture content of a piece of wood plays an important role in determining how elastic it is. Wood is generally more elastic when it contains more moisture. ${ }^{2}$

Although wood's inherent elasticity allows for the creation of complex curvature from initially planar elements, it has rarely been employed in architecture. Some exceptions to this include work being done by the ICD/ITKE in Stuttgart, such as their 2010 Research Pavilion, as well as a handful of wooden gridshell structures that have been built in the past.

In addition to its inherent elasticity, wood can be treated in ways that take it beyond its elastic range and into its plastic range. This is done through steam bending or 
chemical plasticization. ${ }^{3}$ Together, heat and moisture can soften wood and produce a degree of plasticity roughly 10 times that of dry wood at normal temperatures. ${ }^{4}$ It is important to note that a bent piece of wood possesses less strength than a similar but unbent piece. ${ }^{5}$ Therefore applications of steam bent wood have been limited to furniture, boats, ships and musical instruments. In general, hardwoods are better for bending than softwoods and the most commonly used species to produce bent members are white oak, red oak, elm, hickory, ash, beech, birch, maple, walnut, sweetgum, and mahogany. ${ }^{6}$ Although green wood can be bent to produce many curved members, difficulties are encountered in drying and fixing the bend. ${ }^{7}$ On the contrary, bending wood that has been dried to a low moisture content requires a long steaming or soaking process to increase its moisture content to the point where it can be made sufficiently plastic for successful bending. ${ }^{8}$ To avoid both drying troubles with wood that is too wet and bending difficulties with wood that is too dry, wood should be seasoned to a moisture content that is optimal for the desired application. ${ }^{9}$

One of the first to popularize the steam bending of wood was Michael Thonet-a furniture maker who began steam bending wood in the 1840s. After much experimentation, he developed the famous Michael Thonet chair. His work would go on to inspire many mid-century luminaries such as Charles and Ray Eames, and Eero Saarinen, who designed furniture constructed by molding laminated wood veneer into three-dimensional forms. Today, steam bending is still quite common in furniture design, and although designs have evolved, the technique remains very similar.

In this study, a number of wood samples varying in species, shape, and size were bent using steam. The findings made it possible to speculate on potential architectural applications for steam bent wood at various scales.

Figure 7-3 (left) Michael Thonet Chair No 14., 1881

Figure 7-4 (right) Eames Lounge Chair, 1956, Charles and Ray Eames
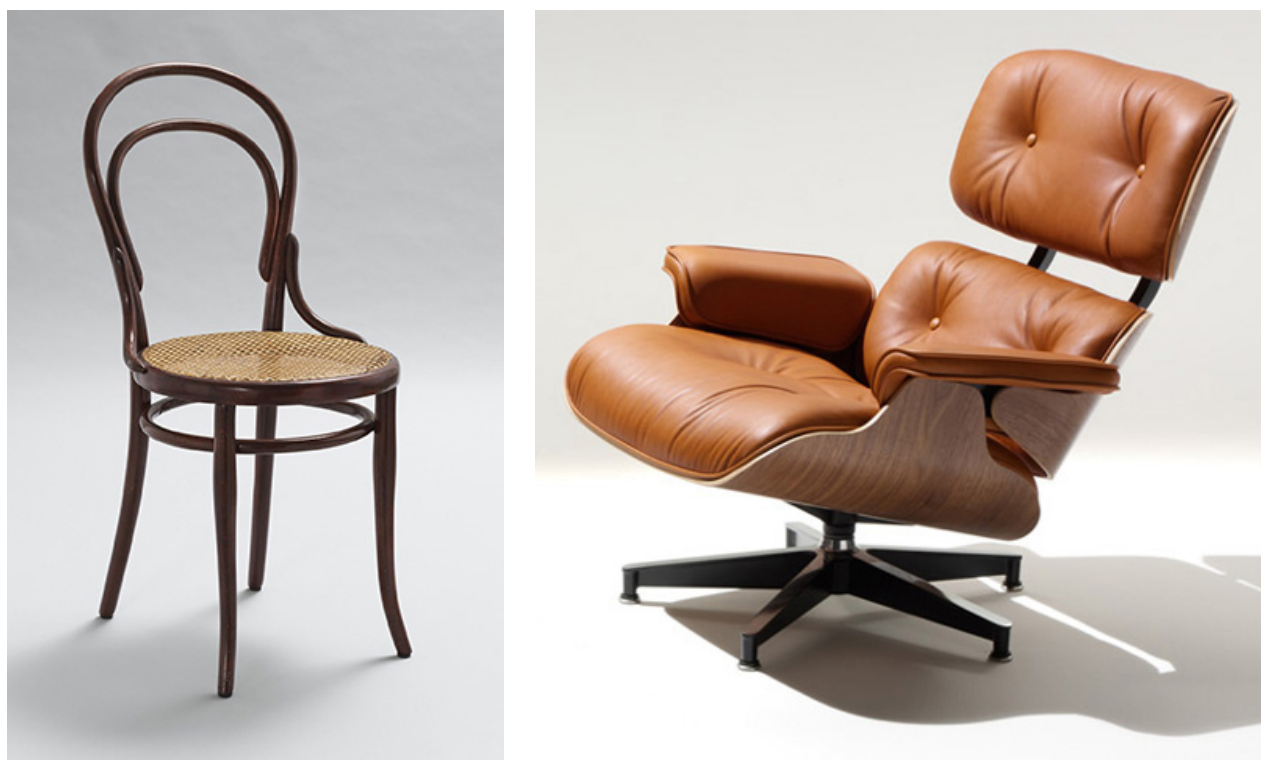



\section{Joinery}

In the book Thinking Architecture, Peter Zumthor describes buildings as artificial constructions consisting of parts that must be joined together. ${ }^{10}$ He goes on to argue that to a large extent, the quality of a building is determined by the quality of the joinery. ${ }^{11}$

This study investigates the use of moisture in the joinery of wooden members. Wood joinery using moisture is based on the principle that wood changes shape as it absorbs and releases moisture. As such, there is potential for members to be joined together forming tight fitting connections without the use of glue and/or metal fasteners.

Making use of wood's responsiveness to moisture for the purpose of joining wooden components is rooted in Japanese tradition and highlights the depth of knowledge that Japanese woodworkers have for the material. One example of this is the design of Japanese buckets that are used to carry water. Staves of wood are joined together to form the sides of the bucket, and the base is inserted at the end in a tight-fitting groove. ${ }^{12}$ After sizing the base to fit perfectly in the groove of the bucket, a hammer is used to compress the fibres all around the edge of the base, making the base slightly smaller, and allowing it to be positioned into the groove of the bucket. ${ }^{13}$ The base of the bucket is then soaked in warm water, expanding the compressed fibres into the groove of the bucket. ${ }^{14}$ When dried, the wood remains in its expanded state, sealing the base in the bucket whether wet or dry. ${ }^{15}$

A contemporary example of using wood's moisture responsiveness for joinery is dowel laminated timber (DLT). DLT is a mass timber product produced by stacking a series of rectangular wood sections and joining them together using hardwood dowels. ${ }^{16}$ The dowels range from $12-24 \mathrm{~mm}$ in diameter, and are dried prior to installation to a moisture content that is lower than the surrounding laminations and the in-service moisture equilibrium. ${ }^{17}$ As the hardwood dowels re-absorb moisture, they begin to swell, securing the laminations together to form a solid panel made entirely of wood. ${ }^{18}$

Wooden nails can also be used in the joinery of wood systems. A treenail is a wooden peg pin, or dowel used to fasten wooden members together. In the past they have mainly been used in the construction of wooden ships. Ancient shipbuilding used treenails to bind a boat together. ${ }^{19}$ Exposure to water caused the treenails to expand, keeping the planks tightly together. ${ }^{20}$

In this study, a series of joints were developed that rely on the moisture responsiveness of wood. 


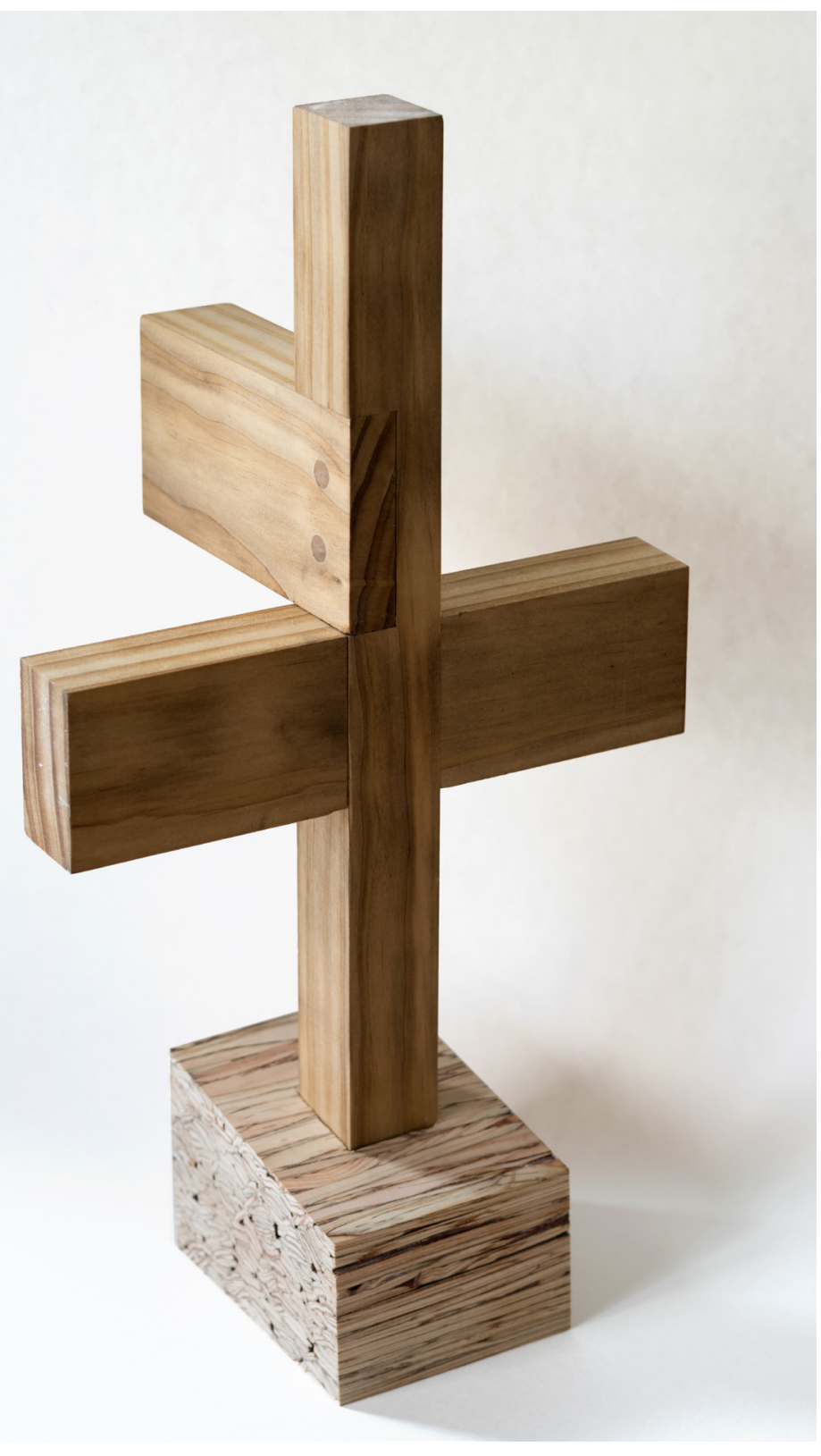




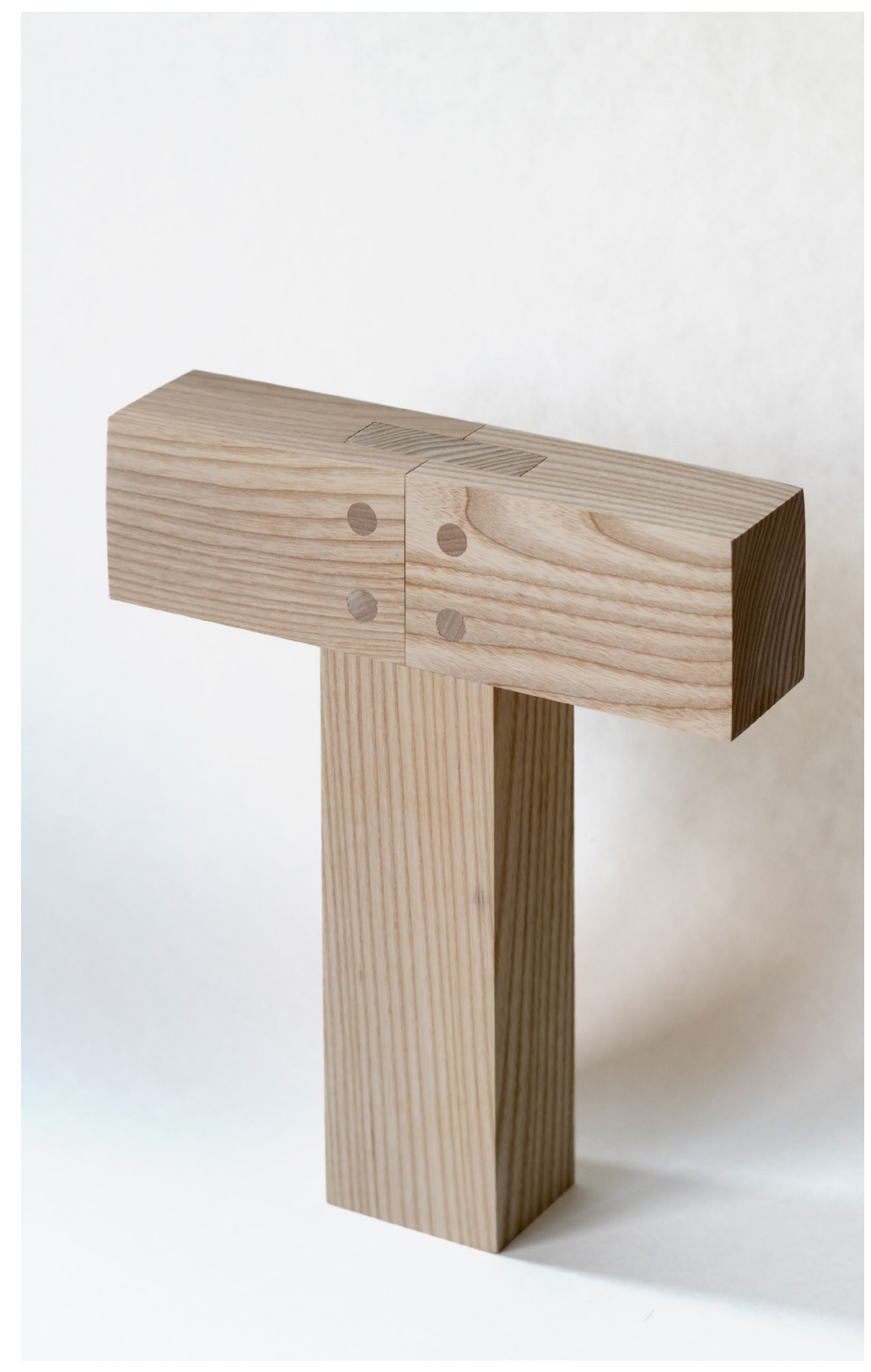




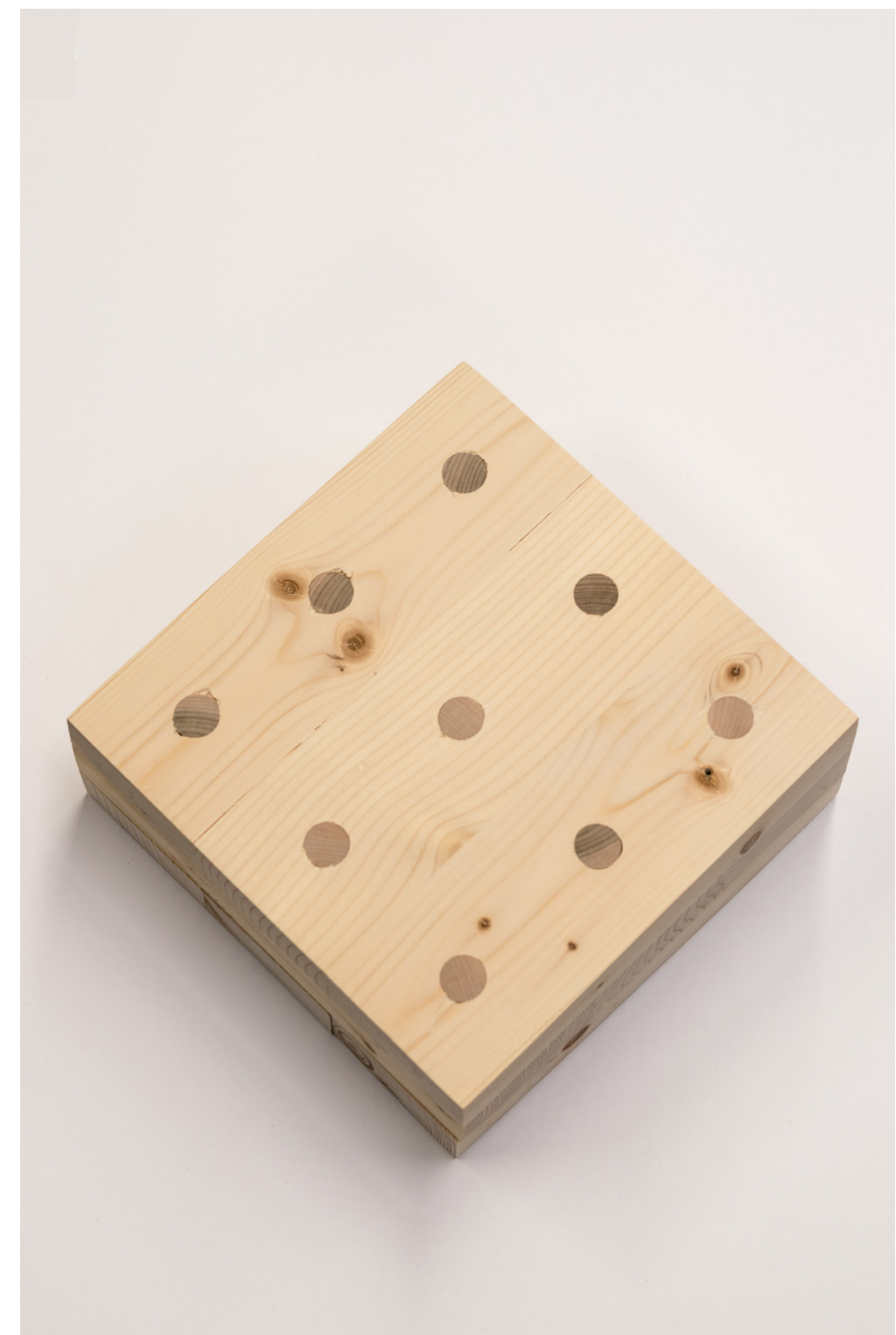

Figure 7-8

Wood joinery study 3 


\section{ENVIRONMENTAL STUDIES}

\section{Moisture Buffering}

One of the most important factors in determining human comfort and productivity is humidity. ${ }^{21}$ While the human body can make limited adjustments with long-term exposure to certain conditions, it is less able to adjust quickly to sudden or frequent changes. For example, it is commonly known that in the winter low humidity often results in dry skin and respiratory irritations.

Although the humidity level in a building depends on a combination of factors such as moisture sources, ventilation and air movement, sources and sinks, heating, insulation, external conditions and occupant behaviour, the moisture buffering performance of the materials within a space plays an important role. In fact, the moisture buffering performance of hygroscopic materials such as wood has been confirmed to significantly reduce the amplitude of relative humidity fluctuations, which has a favourable effect on perceived indoor air quality and thermal comfort. ${ }^{22}$

This study investigates the potential for wood to buffer moisture levels in interior environments. In high humidity environments, wood absorbs moisture, whereas in low humidity environments wood releases moisture, thus adjusting the indoor relative humidity without energy consumption. The ability of materials to buffer changes in indoor humidity depends on their active thickness, vapour permeability and moisture storage capacity. ${ }^{23}$

To date, the moisture buffering capacity of materials has largely been ignored by designers. One exception to this, as noted by Hassan Fathy, is the vernacular architecture of hot arid regions. ${ }^{24}$ Fathy explains how Islamic screen walls called mashrabiyas utilize the hygroscopic behaviour of wood to modulate the humidity of the air current passing through them for the purpose of cooling:

Wind passing through the interstices of the porous-wooden mashrabiya will give up some of its humidity to the wooden balusters if they are cool at night. When the mashrabiya is directly heated by sunlight, this humidity is released into the air that may be flowing through the interstices... The balusters and interstices of the mashrabiya have optimal absolute and relative sizes that are based on the area of the surfaces exposed to the air and the rate at which the air passes through. Thus if the surface area is increased by increasing baluster size, the cooling and humidification are increased. Furthermore, a larger baluster has not only more surface area to absorb water vapour and to serve as a surface for evaporation but also more volume, which means that it has more capacity and will therefore release the water for evaporation over a longer period of time. ${ }^{25}$

While the moisture buffering capacity of wood has been recognized for hundreds of years, it has rarely been employed in architecture, and only very recently has it been studied scientifically. Studies have shown that untreated wood covering 
products can reduce the extreme values caused by variations in indoor air humidity up to $63 \%$, when compared to rooms with painted drywall. ${ }^{26}$ The buffering of indoor humidity through the use of wood-based hygroscopic materials has also been shown to reduce heating and cooling energy consumption by up to 5\% and $30 \%$, respectively. ${ }^{27}$ Direct savings (savings in the heating and cooling of a building that result when applying hygroscopic materials) were found to be in the order of $2-3 \%$ for heating and $5-30 \%$ for cooling. ${ }^{28}$ Indirect savings (savings that result from adjusting the ventilation rate and indoor temperature while maintaining adequate indoor air quality and comfort with hygroscopic materials) were found to be in the order of $5 \%$ for heating and $5-20 \%$ for cooling. ${ }^{29}$

The study conducted for this thesis investigates methods of increasing the rate of moisture absorption and release in wood. In this study, the rate of moisture absorption of various wood samples varying in species and surface area was measured. First, the weight of the samples was recorded. Then the samples were submerged in a bath of water for two minutes. After an additional two minutes, the samples were weighed again to determine how much moisture they had absorbed. It was found that the samples with a high surface area absorbed significantly more moisture when compared to samples with a low surface area. 


\begin{tabular}{|cccccc|}
\hline Sample & Wood Type & Surface Area & Weight (Dry) & Weight (Wet) & Delta \\
01 & Cedar & Low & 100.9 & 110.0 & $9 \%$ \\
02 & Cedar & High & 78.2 & 108.2 & $38 \%$ \\
03 & Pine & Low & 79.7 & 85.4 & $7 \%$ \\
04 & Pine & High & 61.0 & 89.5 & $47 \%$ \\
\hline
\end{tabular}

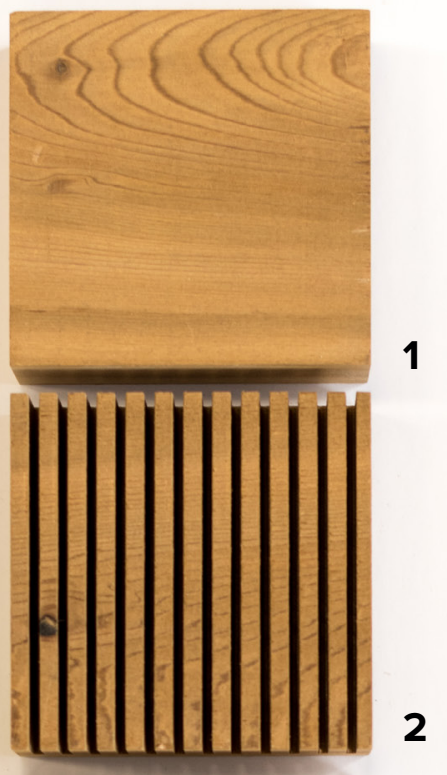

3

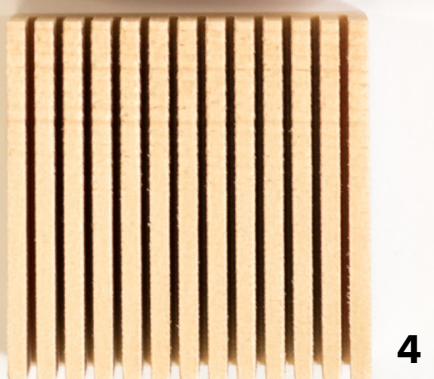

Figure 7-9

Moisture buffering 


\section{Responsive Envelopes}

It is widely recognized that one of the most effective ways to reduce building energy use is to increase the exploitation of natural heating, cooling and light, while reducing dependence on powered systems. This requires building envelopes to intelligently interact with environmental dynamics. This study investigates the use of wood as a responsive material that can be used in the creation of low-tech responsive building systems that react to fluctuating environmental conditions. The programming of such systems gives way to the possibility of a simple yet truly ecologically embedded architecture in constant feedback and interaction with its surrounding environment.

Most attempts towards climate-responsive architecture rely heavily on elaborate technical equipment superimposed on otherwise inert material constructs. In contrast, natural systems embed all the responsive capacity in the structure of the material itself. Menges and Reichert argue that "this physical programming of material systems without using additional technical devices enables a shift from a mechanical [paradigm] towards a biological paradigm of climate-responsiveness in architecture". ${ }^{30}$

As cited by Holstov, Bridgens \& Farmer, the cladding of traditional Norwegian boathouses in Nordmore is an example of a simple climate responsive wood facade dating back to the 19th century. ${ }^{31}$ Contrary to conventional wood panelling methods, the walls of the boathouses were made from plain-sawn wooden planks nailed towards their upper edges allowing them to bow upwards in dry weather to enhance natural ventilation of the interior space, and straighten in wet weather to restore weather tightness. ${ }^{32}$ The planks used for the boatsheds consisted of a single layer of wood, bending as a result of the difference between the shrinkage along and across the growth rings. ${ }^{33}$

More recently, research has been conducted at the ICD relating to weather responsive envelopes using wood veneers. This research has been inspired by biological precedents such as pine cones that offer ways of creating responsive systems using no-tech strategies. Based on the opening and closing of pine cone scales in response to changes in moisture, the HygroSkin-Meteorosensitive Pavilion employs the dimensional instability of wood in relation to moisture content to construct a metereosensitive architectural skin that autonomously opens and closes in response to weather changes but neither requires the supply of operational energy nor any kind of mechanical or electronic control. ${ }^{34}$ The HygroSkinMeteorosensitive Pavilion employs the bilayer principle to transform anisotropic dimensional changes into bending. Bilayer theory, developed for thermally responsive bimetallic alloys, describes the curvature resulting from combining multiple layers with different coefficients of expansion. The bilayer wood composite system used in the HygroSkin-Meteorosensitive Pavilion combines wood veneer with a synthetic glass fiber material to enable fast and reliable responsiveness to environmental conditions. It was found that the curvature can be calculated 


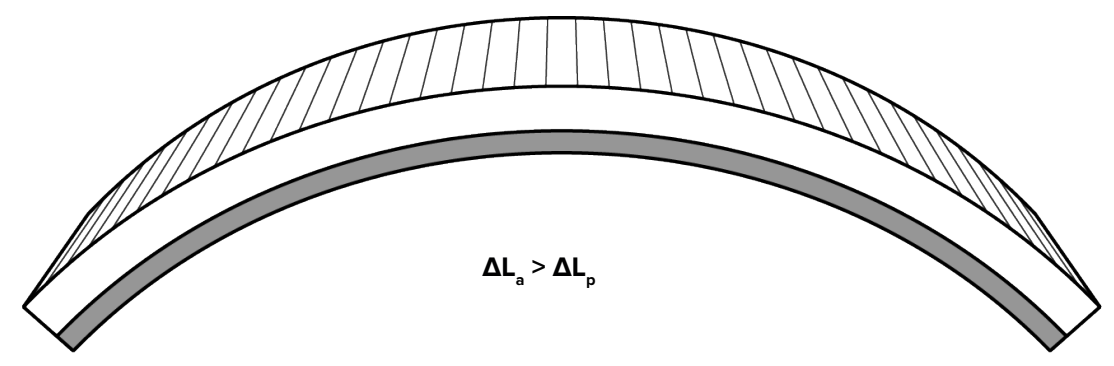

Figure 7-10 Bilayer composite

and predicted employing Timoshenko's theory on bi-metals. ${ }^{35}$ In addition, woodcomposite bilayer systems have proven to retain functionality in long-term field tests. ${ }^{36}$

The main parameters affecting potential applicability of the composites are responsiveness (the magnitude of shape changes), reactivity (response time), actuation capacity (determined by the force produced as a result of the response), structural resistance (ability to withstand applied loads without excessive deflection and irreversible damage), durability (resistance to degradation), sustainability (environmental impact, effects on people and economic considerations) and aesthetics. ${ }^{37}$ Many of these parameters are interrelated and therefore must be considered together to develop an optimal design for a given application. Of all these factors, scaling up is the principal challenge in developing such materialbased systems for the simple reason that materials behave differently, in a nonlinear manner, at different scales. As such, Branko Kolarevic hypothesizes that larger scale adaptive systems that rely on shape or volume changes in materials will likely be based on some kind of hybrid actuation, such as the mechanic amplification of material-based actuation. ${ }^{38}$

In this study, veneers of various shapes, sizes, and wood species were exposed to fluctuating humidity conditions in order to gain firsthand knowledge of how various factors affect the response. Although no long-term tests in a full range of weather conditions were conducted, such tests have been conducted by others. In one study, researchers tested the durability of responsive wood cladding systems over a one-year period, and found that in general, they performed extremely well across the board. ${ }^{39}$ These results provide the basis to speculate more accurately on the design of responsive wood systems for the built environment. 
Figure 7-11 (left)

Impact of venner cut on response

Figure 7-12 (right) Impact of grain direction on response

Figure 7-13
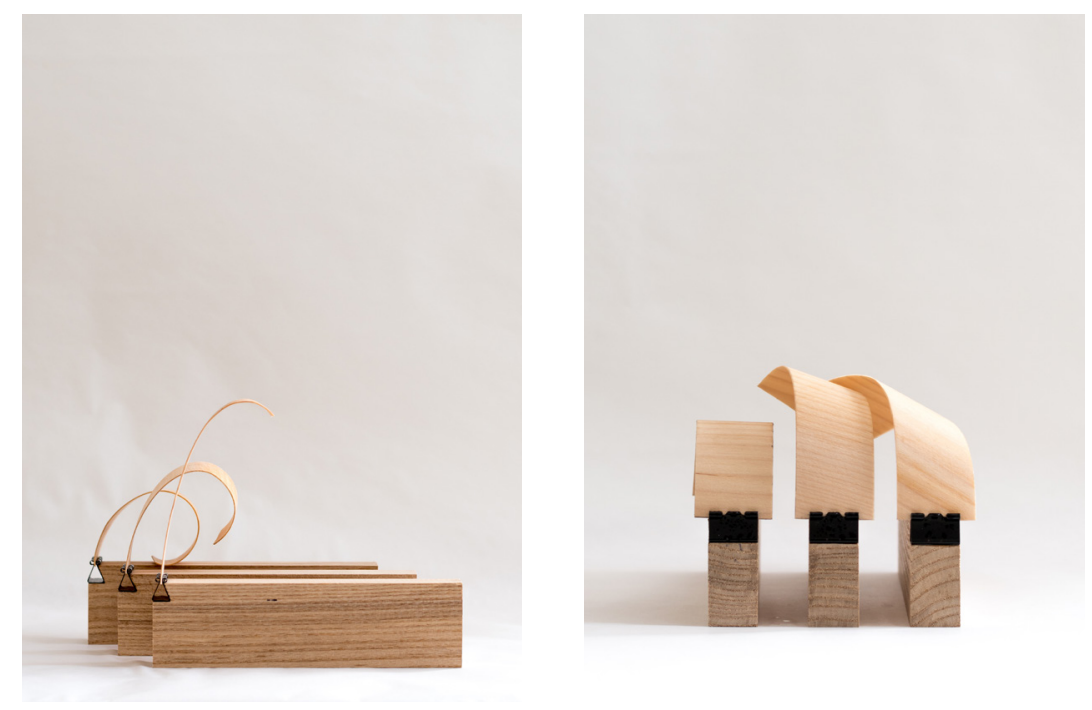

Impact of aspect ratio on response

Figure 7-14

Pre-programming hygromorph response 
In addition, a study of Shou Sugi Ban investigated how wood's responsiveness to moisture can be diminished. In this experiment, a sample of cedar was charred on all of its faces, leaving behind a dense layer of carbon that sealed the wood and made it more resistant to rot, insects, and fire.
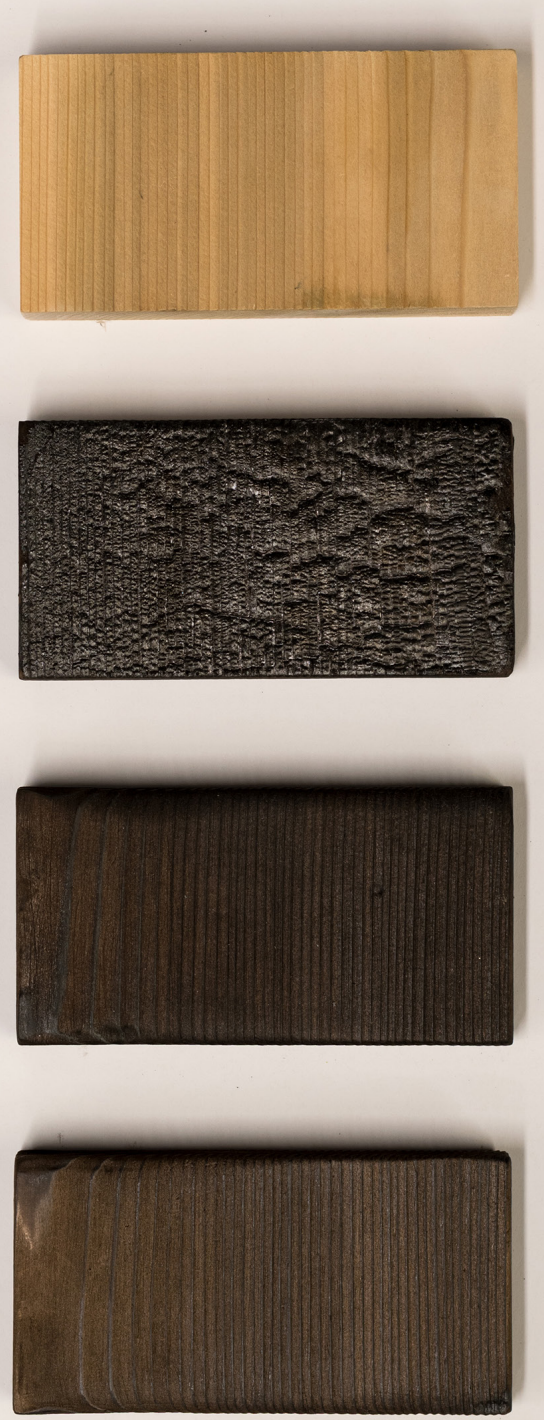


\section{THE EXPRESSION OF HYGROSCOPICITY IN ARCHITECTURE}

Although hygroscopicity is a dynamic process that has the potential to affect our experience of space through design, the expression of hygroscopicity in architecture can often be quite subtle. Take for example the application of wood's hygroscopicity to hold joints together using expanding dowels. Once the kiln-dried dowels are inserted into the joint, they begin to reabsorb moisture, expand, and ultimately lock the joint. The intention is that the dowels will never become as dry as they once were, ensuring that the joint stays tight. Likewise, in the case of steam bending, wood that has been formed into place quickly stiffens and holds its shape permanently. In these two examples, the dynamic nature of wood's hygroscopicity is no longer apparent after it has been employed for the intended purpose. All that is left is a seemingly static object that provides evidence of the hygroscopic nature of wood. On the other hand, the hygroscopicity of wood can be employed in design in a way that expresses its dynamism in a more pronounced manner. An example of this is the use of wood veneers that change shape in response to fluctuations in humidity. Here, the shape change of the wood veneers is easily perceptible to most and the changes are continuous.

The examples mentioned above demonstrate the broad spectrum on which wood's hygroscopicity can find expression in architecture. In the former examples, the dynamic nature of wood's hygroscopicity is barely perceivable after a certain point in time, whereas in the latter example, it is much more pronounced, and continuously so. Somewhere within this spectrum lie other applications of wood's hygroscopicity in architecture. In the moisture buffering study discussed in the previous section, profiles were cut into the surface of a piece of wood to enhance its hygroscopic properties. If this was applied to a series of walls that defined a space, one would be able to perceive the impact of wood's hygroscopicity by their ability to sense humidity. Here, one would not be able to see how the hygroscopicity of wood affects design, but instead, one would feel it. Finally, in some architectural applications the hygroscopic nature of wood may need to be diminished. Here, the dynamic process is eliminated altogether, and thus its potential for expression in architecture is also lost.

The design of the bathhouse for this thesis utilizes the hygroscopic nature of wood in various ways, resulting in various architectural expressions. In some instances the expression will be highly visible and pronounced, whereas in other instances it will be more subtle. In some instances the hygroscopic nature of the wood being used may need to be eliminated altogether. Ultimately, what is most important is how these different expressions are layered together to create a rich experience of the space. 


\section{NOTES}

01 Gilles Deleuze, Félix Guattari, A thousand plateaus:" Capitalism and schizophrenia, (University of Minnesota Press, 1987$), 451$.

02 Edward Peck. Bending Solid Wood to Form. (USDA, Forest Service, 1957), 8.

03 Ibid., 2.

04 Ibid., 8.

05 Laboratory, Building News Inc. \& Forest Products. Wood Engineering Handbook (2nd Edition), (BNI Publications Inc., 2000$), 136$.

06 Ibid., 134.

07 Ibid., 134.

08 Ibid., 134.

09 Peck, Op. cit., 6.

10 Peter Zumthor, Thinking Architecture, (Birkhauser, 1998), 13.

11 Ibid., 13.

12 Hugh Miller, “Japanese Wood Craftsmanship," Hugh Miller Furniture, accessed November 2018, https://goo.gl/XnWutZ

13 Ibid.

14 Ibid.

15 Ibid.

16 "Dowel Laminated Timber Design Guide \& Profile Handbook," StructureCraft, accessed November 2018, https://goo.gl/e8XgFH

17 Ibid.

18 Ibid.

19 Pentti Kettunen, Wood: Structure and Properties, (Trans Tech Publications, Ltd., 2006), 377.

20 Ibid., 377.

21 Olalekan F. Osanyintola \& Carey J. Simonson, "Moisture buffering capacity of hygroscopic building materials: Experimental facilities and energy impact," Energy and Buildings 38, 10 (2006): 1270.

22 Ibid., 1270-1282.

23 Ibid., 1271.

24 Hassan Fathy, Natural Energy and Vernacular Architecture: Principles and Examples with Reference to Hot Arid Climates, (University of Chicago Press, 1986), 48-49.

25 Ibid., 48-49.

26 Hartwig M. Künzel et al., "Moisture buffering effects of interior linings made from wood or wood based products," (IBP report, 2004).

27 Olalekan F. Osanyintola \& Carey J. Simonson, Op. cit., 1270.

28 Ibid., 1281.

29 Ibid., 1281.

30 Achim Menges \& Steffen Reichert, "Material capacity: Embedded responsiveness," Architectural Design 82, 2 (2012): 54.

31 Artem Holstov, Ben Bridgens \& Graham Farmer, "Hygromorphic materials for sustainable responsive architecture," Construction and Building Materials 98 (2015): 571.

32 Ibid., 571.

33 Artem Holstov, Ben Bridgens \& Graham Farmer, "Hygromorphic materials for sustainable responsive architecture," Construction and Building Materials 98 (2015): 572.

34 Oliver David Krieg. "HygroSkin - Meteorosensitive Pavilion," in Advancing Wood Architecture eds. Achim Menges, Tobias Schwinn \& Oliver David Krieg. (Routledge Taylor \& Francis Group, 2017), 125-136.

35 S. Timoshenko, "Analysis of bi-metal thermostats," JOSA 11, 3 (1925): 233-255.

36 Markus Rüggeberg \& Ingo Burgert, "Bio-inspired wooden actuators for large scale applications," PloS One 10, 3 (2015).

37 Artem Holstov, Ben Bridgens \& Graham Farmer, Op. cit., 574.

38 Branko Kolarevic, "Actualising (overlooked) material capacities," Architectural Design 85, 5 (2015): 131.

39 Artem Holstov, Graham Farmer \& Ben Bridgens, "Sustainable Materialisation of Responsive Architecture," Sustainability 9,3 (2017): 435. 
Figure 8-1

Bathhouse west elevation

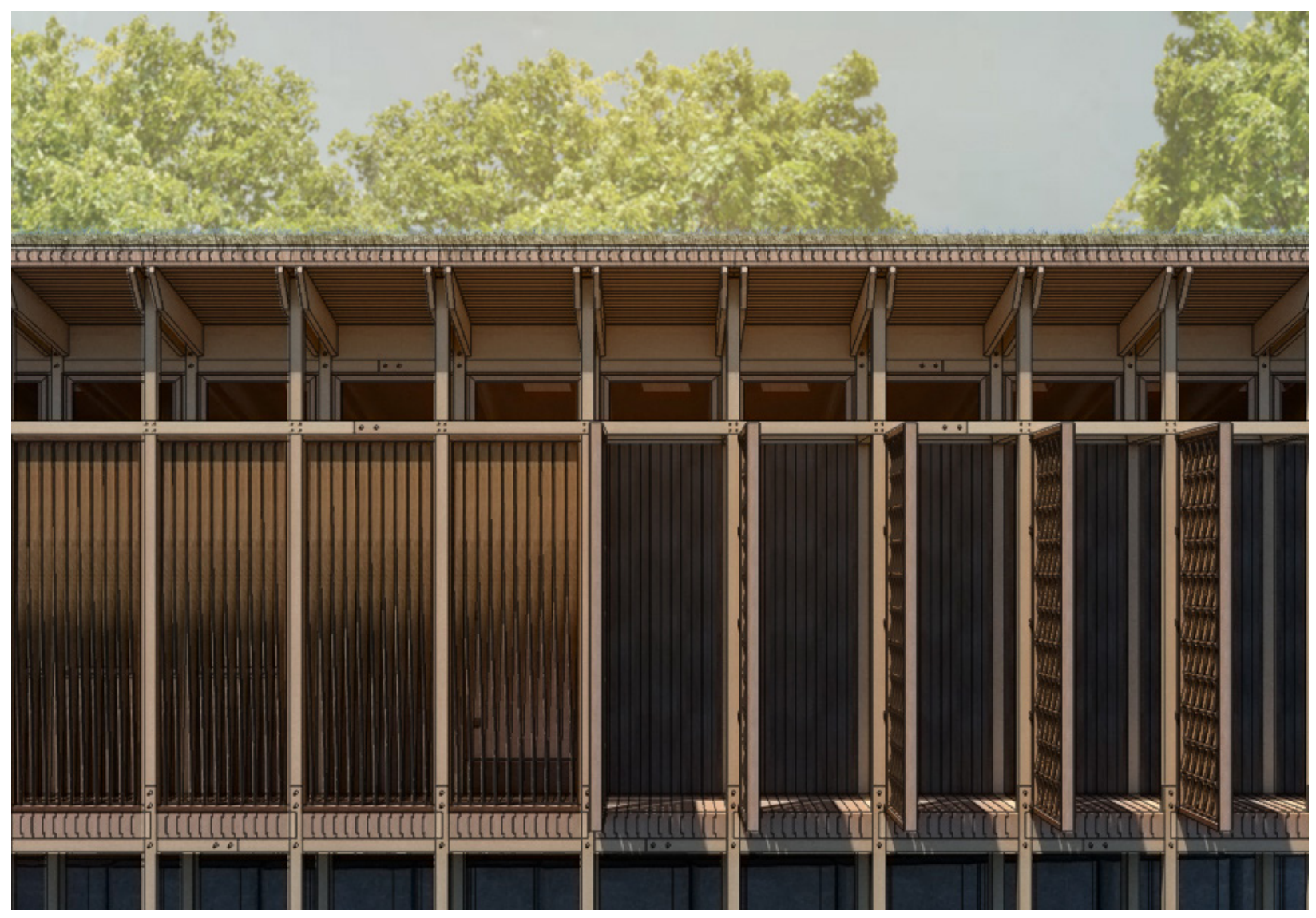




\section{8 | BATHHOUSE}

\section{DESIGN}

The design of the bathhouse on Villiers Island was informed by the previously presented design research, which investigated the implications of wood's responsiveness to environmental conditions. The bathhouse serves as a vehicle for testing this research against real world constraints.

The bathhouse is situated within a rich context. It is located at the northwest shore of Villiers Island overlooking Toronto's inner harbour. Placing the building within its context was a very important part of the design process. As Peter Zumthor argues, when a building is placed within a landscape, it must be welcomed by it and appear to have always belonged there. ${ }^{1}$ In order to have the landscape accept the building, one of the critical considerations was the choice of materials. Ideally, a building should be made of materials that belong to the site and can be sourced from it. In the case of the bathhouse, the building is constructed of wood sourced almost entirely from trees native to the area. The bathhouse aims to unravel the very essence of the selected wood species, and use each one in a precise and sensuous way, expressing and celebrating their natural characteristics. At the same time, the design carefully considers the role of water, fire, and stone.

The bathhouse is open to all members of the public, and can be used by up to 10 people at a time. To get to the bathhouse, one follows a path originating from an urban plaza located 100 meters south of the site. As one walks along the path, they 


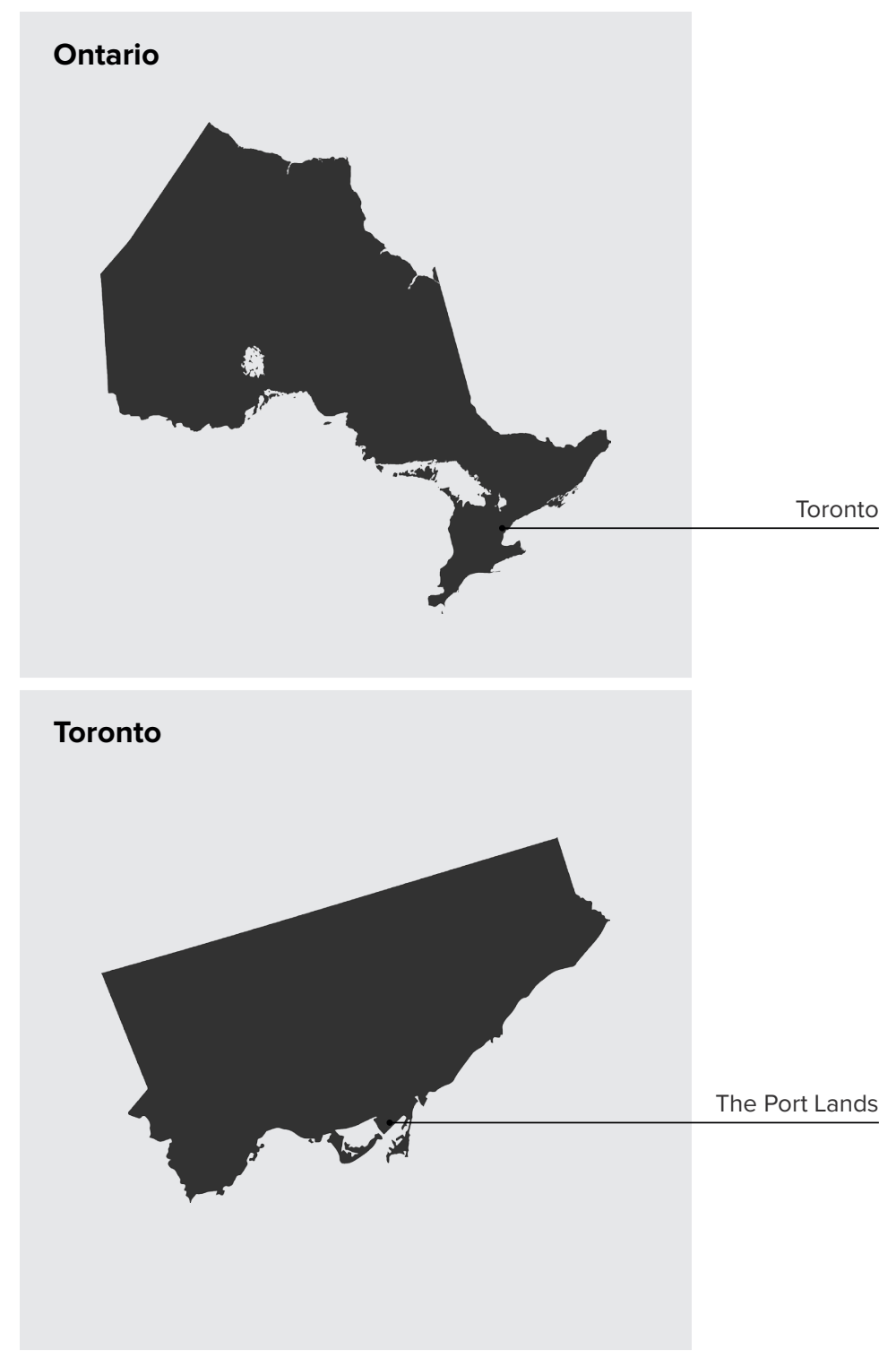

\section{Villers Island}

Figure 8-2

Site location 


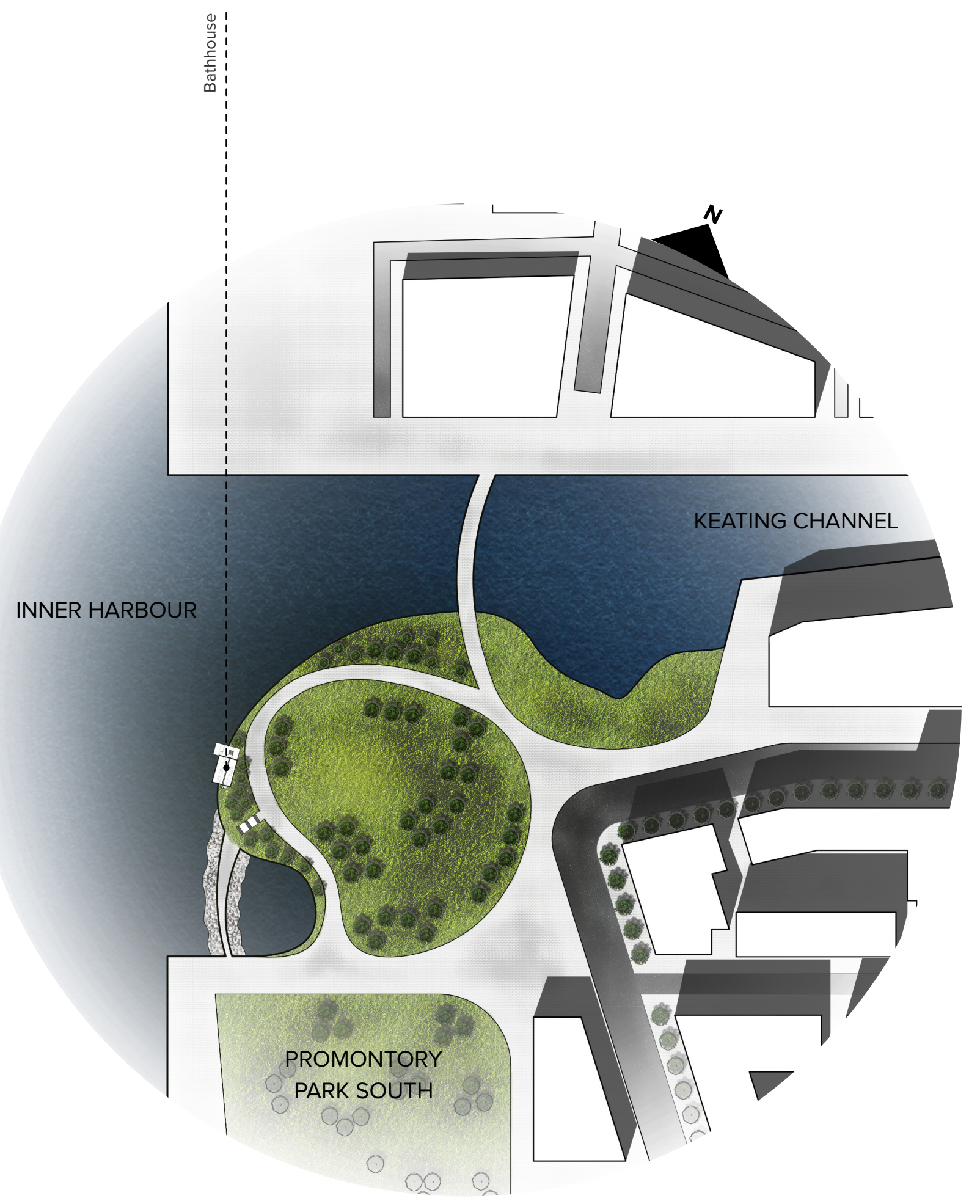

Figure 8-3

Site plan 
quickly become immersed in greenery and begin to leave behind the excitement of the city. Similar to the Japanese practice of shinrin-yoku or "forest bathing", the journey of getting to the bathhouse provides the opportunity for one to wander through nature, mindful of their surroundings. The sounds and smell of the trees, the sunlight filtering through the leaves, the fresh air-all of these things help to dissolve one's stress and worry while giving them energy and vitality.

As one nears the bathhouse, its charred wood exterior begins to emerge. At once it feels both ancient and modern. In fact, the entire building exudes a primal auraboth in the way that it functions, and the way it was constructed. Like many of the earliest bathing structures, it embraces minimalism, and advocates for a life stripped down to the bare necessities. Though the construction of the building is simple in its concepts, it is also highly sophisticated, with well-conceived details that embrace the joints and reveal methods of construction.

From the outside, the building appears to be firmly rooted, yet in actuality it touches the site very gently. For the most part, it rests on a wooden structure that hovers just barely above the earth. In order to bring visitors closer to the lake, part of the building extends beyond the shore, bearing on wooden posts submerged in the lake water. The lack of oxygen in the water prevents the submerged wood from rotting over time. Furthermore, using wood that has been cut from the centre of the log gives the structural members enhanced moisture and decay resistance. These submerged timber posts form the basis of the structural grid for the building. Bearing on these posts are beams that carry the weight of the building above. At the intersection of the post and beam, the general approach to joinery is apparent. Structural members interlock and are secured with wooden dowels that were dried prior to installation. Once in place, the dowels naturally re-absorb moisture from the air, expanding in volume, and forming a very tight connection without the use of

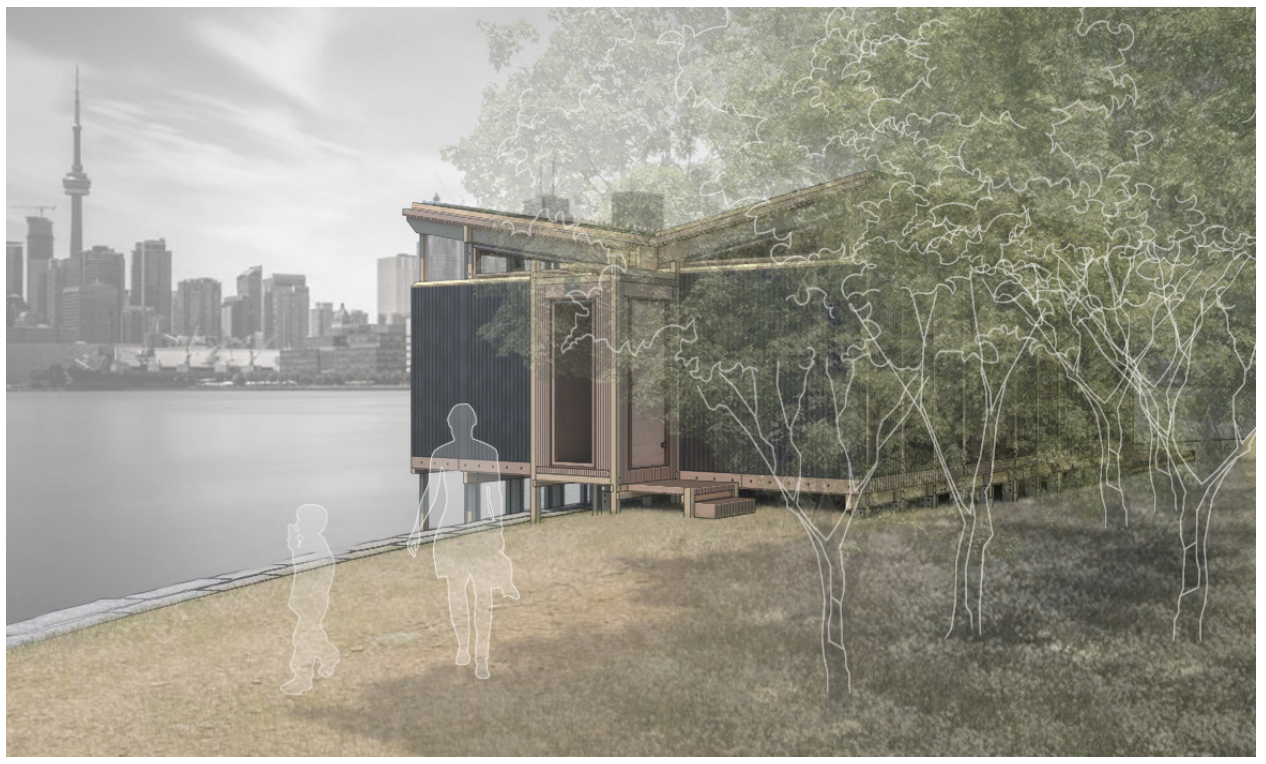


glue or metal fasteners. Here, and in several other instances throughout building, the dowels used to secure the joints become an important part of the building's expression.

Within the post and beam framework sits the building-a rectangular bar that emphasizes the sloping terrain of the site. The exterior walls of the bathhouse consist of $4 \times 8$ cedar planks laminated together without glue, but rather with a combination of dowels, and dovetail joints to ensure air tightness. This simple assembly is at once the interior finish, exterior finish, insulation, air barrier, and structure. Cedar was chosen for its durability, pleasant aroma, and high insulating capacity. At R-10, the assembly provides just enough of a thermal buffer so that on the coldest of days, one's thermal experience of the bathhouse is amplified and elevated. On the interior side of the walls, custom profiles are milled into the cedar planks to increase the surface area to volume ratio, thereby increasing the moisture buffering capacity of the wall. This in turn helps to maintain a comfortable humidity level within the space. At the same time, the milled profiles increase the potential for the wood to absorb and diffuse sound, thereby improving the acoustics of the space. On the exterior face of the walls, the cedar planks are charred to provide resistance to rotting, insects, and fire. Over time, this black and blistered surface will transform as it is touched by various forces.

Cedar is also used for the outdoor terrace located on the north side of the building. As it ages, the cedar will develop a wonderful silver-grey patina and take on a character of its own.

Perhaps the most essential facade is the west façade, which overlooks the lake. It is divided by vertical posts that extend from below the water to the underside of the roof. A narrow passage, accessible to visitors, separates the façade from a timber screen that sits in front of it. Where the façade has windows, the timber screen

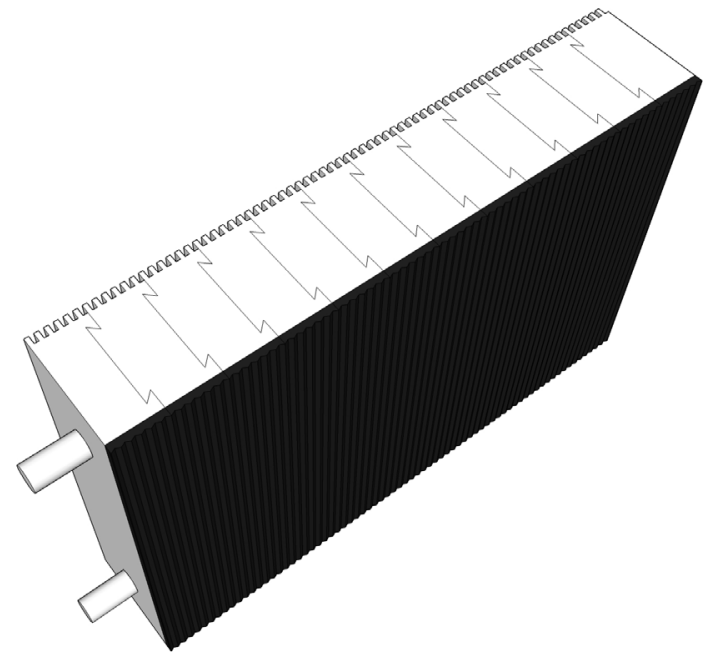


consists of panels of vertical white oak fins. Using a process of steam bending, the fins were strategically twisted to create a system that blocks harsh western sunlight, while at the same time guiding views towards the city skyline. For the rest of the façade, the timber screen consists of panels of thin beech wood strips that change shape in response to fluctuations in humidity and temperature. These panels pivot on wooden hinges and can be opened or closed throughout the year. In the summer, the screens will remain open and enable visitors to sit on the edge of the structure gazing over lake. In the winter, the screens will remain closed and shelter the passage, which will then be used to store firewood.

Inside the bathhouse, natural light enters from above through skylights and clerestory windows that wrap the entire building. On the east and west side, these windows are operable, offering the potential for cross ventilation in the warmer months of the year.

Figure 8-6

Twisted wood shading screen
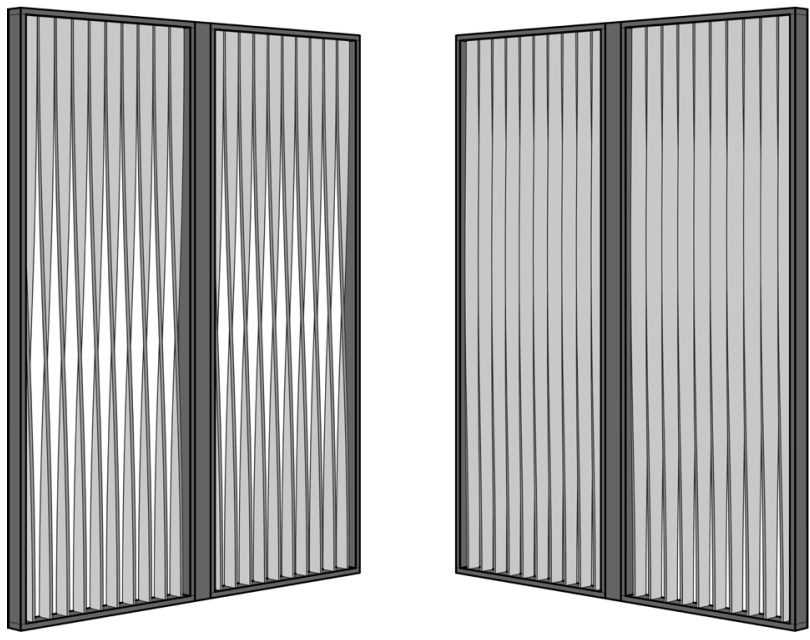

Figure 8-7

North-western corner

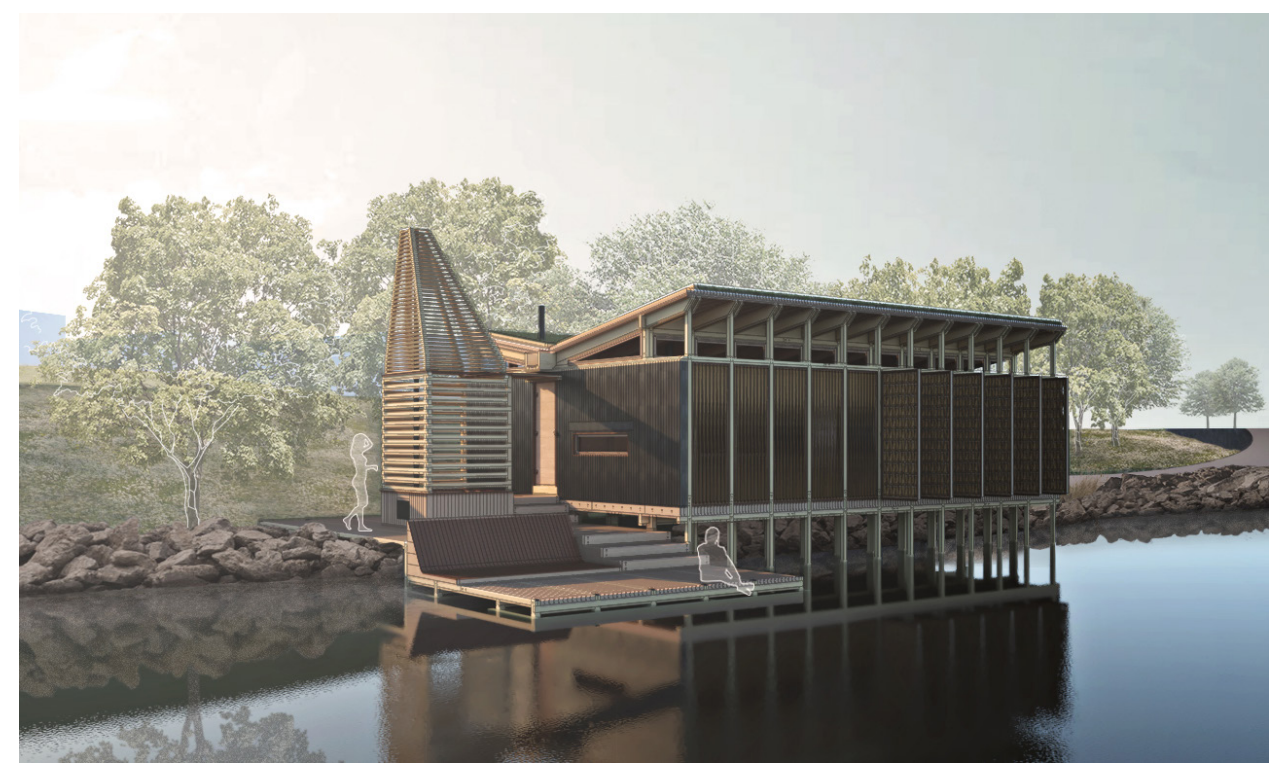



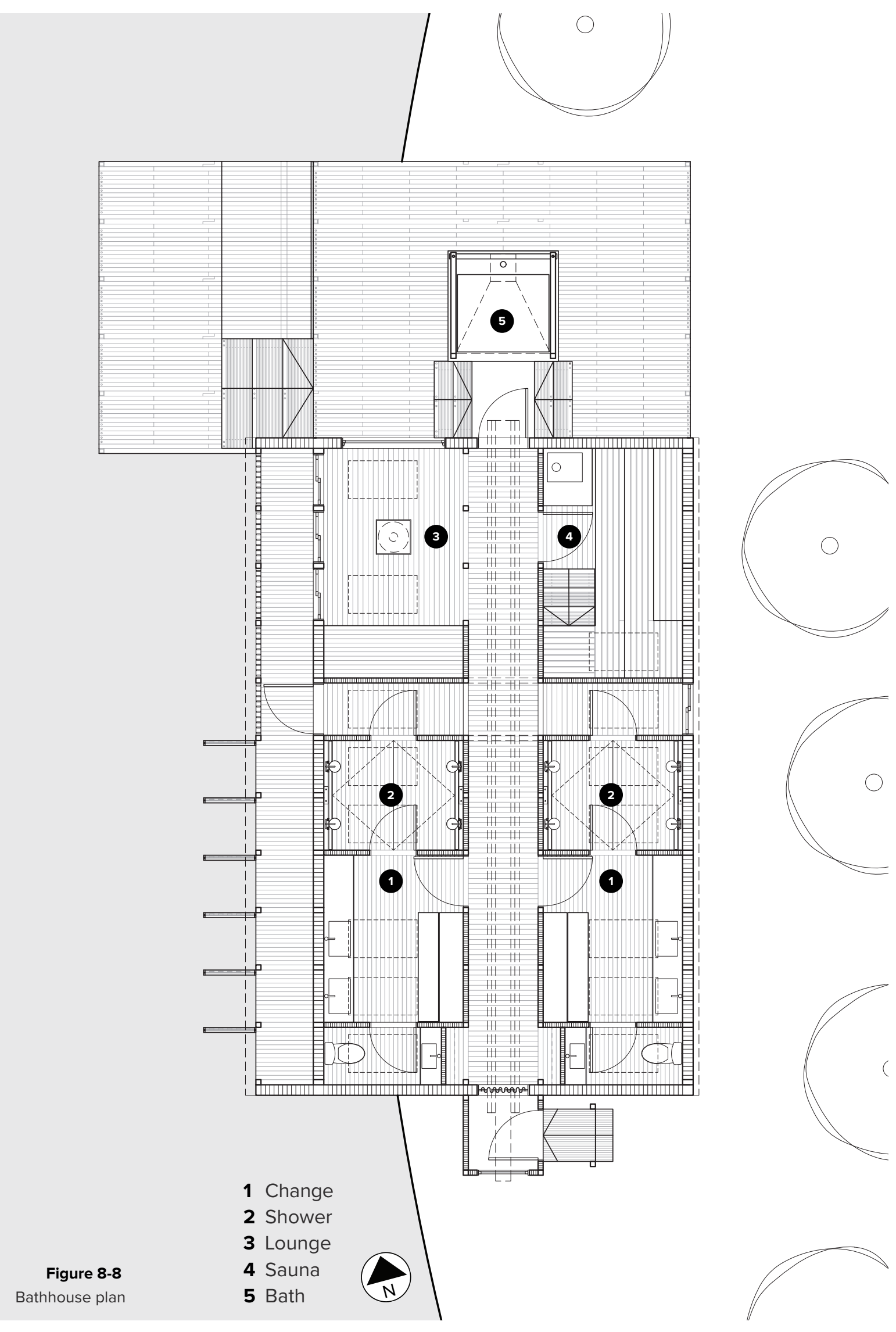
A ' $V$ '-shaped extensive green roof encloses the building, minimizing the volume of interior space, and thus the amount of energy and time required to heat the space in the cooler months. The construction of the roof is based on traditional Norwegian birch bark and sod roofs, which have been said to last 50-70 years before needing to be refurbished. Birch bark is both water and decay resistant, and as such, has been used in the construction of canoes for centuries. The construction of a birch bark and sod roof begins with the harvesting of birch bark in the spring or early summer. One must take care in removing only the outer bark of the tree so as to not damage the tree. The bark must then be pressed and dried for several months before it can be used. Once it is ready to be used, the bark is laid on the structure of the roof in multiple shingled layers without using nails or any other means of fastening. Simultaneously, sod is laid in two layers on top of the birch bark from the eaves of the roof to its peaks. The first layer of sod is traditionally placed with the grass facing down to protect the bark from the acidic humus and act as a drain. Over time, the grass roots from the top layer permeate the lower layer and form one solid structure. At the eaves of the roof, the sod is held in place by strong beams. The sod both insulates the roof and protects the birch bark from sunlight and wind.

The interior of the bathhouse is organized in such a way that guides visitors through the space. One enters the building through a heavy wooden door that leads into a vestibule. To the right is a canvas curtain that brings them into the main hall of the bathhouse. Looking back for just a second, the curtain seems to glow as it filters southern light into the main hall.

The hall is the spine of the building, extending from the south end to the north. The finished flooring consists of 3" wide pale oak planks with 1/2" gaps between them. This configuration ventilates the service space below the floor, and also creates a distinct yet comfortable walking surface. At the same time, the hardness

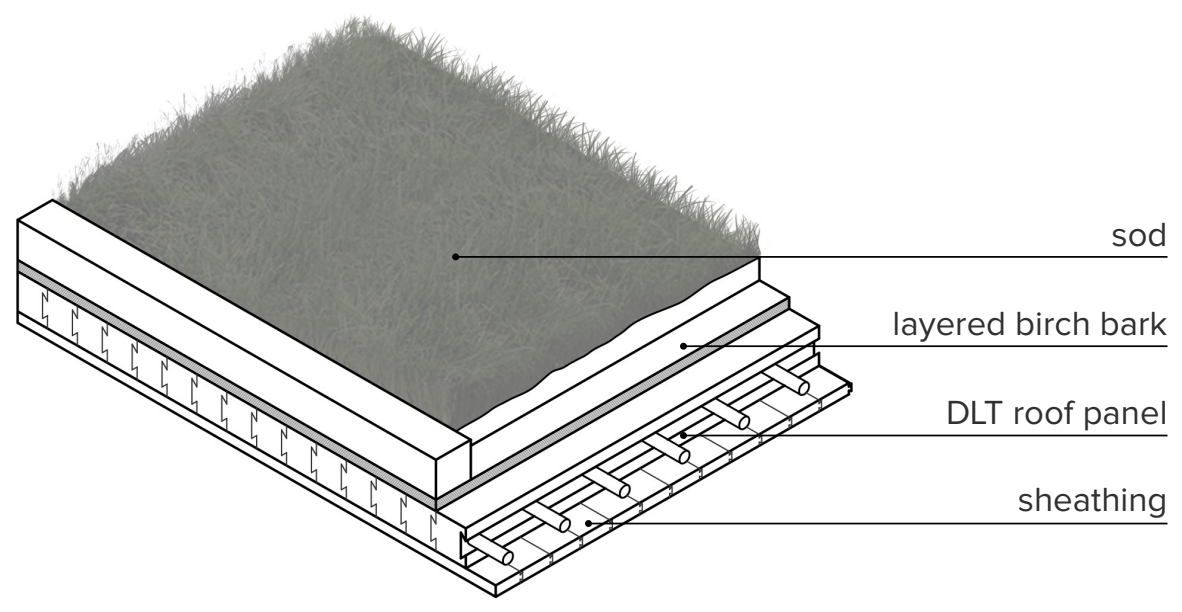

Figure 8-9

Birch bark roof 
Figure 8-10

Hall

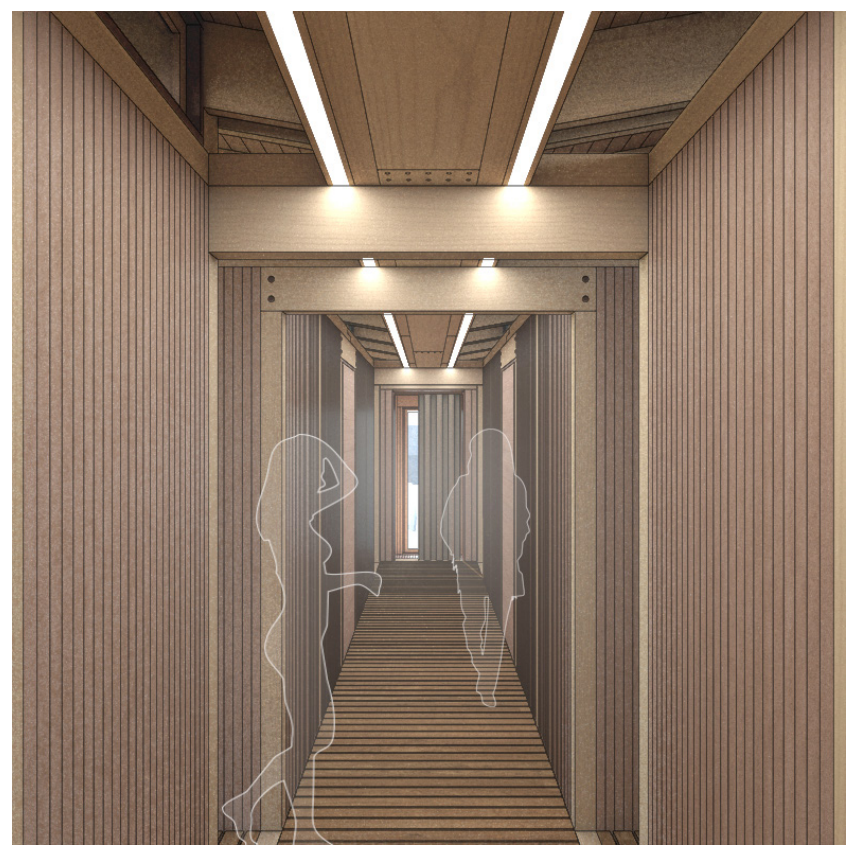

of the wood makes it very durable, ensuring that it will last a very long time. Upon entering the hall, one stores their coat and shoes and proceeds to walk down the hall where they encounter doors on either side. These doors lead to spaces where one leaves their garments and other belongings. Within the space, all the elements including sinks are made of wood. The benches and lockers are made of cedar, the counters of oak, and the sinks are made of ipe-an extremely durable and rot resistant hardwood.

Free of garments, one proceeds to shower. Showering before using a sauna or bath is important both for hygienic reasons and to remove the oily film from one's skin, enabling them to sweat faster. As the water from the shower flows off one's body, it travels across the dense ipe floor, before being naturally filtered and returned to the site. At the same time, some moisture is absorbed by the cedar that surrounds the space, intensifying its aroma. Having showered, one dries their body thoroughly and then makes their way towards the central hall before entering the sauna.

One hangs their towel on a wooden hook just outside the sauna and then proceeds to enter the space through a short door standing just 5.5 feet in height. The low door height prevents hot air from escaping the sauna when it is open. At the same time, as one lowers their body to pass through the door, they are faced with a condition that invites them to reflect on their presence within the space. The sauna is heated by a wood burning stove. Well-dried birch wood is used for the fire to ensure a long lasting burn and pleasant aroma. Inside the sauna, most of the surfaces are made of cedar. When the space is first heated, the cedar absorbs the heat evenly and its pleasant aroma is enhanced. For the benches, the low conductivity of cedar and the selection of planks without any knots ensure that the surfaces that one comes 
into contact with remain at a comfortable temperature. The sauna consists of three levels enabling one to choose the temperature they desire. As one climbs to a higher level, the temperature also rises. In addition, the temperature one experiences varies depending on how one chooses to sit or lie on the benches. Aside from the skylight and clerestory windows within the space, there are no other windows. This aspect of the design, in addition to the sound dampening properties of the sauna's walls, aids in creating an introspective atmosphere. Above the skylight-and all the skylights throughout the building-is a system of responsive apertures made of beech wood that respond dynamically to fluctuations in humidity and temperature. As conditions change throughout the day, the apertures open and close, casting shadows on surfaces within the sauna.

Throughout the session, occupants can ladle water onto the hot rocks in order to create a cloud of steam that envelops the bather. In Finland, this steam is referred to as löyly, which comes from the old Finnish word for spirit or soul. When the steam is created, the level of humidity in the sauna rises sharply, and occupants suddenly feel intense heat. However, this sensation lasts only for a brief period as the increased moisture in the air is quickly absorbed by the wood surfaces in the sauna. This rise and fall in humidity triggers another change within the space. As the humidity within the space fluctuates, the walls of the sauna, which are clad in strips of wood veneer, begin to breathe. When water is poured on the stones, the strips absorb the humidity in the air and begin to curl. Then as they dry out again, they return to their flat state. In this instance, the material assumes a poetic quality. The materials in and of themselves are not poetic, but as Peter Zumthor argues, materials become poetic when a meaningful situation is generated for them. ${ }^{2}$

Figure 8-11 Skylight shading system
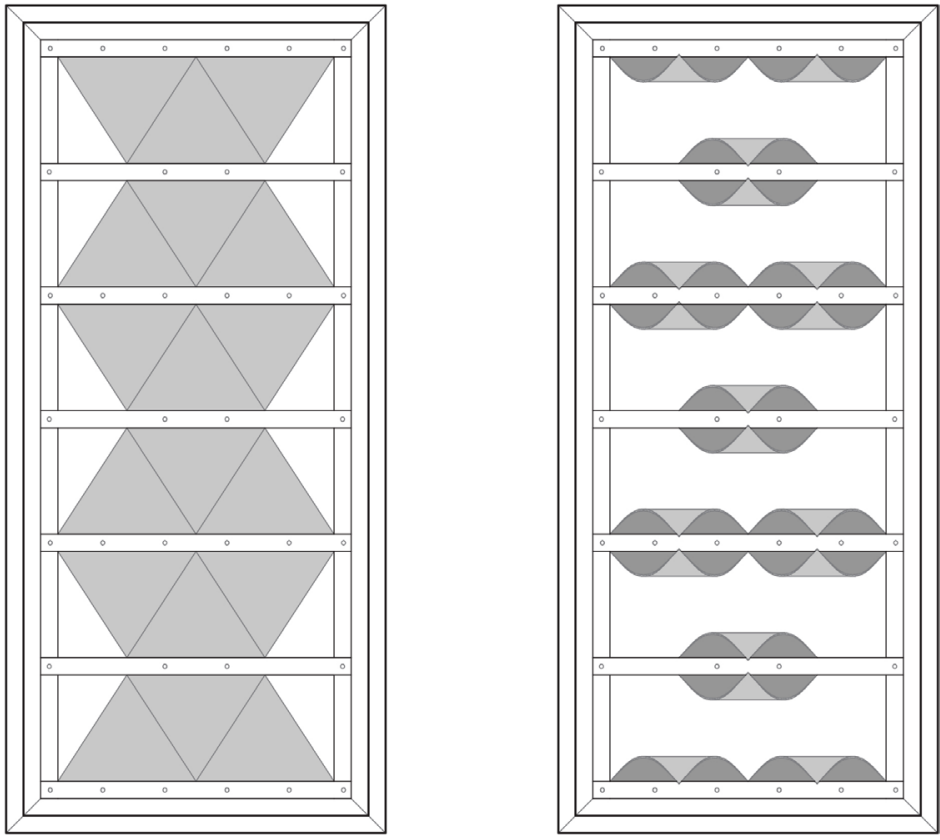

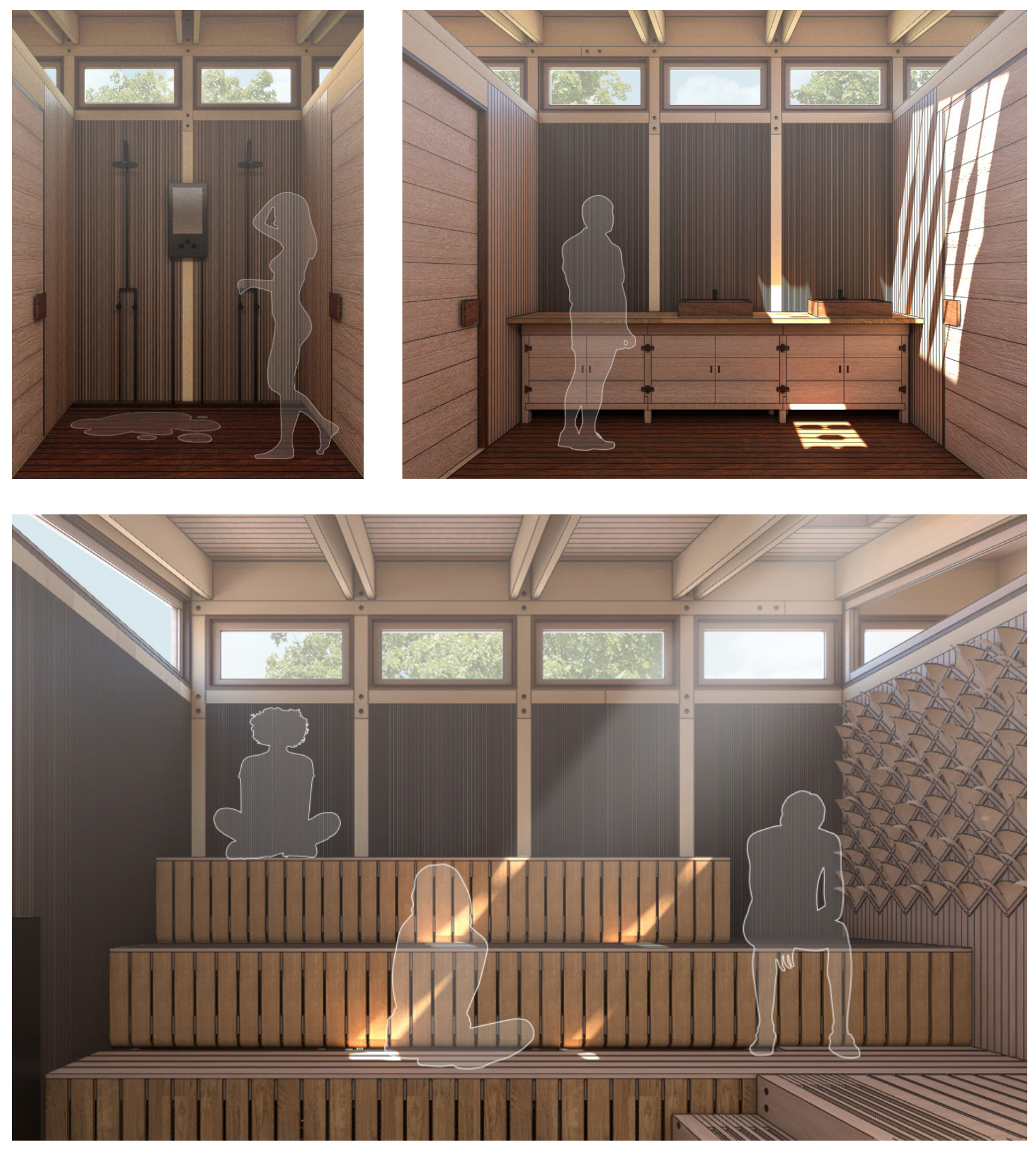

Figure 8-12 (top left)

Shower room

Figure 8-13 (top right)

Change room

Figure 8-14 (bottom)

Sauna 
It is also common in Finnish sauna culture for bathers to gently whisk their skin with a small bundle of fresh tree branches. Proponents argue that the ritual exfoliates the skin, improves circulation and relieves muscle pain. Most often, the whisk, or vihta is made of fresh birch twigs that are warmed in hot water and release a pleasant aroma when used.

Contrasting the heat of the sauna with cold exposure is common in many cultures. The benefits of this ritual are both physical and psychological. The transition from intense heat to intense cold causes the body to increase its heart rate, constrict blood vessels and induce a rush of adrenaline and endorphins. In the context of this project, the chilly water of Lake Ontario provides a convenient means for visitors to cool off after exposing their bodies to the heat of the sauna. The lake can be accessed from the northern terrace which steps down to the water. From here, one has the option to dip their feet in the water, or perhaps submerge their entire body. In any case, the cold water offers an invigorating jolt as it draws heat from the body.

After cooling off, one's body is stimulated and their heart rate elevated. It is thus crucial at this point in time to relax and let one's body return to its natural rhythm before repeating another thermal cycle. This time can be spent outside on the terrace or inside the building.

Should one choose to remain outside, they will be welcomed by a large wooden lounge chair, built into the terrace. Consisting of a series of wood slats that have been bent into shape, the chair is warm to the touch and cradles one's body as they lie on it and take in views of the lake and city skyline.

Inside the building, the main gathering space was designed to facilitate social interaction while offering majestic views of the inner harbour and city skyline. In the centre of the space is a hearth that draws people together, in addition to providing heat for the entire building. Cushions on the floor, made from plant-based materials, invite guests to sit around the fire and interact with one another.

Once one's body has returned to a neutral state, it is ready for another thermal cycle. This time, it begins inside the waters of a hot bath. Baths have often been places of pilgrimage, immersed in the surrounding landscape. The first baths were located at thermal springs, and they have since evolved into various iterations within different cultures. For this project, the design of the bath focuses on reconnecting one's body and mind. As one bathes, the combination of uniquely treated wood elements contributes to a mindful experience of one's body in space and time.

The bath is situated just outside the building to the north. Surrounded by lush greenery and views of the lake, it exists within a space that blurs the boundary between the constructed and the natural. The bath was built using joints that tighten when exposed to moisture. Enclosing the bath is a wood screen consisting of $4 \times 4$ cedar members laid horizontally, and stacked on top of each other with gaps in between. As hot water splashes onto the wood, the aroma from the wood engulfs the bather. Due to the low thermal diffusivity of wood, regardless of the outside 
temperature, the wood structure never feels too hot or too cold when one comes into contact with it, making it comfortable to lean on throughout the year. Above the bath is a vertical shaft that rises beyond the roof of the main building. Its purpose is to exhaust smoke from the wood fire that heats the bath water. At the top of the shaft is a square opening that provides a window to the sky and brings in light. After spending several minutes in the bath, one climbs out to cool off yet again, only to repeat the cycle as many times as they desire.

Figure 8-15

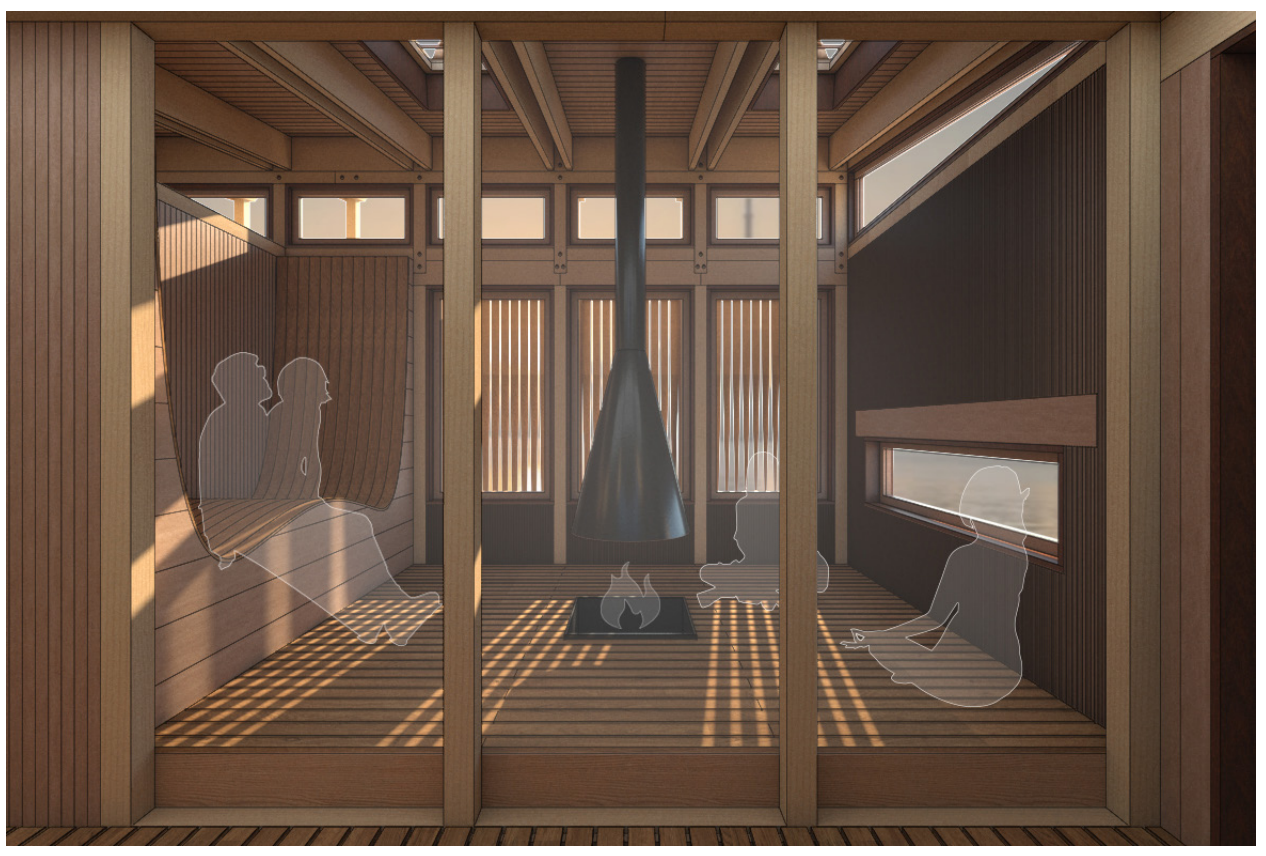

Figure 8-16
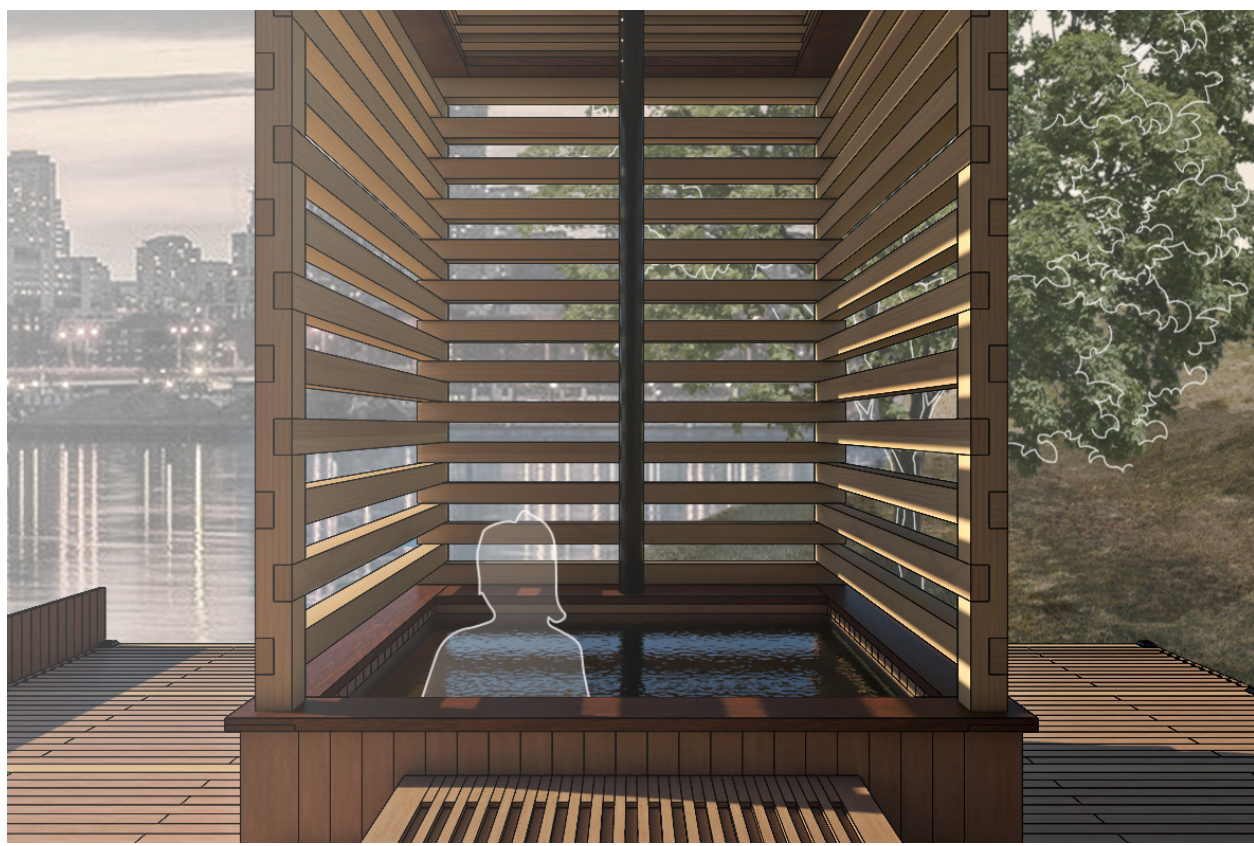

Outdoor bath 
Figure 8-17

Bath section

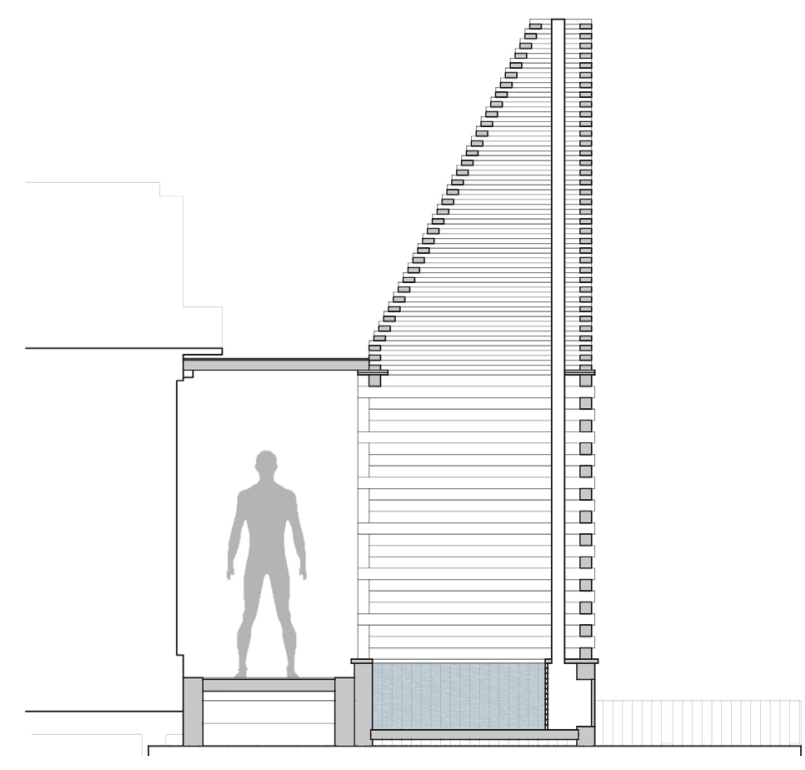

\section{CONCLUSION}

The bathhouse typology has often been used as a vehicle for exploring new architectural ideas. In this thesis, the typology serves as a means for investigating how a new wood architecture can emerge from a deep understanding of how the material responds to the surrounding environment. This is an area of architecture that has largely been neglected to date. The focus of this thesis was on the hygroscopicity of wood-a responsive capacity of the material that is often regarded as a disadvantage. The design project was informed by this potential, as well as its other unique characteristics. As such, emphasis was placed on material performance and behaviour rather than representation and form.

The first step in the design process was to study the physical and mechanical properties of wood, both at a general material level and at the level of individual wood species. This eventually formed the foundation on which the design project was based. After studying the various characteristics and capacities of the material, the focus shifted to one in particular-the material's responsiveness to moisture. From here, several studies were conducted that would later inform the design of the bathhouse.

One important decision that was made early on in the design of the bathhouse was the decision to work exclusively with wood, including avoiding the use of glue and metal fasteners. This decision played a significant role in determining the construction and architectural expression of the building. It demanded a detailoriented approach that led to the creation of unique joints and systems that were informed by the responsiveness of the material being used. Often, the use of the material was inspired by very old techniques that had fallen out of favour and have since rarely if ever been reconsidered. Looking at the historic use of the material 
with an understanding of today's technology brought to light new and improved ways of working with the material throughout the design process. This challenged mainstream approaches to design which often apply materiality to previously defined forms. Through the design of the bathhouse on Villiers Island, this approach was tested, and from it emerged a low-tech and ecologically embedded responsive architecture. 


\section{NOTES}

01 Peter Zumthor, Thinking Architecture, (Birkhauser, 1998), 98-99.

02 Ibid., 10 


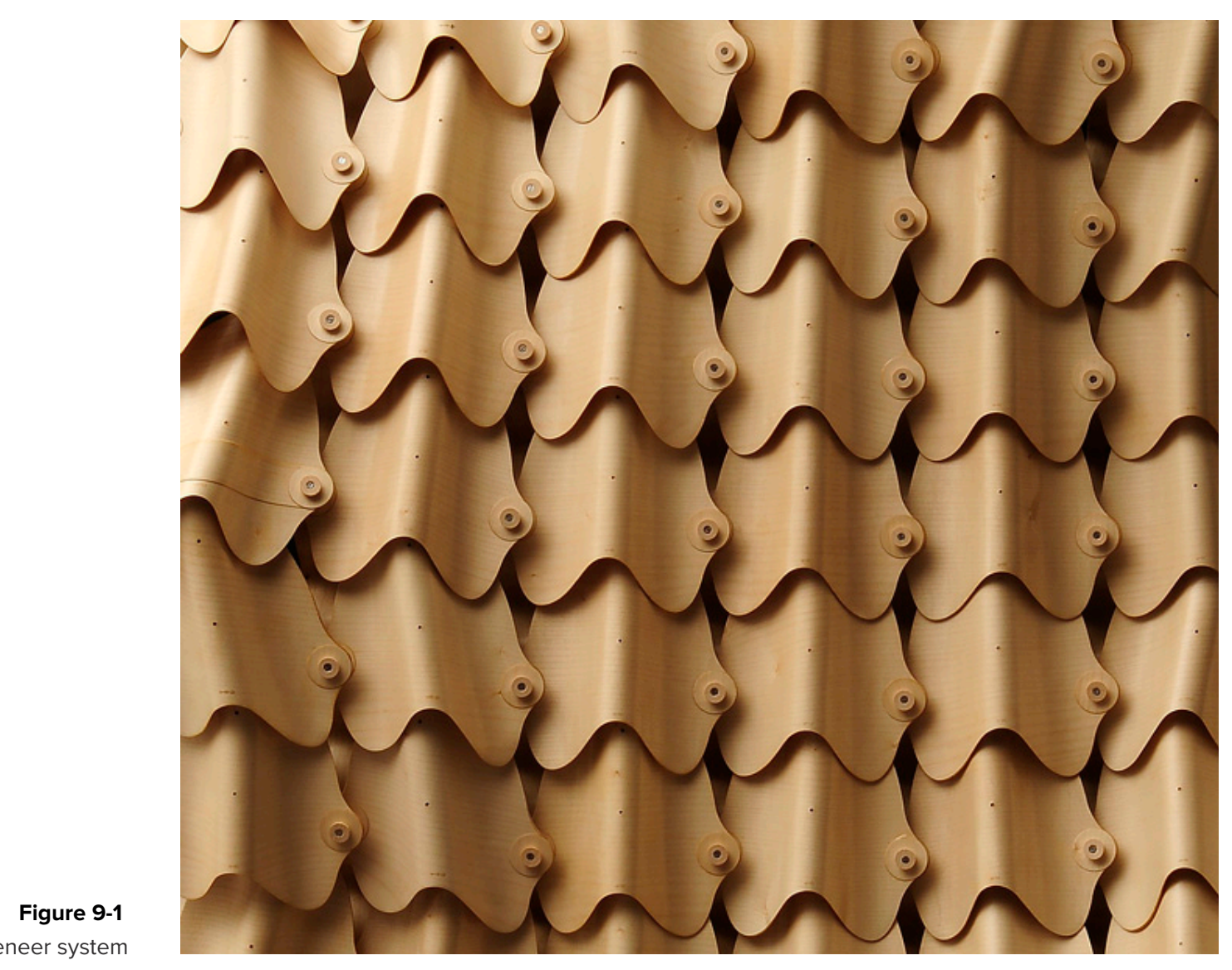

Wood veneer system 


\section{9 | POSTSCRIPT}

This thesis has advocated for the intelligent use of materials based on their unique tendencies and capacities. More specifically, it brings to light the tremendous potential of wood as a functional, beautiful, and sustainable building material.

Today more than ever, the virtues of using wood as a building material cannot be understated. We are living in an era that will be defined by our relationship to the planet. As the effects of climate change continue to reveal themselves, the way we live will need to be transformed. This includes changing the way we build our cities, as well as the materials we use to build them. Of all the materials, wood is the only one that can be grown by the power of the sun; not to mention, as it grows it consumes carbon. Wood is not only good for our planet, but for humans too. Humans are naturally drawn to the warmth of wood, and wood buildings are beneficial to our health.

In Canada, a country in which $40 \%$ of the land is covered by forests and wooded areas, there is a tremendous opportunity to significantly advance the art and craft of building with wood. If taken, this will help reduce our impact on the planet, and at the same time help to establish a national architecture that expresses regional identity. After all, Canada first developed as a forest nation, with a rich tradition of building with wood.

Excitingly, the revival of wood building culture in Canada is already beginning to take place, and innovation in wood building is on the rise across the country. As 
we strive towards a new wood architecture, it would be wise to look to the past, as much can be learned from the technical ingenuity embodied in historical wooden structures, both at home and abroad. In addition, we must approach design with feet strongly planted both in the abstract world, as well as the physical world, striving towards a design approach that is informed by the unique capacities of the materials we build with. Pursuing this kind of a design approach is not easy, but it can be remarkably fulfilling. It requires a tremendous amount of dedication and humility, which only comes from learning to respect the materials we use; which is why I choose to conclude this thesis with the following quote from Michael Green:

Each tree is a beautiful part of the answer to climate change, and yet we are only beginning to ask of its potential... [E]ach time [we] choose to build in wood [we are] part of a critically important chain of responsibility that will see the elegance of the living tree through to a new life in a building. That responsibility includes understanding the tree's genesis, its place in the ecosystem, its unique characteristics, and its remarkable potential when incorporated into the built world. ${ }^{1}$ 


\section{NOTES}

01 Jim Taggart, Toward a culture of wood architecture, (Abacus Editions, 2011), 7. 

APPENDIX A |PROPERTIES OF VARIOUS WOODS SPECIES 
Figure A-1

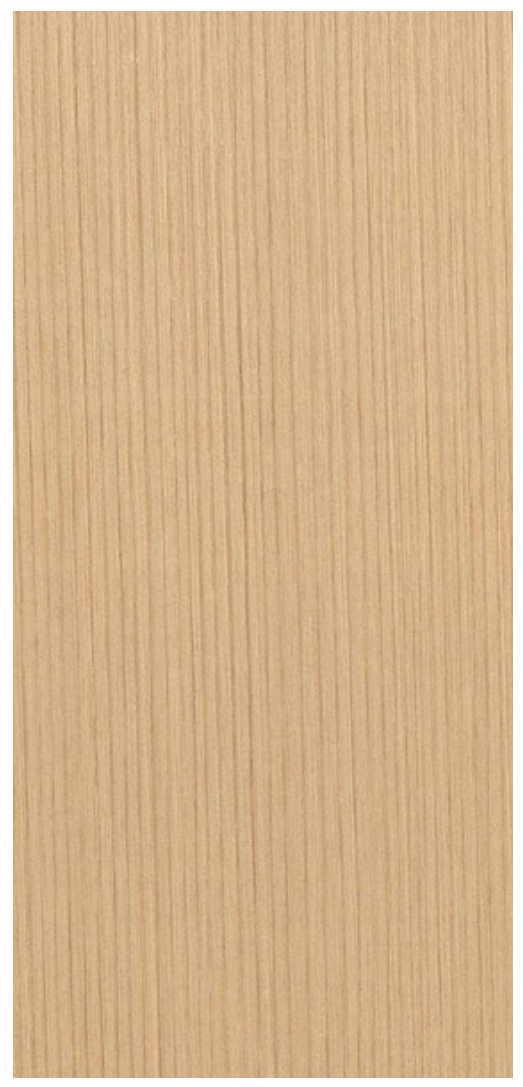

\section{WESTERN RED CEDAR}

Thuja plicata

Wood Type: softwood

Distribution: Pacific Northwest United States/Canada

Appearance: reddish to pinkish-brown heartwood (often with random streaks and bands of darker red/brown areas), pale yellowish-white sapwood

Grain/Texture: straight grain, medium to coarse texture Modulus of Rupture: $51.7 \mathrm{MPa}$

Crushing Strength: $31.4 \mathrm{MPa}$

Janka Hardness: $1560 \mathrm{~N}$

Elastic Modulus: 7.66 GPa

Shrinkage: radial: $2.4 \%$, tangential: $5.0 \%$

Rot Resistance: durable to very durable

Odour: strong, aromatic scent when being worked

Workability: easy to work with both hand or machine tools, dents and scratches very easily

Pricing: $\$-\$$ 
Figure A-2

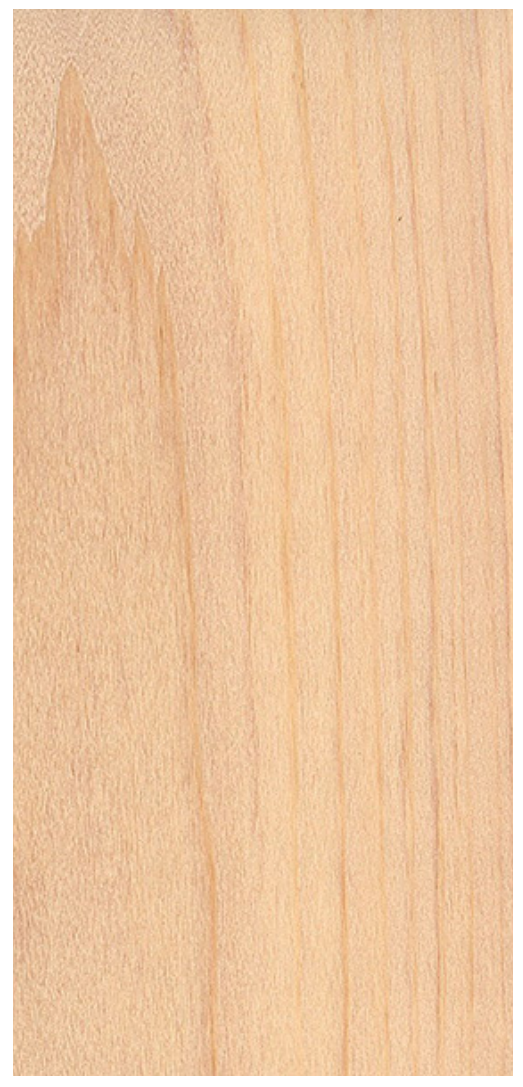

\section{NORTHERN WHITE CEDAR}

Thuja occidentalis

Wood Type: softwood

Distribution: Northeastern North America

Appearance: heartwood is pale brown or tan, while the narrow sapwood is nearly white. Numerous small knots are common in the wood.

Grain/Texture: generally straight, with a fine, even texture; moderate natural luster

Modulus of Rupture: 44.8 MPa

Crushing Strength: $27.3 \mathrm{MPa}$

Janka Hardness: $1420 \mathrm{~N}$

Elastic Modulus: $5.52 \mathrm{GPa}$

Shrinkage: radial: 2.2\%, tangential: 4.9\%

Rot Resistance: rated as durable to very durable

Odour: has a distinct (though moderate) cedar-like smell when being worked

Workability: good overall working characteristics; poor screwholding capabilities; glues and finishes well

Pricing: $\$ \$$ 
Figure A-3

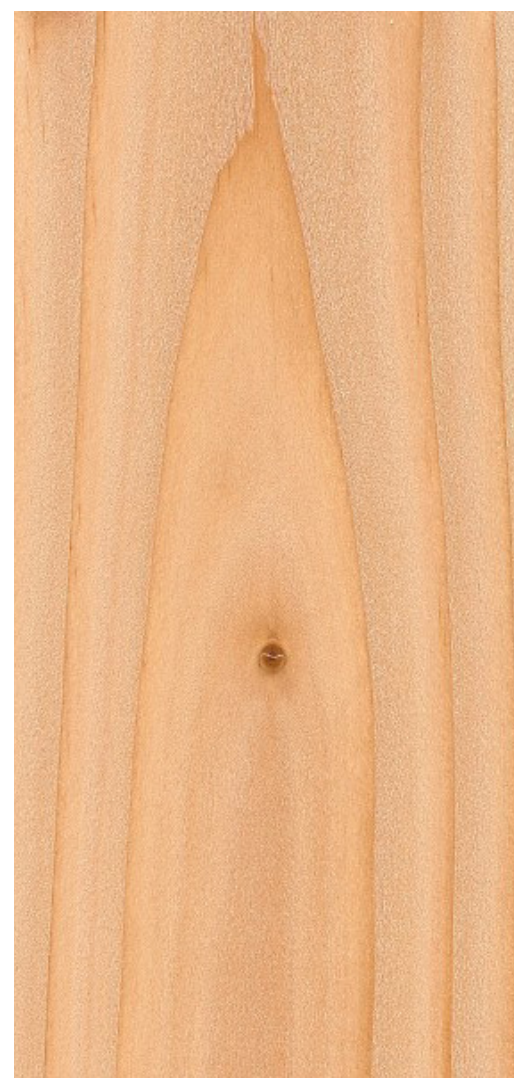

\section{DOUGLAS FIR}

Pseudotsuga menziesii

Wood Type: softwood

Distribution: Western North America

Appearance: varies in color based upon age and location of tree, usually light brown with a hint of red and/or yellow

Grain/Texture: generally straight or slightly wavy, medium to coarse texture

Modulus of Rupture: $86.2 \mathrm{MPa}$

Crushing Strength: 47.9 MPa

Janka Hardness: $2760 \mathrm{~N}$

Elastic Modulus: $12.17 \mathrm{GPa}$

Shrinkage: radial: $4.5 \%$, tangential: $7.3 \%$

Rot Resistance: moderately durable, susceptible to insect attack

Odour: distinct, resinous odour when being worked

Workability: machines well, accepts stains, glues, and finishes well

Pricing: $\$-\$$ 
Figure A-4

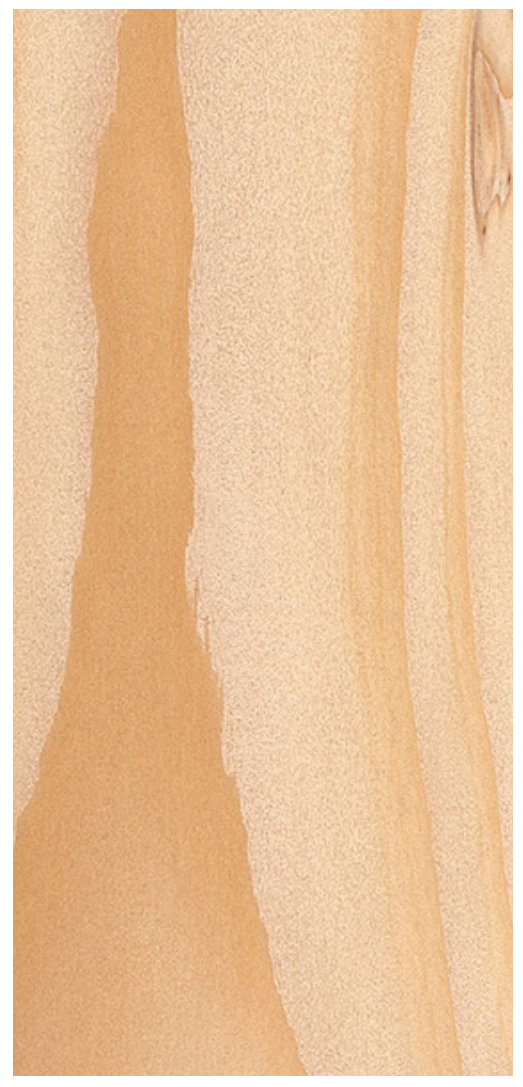

\section{EASTERN HEMLOCK}

Tsuga canadensis

Wood Type: softwood

Distribution: Eastern North America

Appearance: heartwood is light reddish brown. Sapwood may be slightly lighter in color but usually isn't distinguished from the heartwood

Grain/Texture: generally straight, but may be interlocked or spiraled. Has a coarse, uneven texture

Modulus of Rupture: $61.4 \mathrm{MPa}$

Crushing Strength: $37.3 \mathrm{MPa}$

Janka Hardness: $2220 \mathrm{~N}$

Elastic Modulus: $8.28 \mathrm{GPa}$

Shrinkage: radial: $3.0 \%$, tangential: $6.8 \%$

Rot Resistance: non-durable regarding decay resistance, and also susceptible to insect attack

Odour: no distinct odour

Workability: tends to splinter easily; tends to plane poorly; sanding can create dips and uneven surfaces; glues, stains, and finishes well

Pricing: $\$-\$$ 
Figure A-5

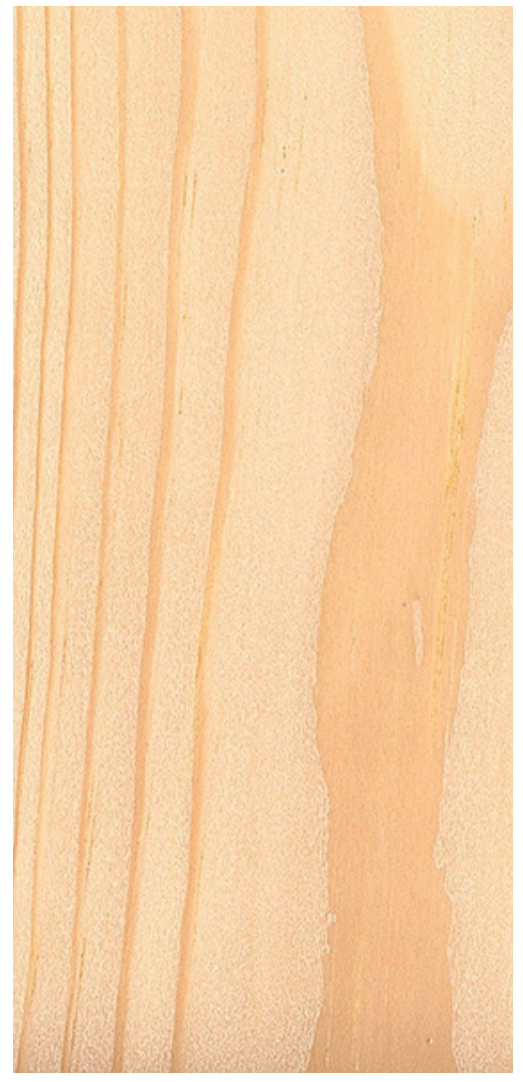

\section{JACK PINE}

Pinus banksiana

Wood Type: softwood

Distribution: Canada and northern United States

Appearance: orangish brown heartwood, yellowish white sapwood

Grain/Texture: straight grain, medium to coarse texture Modulus of Rupture: $68.3 \mathrm{MPa}$

Crushing Strength: 39.0 MPa

Janka Hardness: $2540 \mathrm{~N}$

Elastic Modulus: $9.31 \mathrm{GPa}$

Shrinkage: radial: $3.7 \%$, tangential: $6.6 \%$

Rot Resistance: heartwood is rated as moderate to low in decay resistance

Odour: faint, resinous odour while being worked

Workability: easy to work with both hand or machine tools, glues and finishes well

Pricing: \$ 
Figure A-6

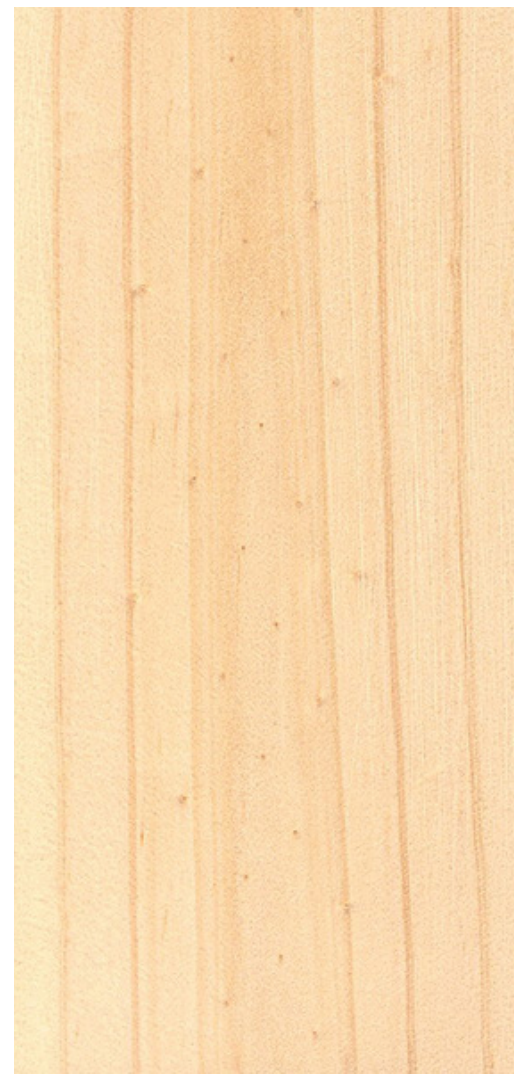

\section{RED PINE}

Pinus resinosa

Wood Type: softwood

Distribution: Northeastern North America

Appearance: heartwood is light reddish brown, sapwood is pale yellow to nearly white

Grain/Texture: grain is straight, with a medium, even texture and a somewhat oily feel

Modulus of Rupture: $75.9 \mathrm{MPa}$

Crushing Strength: 41.9 MPa

Janka Hardness: $2490 \mathrm{~N}$

Elastic Modulus: 11.24 GPa

Shrinkage: radial: $3.8 \%$, tangential: $7.2 \%$

Rot Resistance: heartwood is rated as moderately durable to nondurable regarding decay resistance

Odour: distinct, resinous odor when being worked

Workability: easy to work with both hand and machine tools; glues and finishes well, though excess resin can sometimes cause problems with its paint-holding ability

Pricing: $\$$ 
Figure A-7

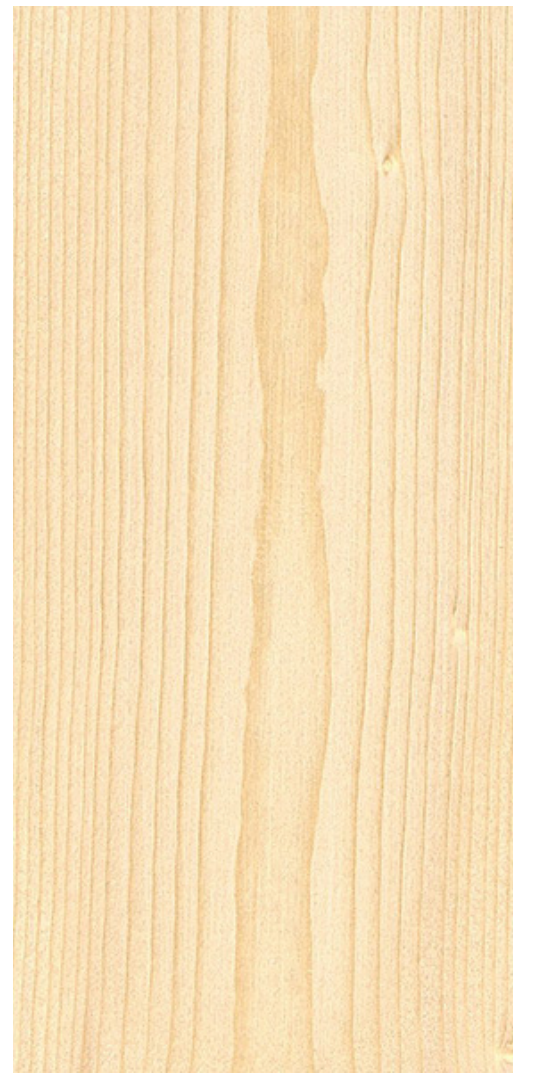

\section{BLACK SPRUCE}

Picea mariana

Wood Type: hardwood

Distribution: Northern North America

Appearance: typically creamy white, with a hint of yellow

Grain/Texture: straight grain, fine and even texture

Modulus of Rupture: 69.7 MPa

Crushing Strength: $37.3 \mathrm{MPa}$

Janka Hardness: $2320 \mathrm{~N}$

Elastic Modulus: $10.5 \mathrm{GPa}$

Shrinkage: radial: $4.1 \%$, tangential: $6.8 \%$

Rot Resistance: heartwood is rated as being slightly resistant to non-resistant to decay

Odour: no characteristic odour

Workability: generally easy to work with as long as there are no knots present, glues and finishes well

Pricing: \$ 
Figure A-8

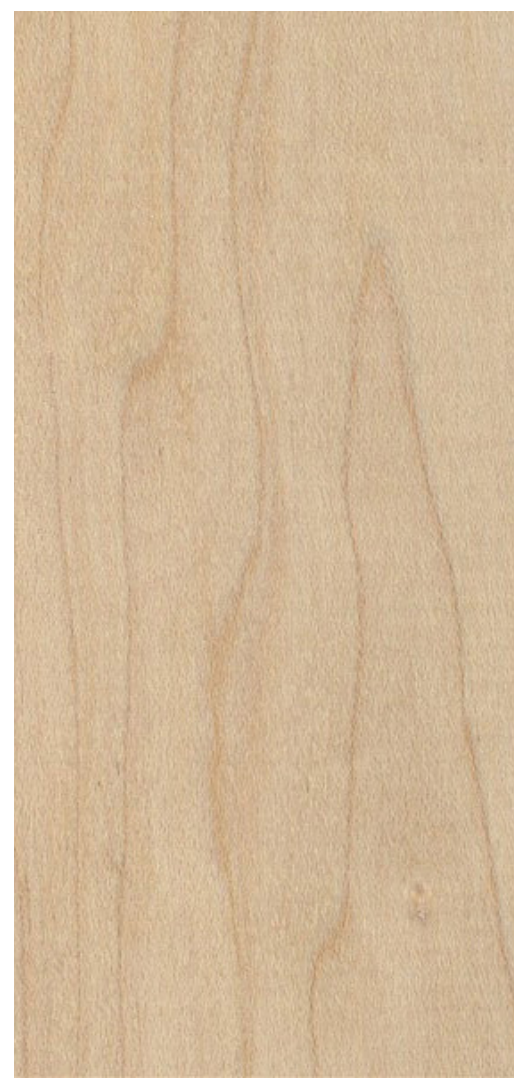

HARD MAPLE

Acer saccharum

Wood Type: hardwood

Distribution: Northeastern North America

Appearance: reddish-brown heartwood (often with random streaks and bands of darker red/brown areas), white to off-white cream sapwood (often with a reddish or golden hue)

Grain/Texture: straight grain, fine and even texture Modulus of Rupture: 109.0 MPa

Crushing Strength: 54.0 MPa

Janka Hardness: $6450 \mathrm{~N}$

Elastic Modulus: $12.62 \mathrm{GPa}$

Shrinkage: radial: 4.8\%, tangential: 9.9\%

Rot Resistance: non-durable, susceptible to insect attack Odour: no characteristic odour

Workability: easy to work with both hand or machine tools

Pricing: \$\$ 
Figure A-9

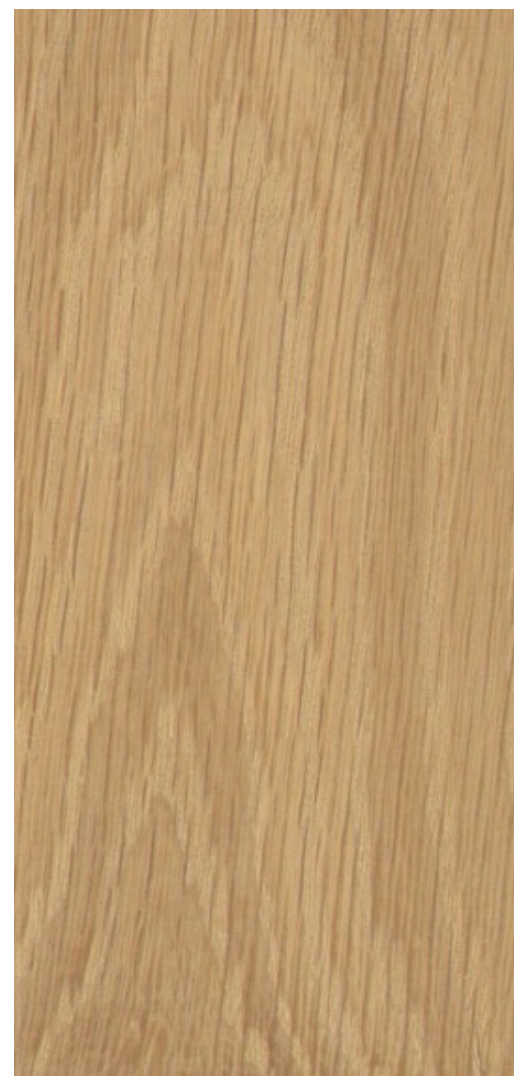

\section{WHITE OAK}

Quercus alba

Wood Type: hardwood

Distribution: Southern Ontario

Appearance: heartwood is a light to medium brown, commonly with an olive cast. Nearly white to light brown sapwood is not always sharply demarcated from the heartwood

Grain/Texture: straight grain, with a coarse, uneven texture Modulus of Rupture: 102.3 MPa

Crushing Strength: $50.8 \mathrm{MPa}$

Janka Hardness: $5990 \mathrm{~N}$

Elastic Modulus: $12.15 \mathrm{GPa}$

Shrinkage: radial: 5.6\%, tangential: 10.6\%

Rot Resistance: rated as very durable

Odour: tell-tale smell that is common to most oaks; most find it appealing

Workability: produces good results with hand and machine tools; responds well to steam-bending; glues, stains, and finishes well

Pricing: \$ 
Figure A-10

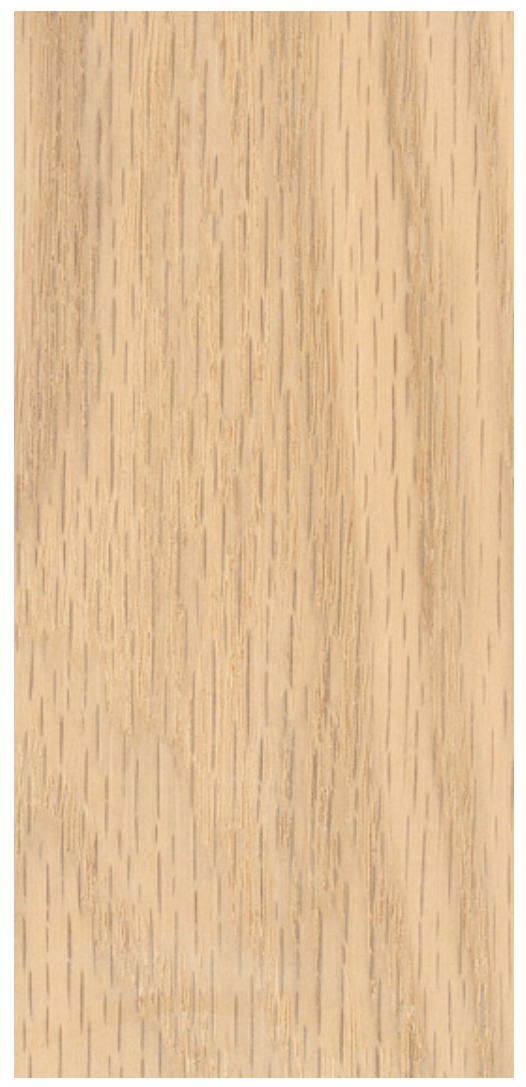

\section{RED OAK}

Quercus rubra

Wood Type: hardwood

Distribution: Northeastern United States and Southeastern Canada

Appearance: light to medium brown heartwood (commonly with a reddish cast), nearly white to light brown sapwood

Grain/Texture: straight grain, coarse and uneven texture

Modulus of Rupture: 99.2 MPa

Crushing Strength: $46.8 \mathrm{MPa}$

Janka Hardness: $5430 \mathrm{~N}$

Elastic Modulus: $12.14 \mathrm{GPa}$

Shrinkage: radial: $4.0 \%$, tangential: $8.6 \%$

Rot Resistance: non-durable to perishable, poor insect resistance

Odour: odour common to most oaks (most find it appealing)

Workability: easy to work with both hand or machine tools, responds well to steam-bending

Pricing: \$ $\$$ 
Figure A-11

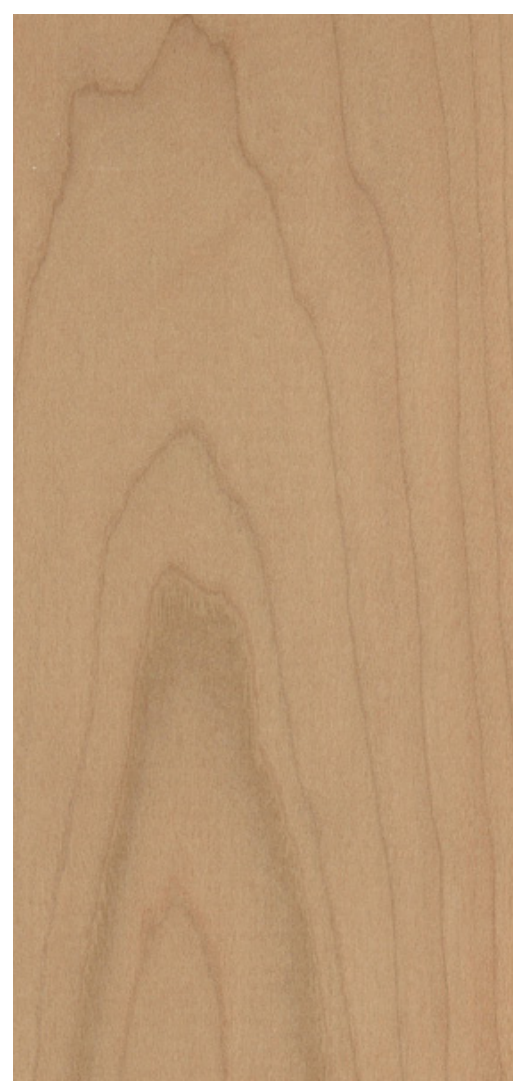

\section{BLACK CHERRY}

Prunus serotina

Wood Type: hardwood

Distribution: Eastern North America

Appearance: heartwood is a light pinkish brown when freshly cut, darkening to a medium reddish brown over time. Sapwood is a pale yellowish color

Grain/Texture: usually straight grain, fine and even texture Modulus of Rupture: 84.8 MPa

Crushing Strength: 49.0 MPa

Janka Hardness: $4230 \mathrm{~N}$

Elastic Modulus: $10.3 \mathrm{GPa}$

Shrinkage: radial: 3.7\%, tangential: 7.1\%

Rot Resistance: heartwood is rated very durable and resistant to decay

Odour: mild, distinctive scent when being worked

Workability: one of the best all-around woods for workability

Pricing: $\$ \$-\$ \$$ 
Figure A-12

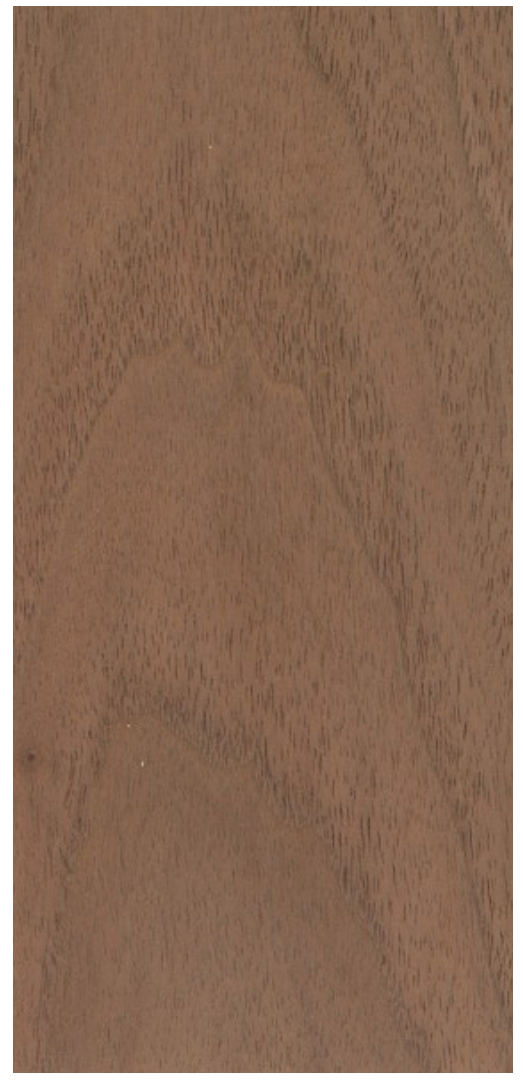

\section{BLACK WALNUT}

Juglans nigra

Wood Type: hardwood

Distribution: Eastern United States

Appearance: lighter pale brown to dark chocolate brown heartwood with darker brown streaks, pale yellow-gray to nearly white sapwood

Grain/Texture: usually straight grain, medium texture Modulus of Rupture: 100.7 MPa

Crushing Strength: $52.3 \mathrm{MPa}$

Janka Hardness: $4490 \mathrm{~N}$

Elastic Modulus: $11.59 \mathrm{GPa}$

Shrinkage: radial: $5.5 \%$, tangential: $7.8 \%$

Rot Resistance: rated as very durable in terms of decay resistance, susceptible to insect attack

Odour: faint, mild odour when being worked

Workability: generally easy to work provided the grain is straight and regular, glues, stains and finishes well, reponds well to steam bending

Pricing: $\$ \$-\$ \$$ 
Figure A-13

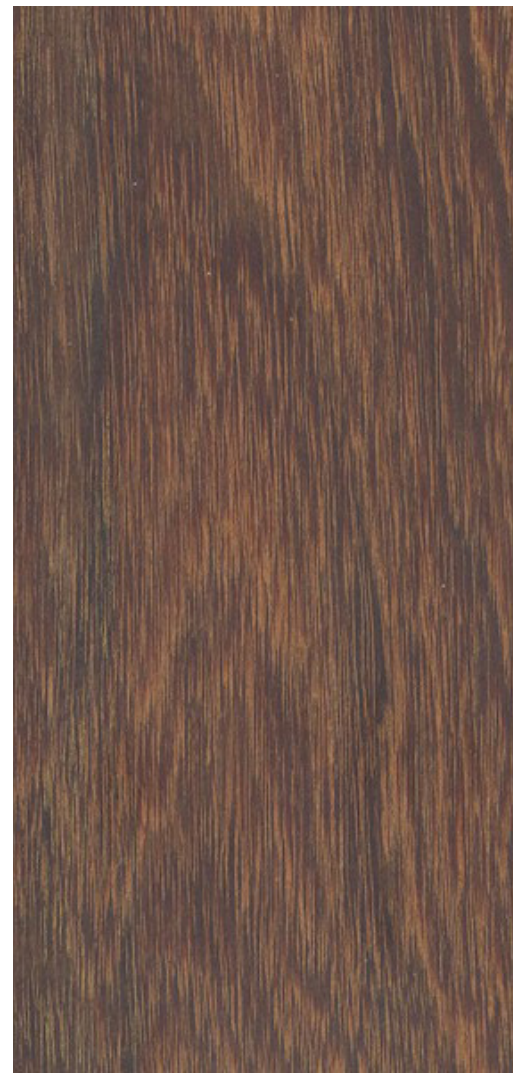

IPE

Handroanthus spp.

Wood Type: hardwood

Distribution: Tropical Americas (Central and South America); also farmed commercially

Appearance: heartwood can vary in color from reddish brown, to a more yellowish olive brown or darker blackish brown; sometimes with contrasting darker brown/black stripes

Grain/Texture: fine to medium texture, with the grain varying from straight to irregular or interlocked. Moderate natural luster

Modulus of Rupture: $177.0 \mathrm{MPa}$

Crushing Strength: $93.8 \mathrm{MPa}$

Janka Hardness: $15620 \mathrm{~N}$

Elastic Modulus: $22.07 \mathrm{GPa}$

Shrinkage: radial: $5.9 \%$, tangential: $7.2 \%$

Rot Resistance: very durable; excellent insect resistance

Odour: mild scent while being worked

Workability: difficult to work; high cutting resistance during sawing; pronounced blunting effect on cutting edges; generally planes smoothly; can be difficult to glue properly

Pricing: $\$$ 
Figure A-14

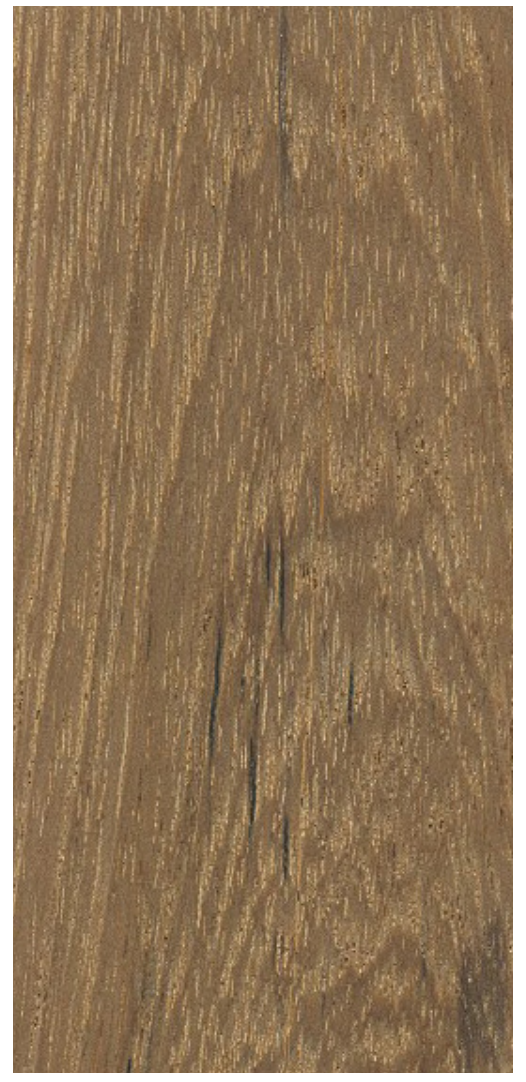

\section{TEAK}

Tectona grandis

Wood Type: hardwood

Distribution: Native to southern Asia

Appearance: heartwood tends to be a golden or medium brown, with color darkening with age

Grain/Texture: straight grain, sthough it can occasionally be wavy or interlocked; Coarse, uneven texture and moderate to low natural luster; raw, unfinished wood surfaces have a slightly oily or greasy feel due to natural oils

Modulus of Rupture: $97.1 \mathrm{MPa}$

Crushing Strength: $54.8 \mathrm{MPa}$

Janka Hardness: $4740 \mathrm{~N}$

Elastic Modulus: $12.28 \mathrm{GPa}$

Shrinkage: radial: 2.6\%, tangential: 5.3\%

Rot Resistance: rated as very durable

Odour: can have a leather-like scent when freshly milled

Workability: generally easy to work, with the only caveat being that Teak contains a high level of silica which has a pronounced blunting effect on cutting edges

Pricing: $\$ \$ \$$ 
Figure A-15

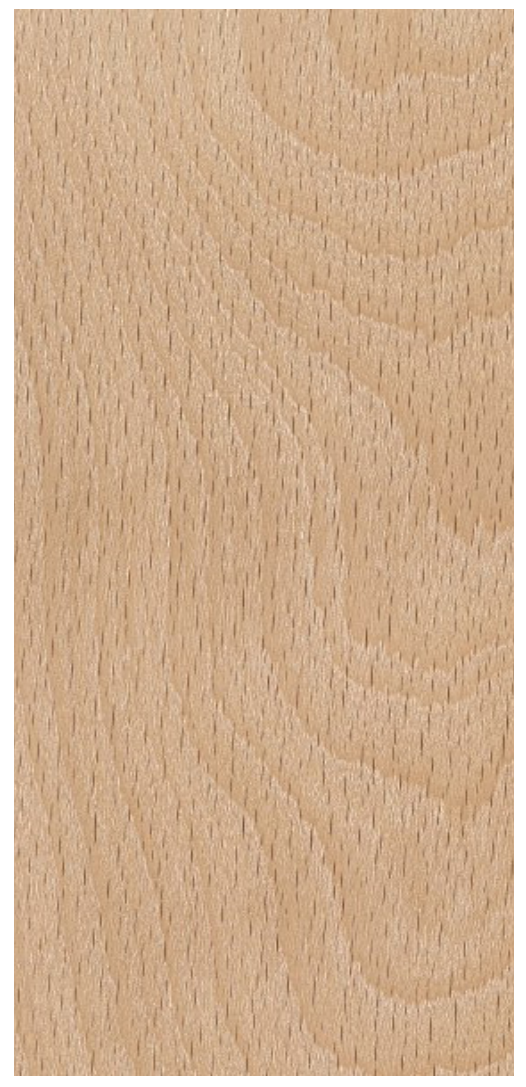

\section{AMERICAN BEECH}

Fagus grandifolia

Wood Type: hardwood

Distribution: Eastern United States, Southern and Central Ontario Appearance: typically a pale cream color, sometimes with a pink or brown hue

Grain/Texture: generally straight, with a fine to medium uniform texture; moderate natural luster

Modulus of Rupture: $102.8 \mathrm{MPa}$

Crushing Strength: $51.1 \mathrm{MPa}$

Janka Hardness: $5780 \mathrm{~N}$

Elastic Modulus: $11.86 \mathrm{GPa}$

Shrinkage: radial: 5.5\%, tangential: $11.9 \%$

Rot Resistance: non-durable or perishable; it is also susceptible to insect attack

Odour: no distinct odour

Workability: good workability; machines well, and glues, finishes, and turns well; responds superbly to steam-bending

Pricing: \$ 
Figure A-16

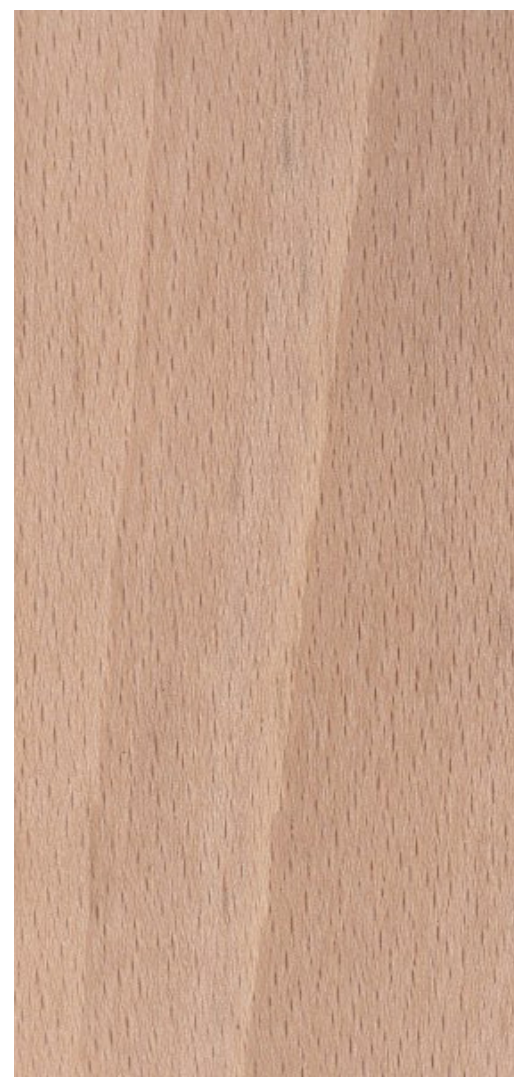

\section{EUROPEAN BEECH}

Fagus sylvatica

Wood Type: hardwood

Distribution: Europe

Appearance: pale cream color, sometimes with a pink or brown hue

Grain/Texture: straight grain, fine to medium uniform texture Modulus of Rupture: 110.1 MPa

Crushing Strength: 57.0 MPa

Janka Hardness: $6460 \mathrm{~N}$

Elastic Modulus: $14.31 \mathrm{GPa}$

Shrinkage: radial: $5.7 \%$, tangential: $11.6 \%$

Rot Resistance: non-durable, susceptible to insect attack

Odour: no characteristic odour

Workability: overall good workability, responds superbly to steam-bending

Pricing: $\$-\$$ 

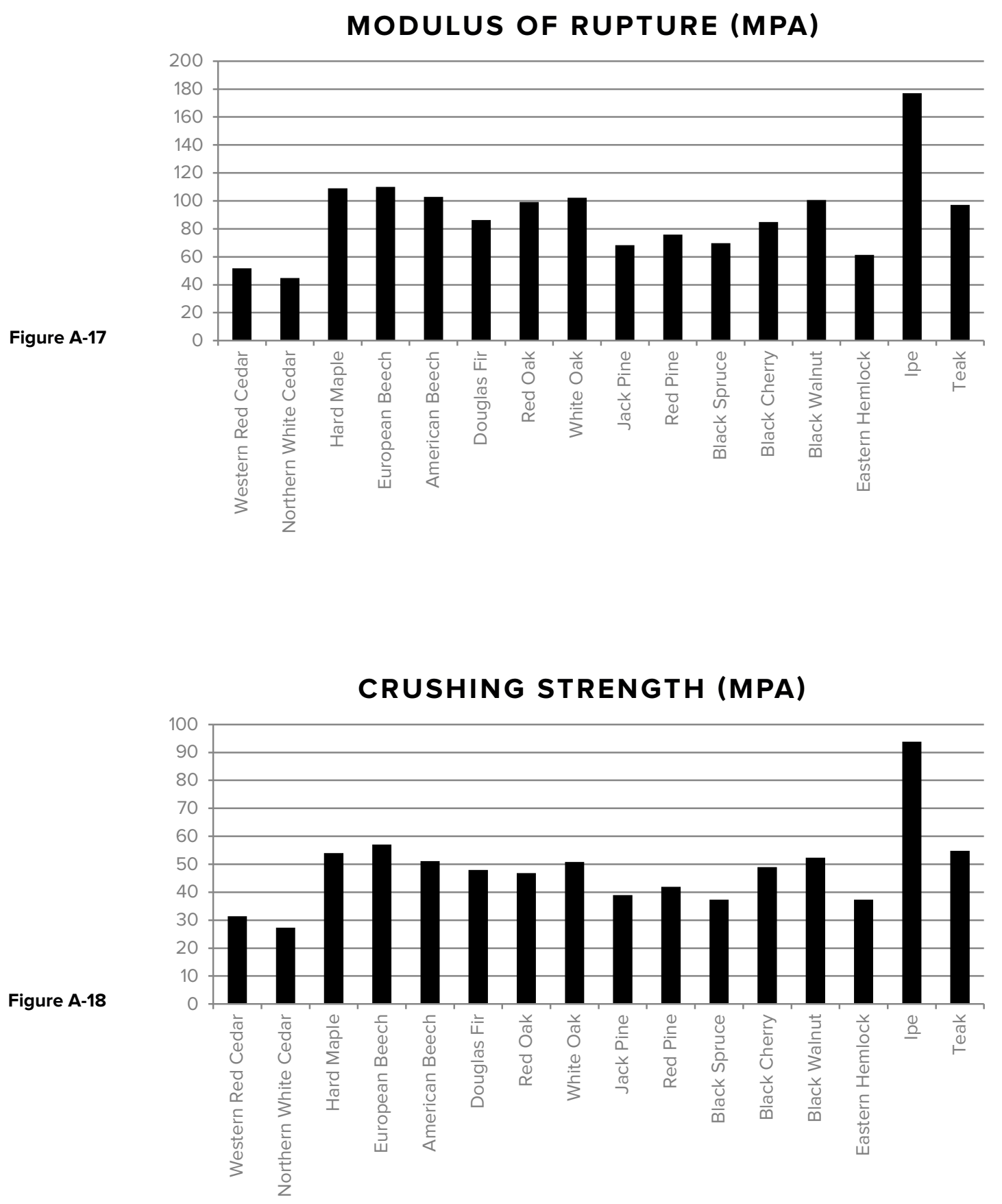


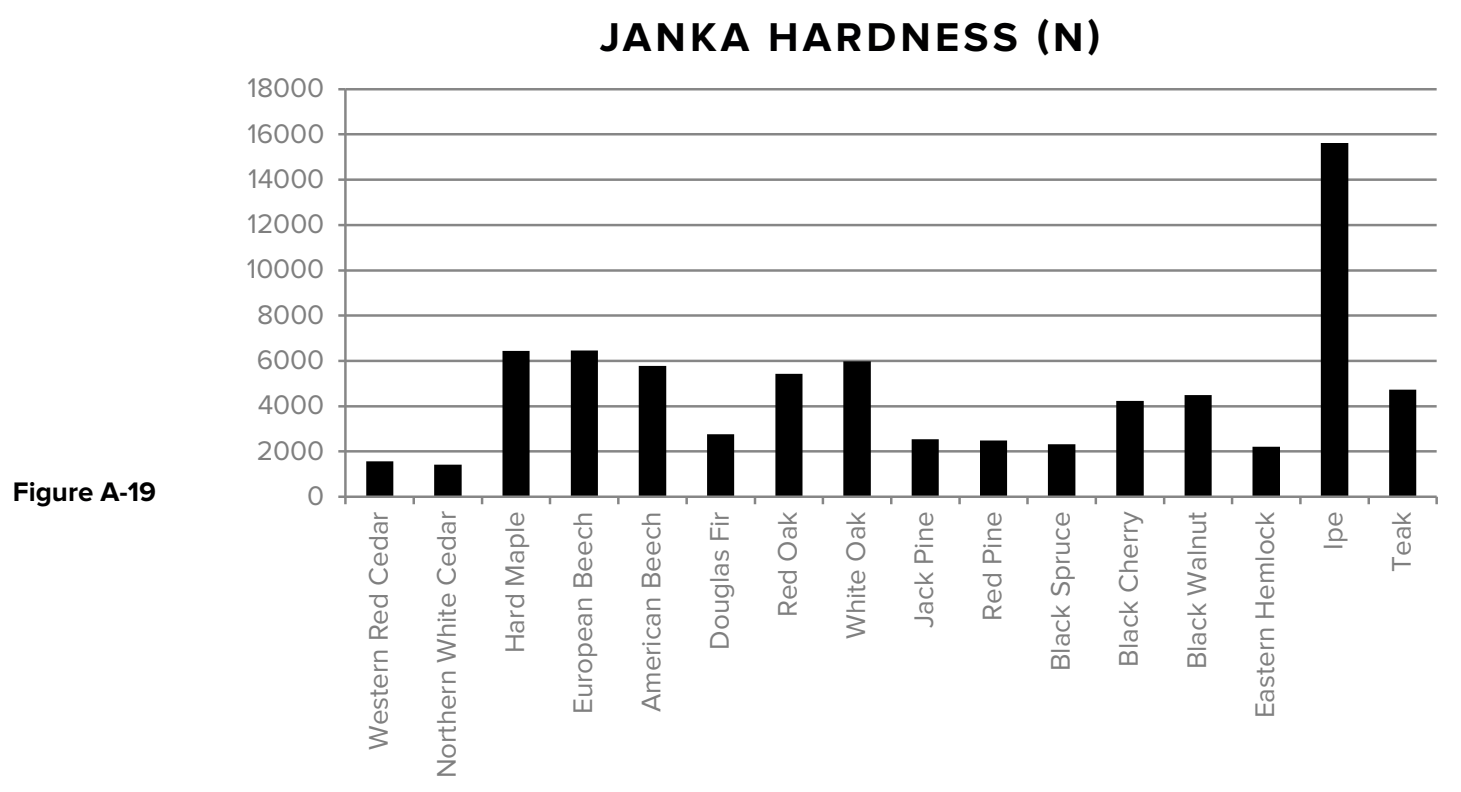

ELASTIC MODULUS (GPA)

Figure A-20

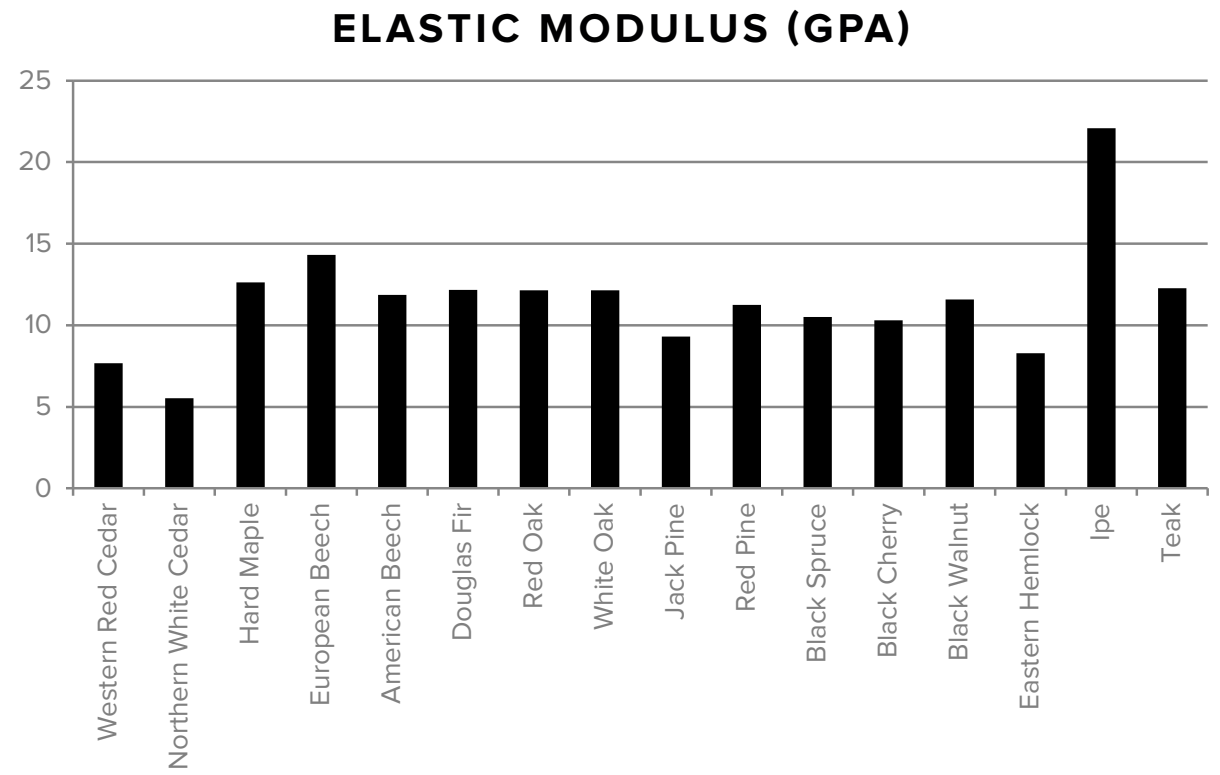


SHRINKAGE (\%)

Figure A-21

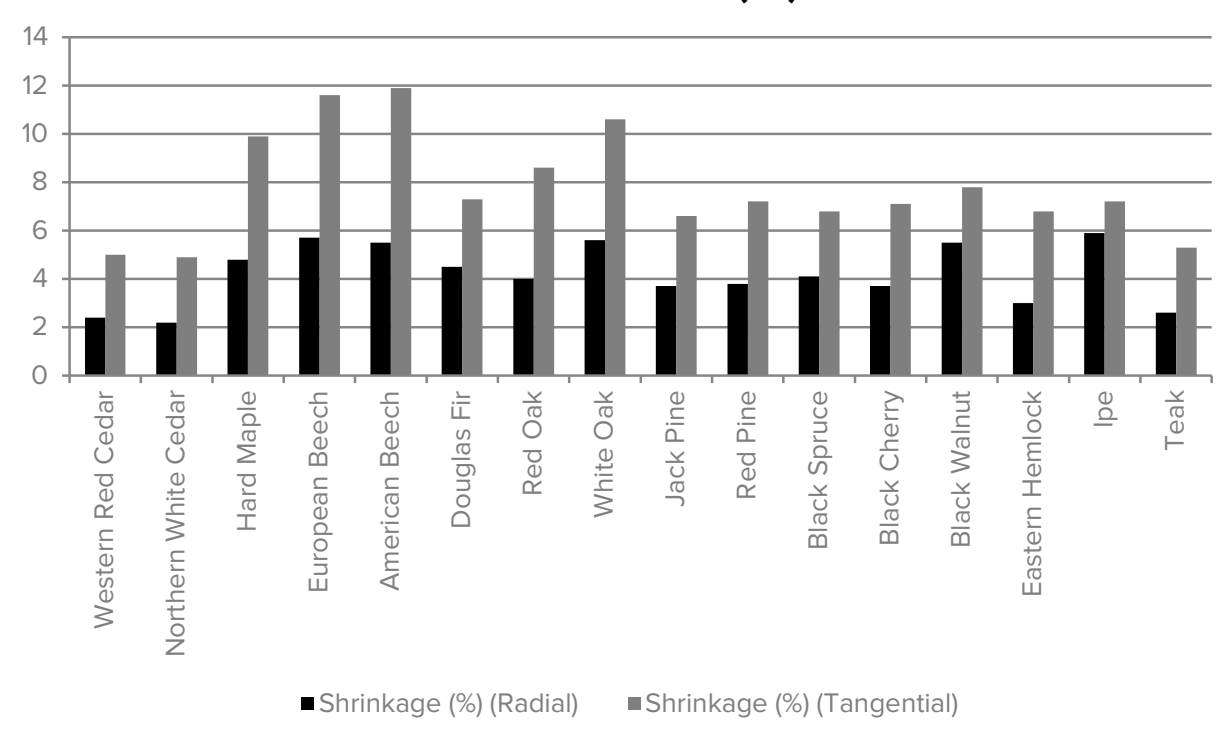

Figure A-22

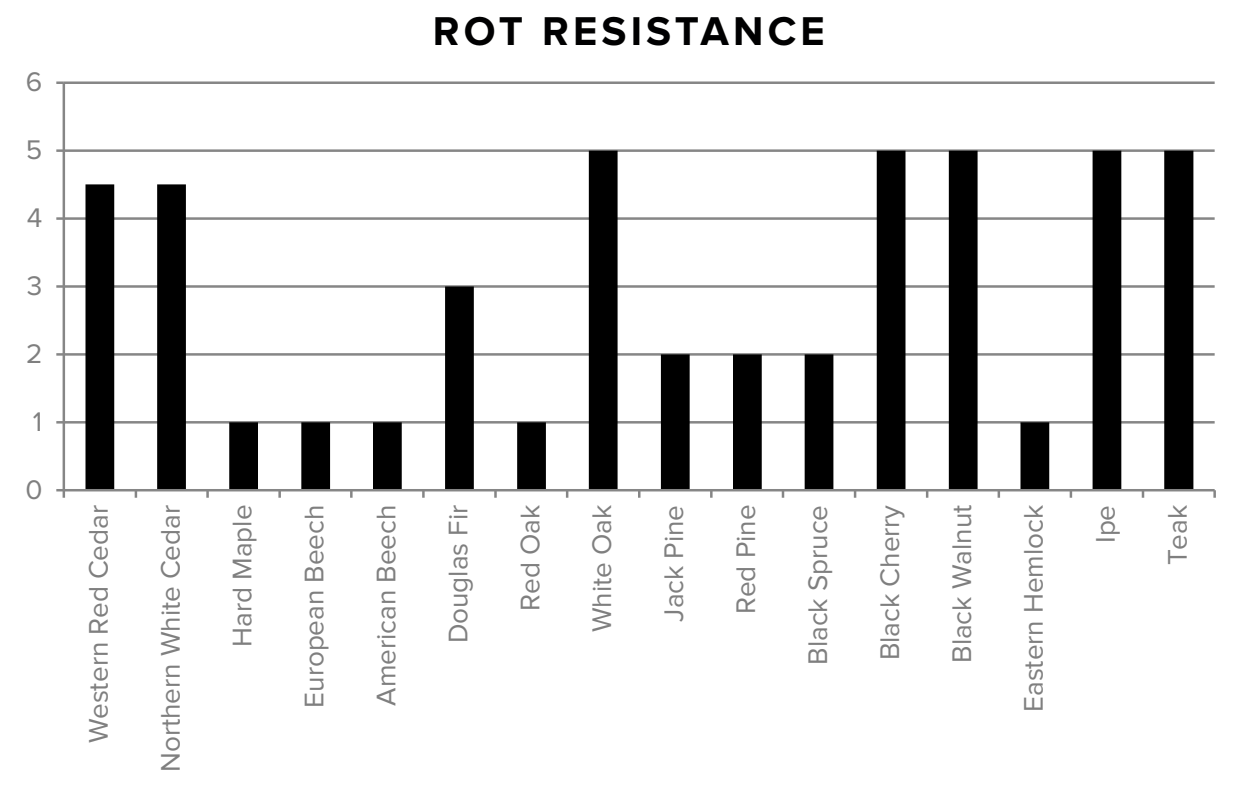

Note:

1: non-durable

2: slightly durable

3: moderately durable
4: durable

5: very durable 


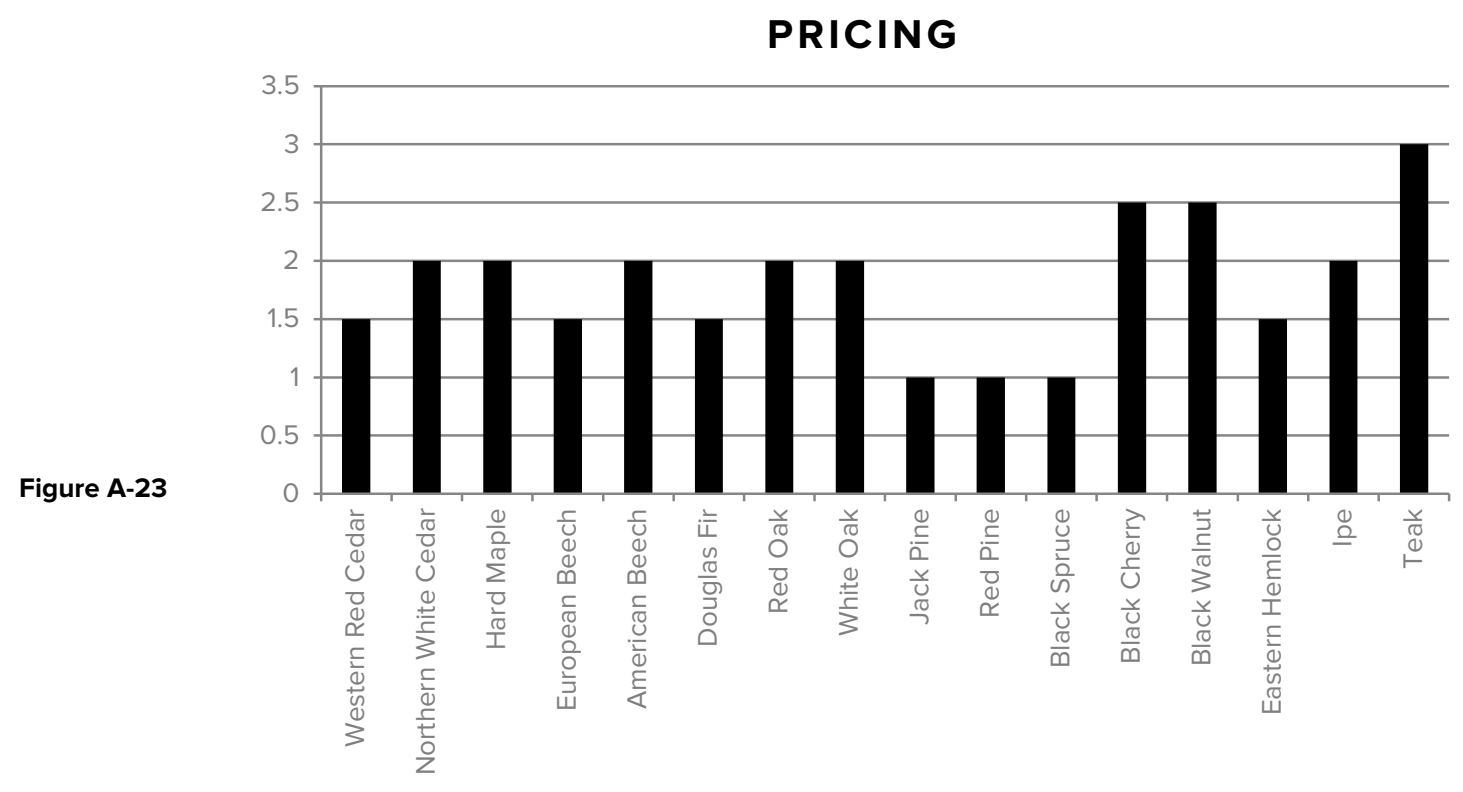

Note:

1: \$

2: $\$ \$$

3: $\$ \$ \$$ 



\section{APPENDIX B |MISCELLANEOUS DRAWINGS}




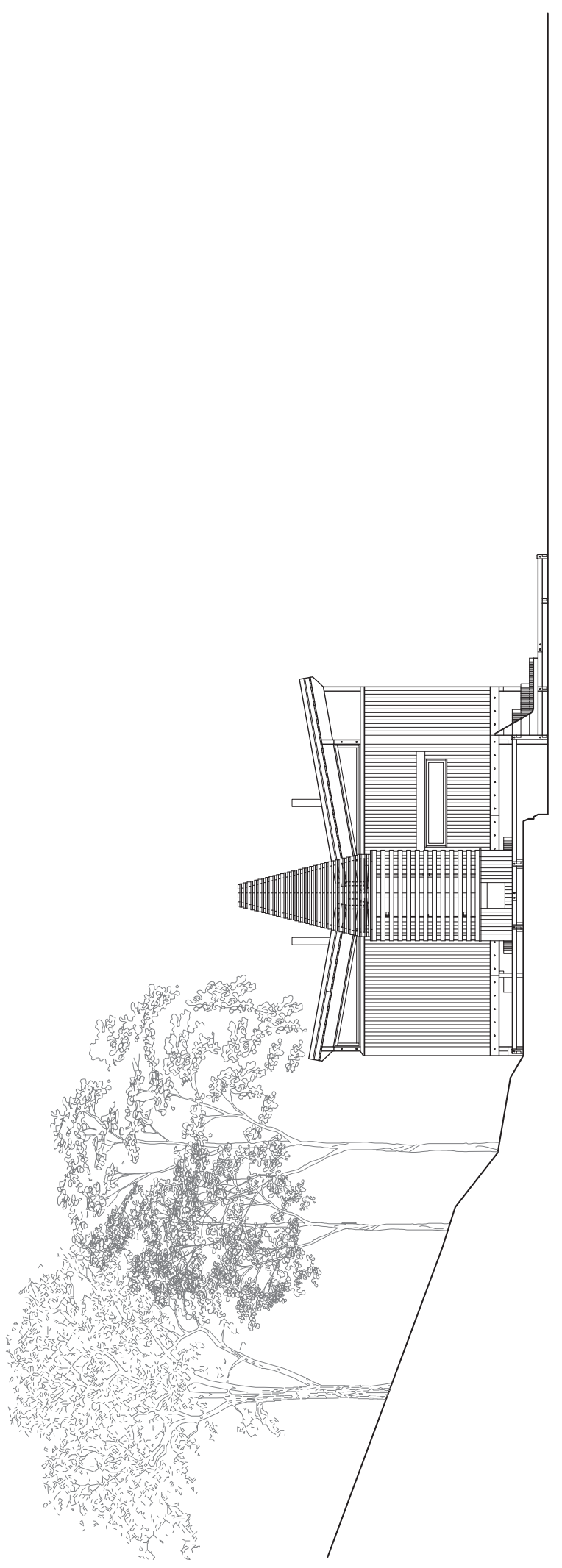

Figure B-1

North elevation 


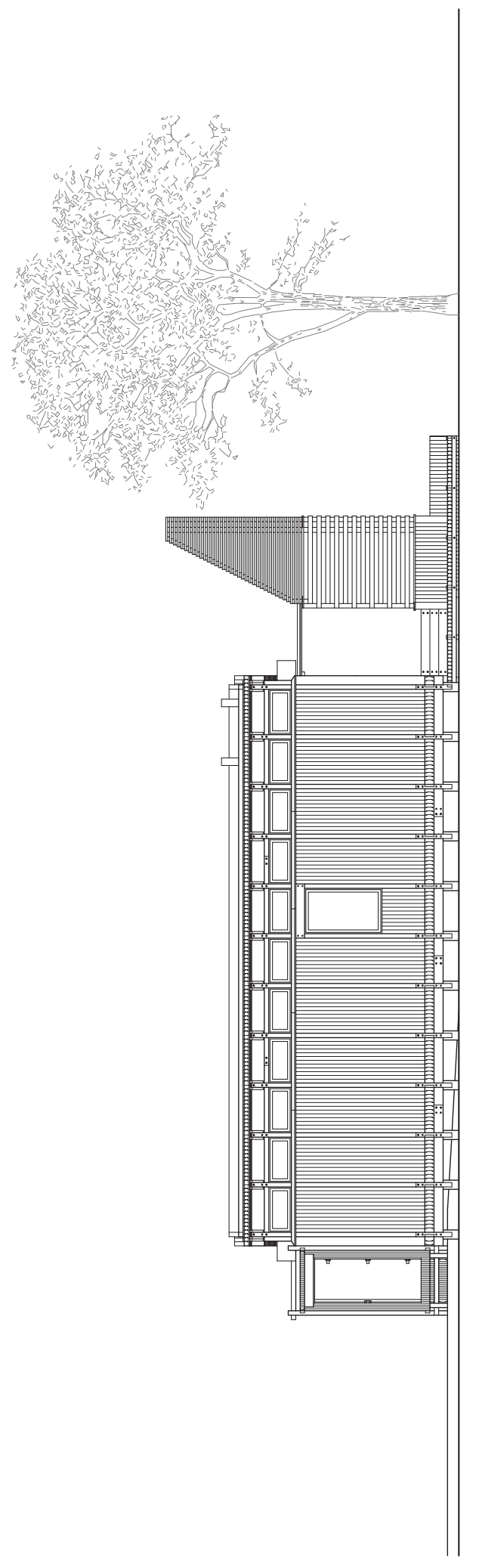

Figure B-2

East elevation 


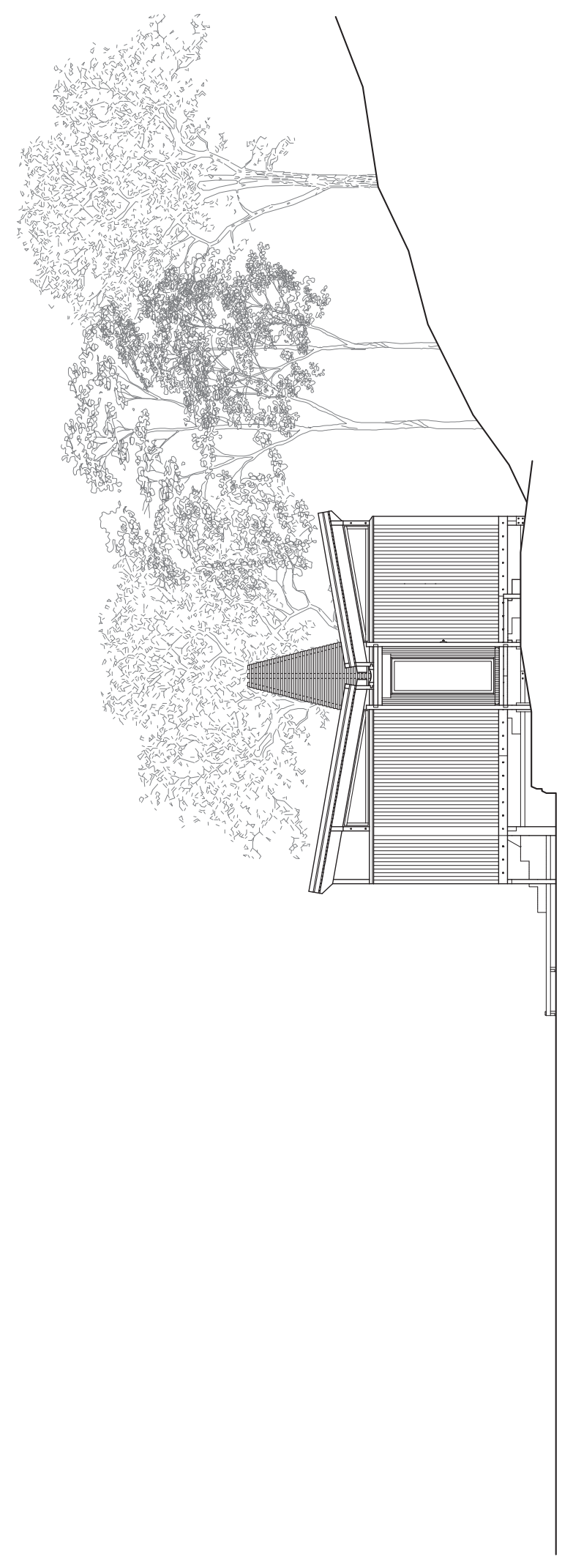

Figure B-3

South elevation 


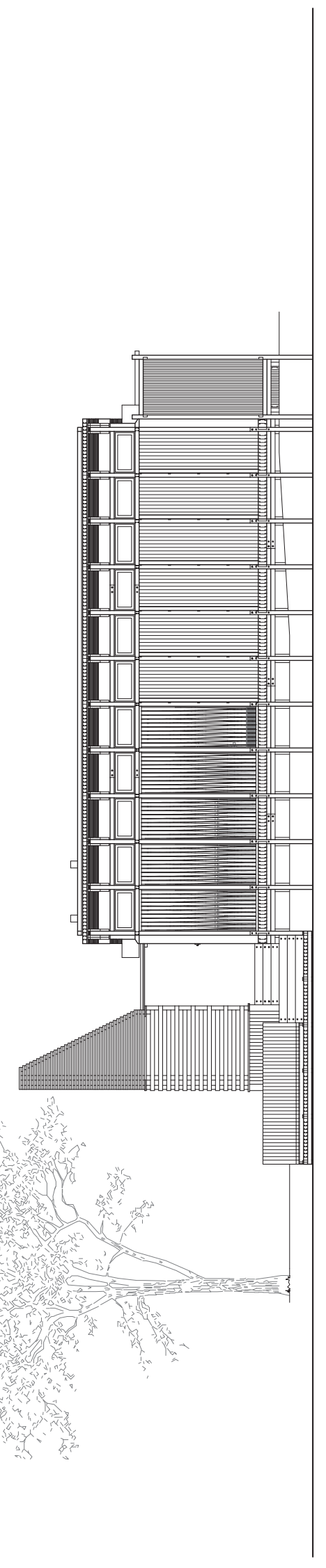

Figure B-4

West elevation 


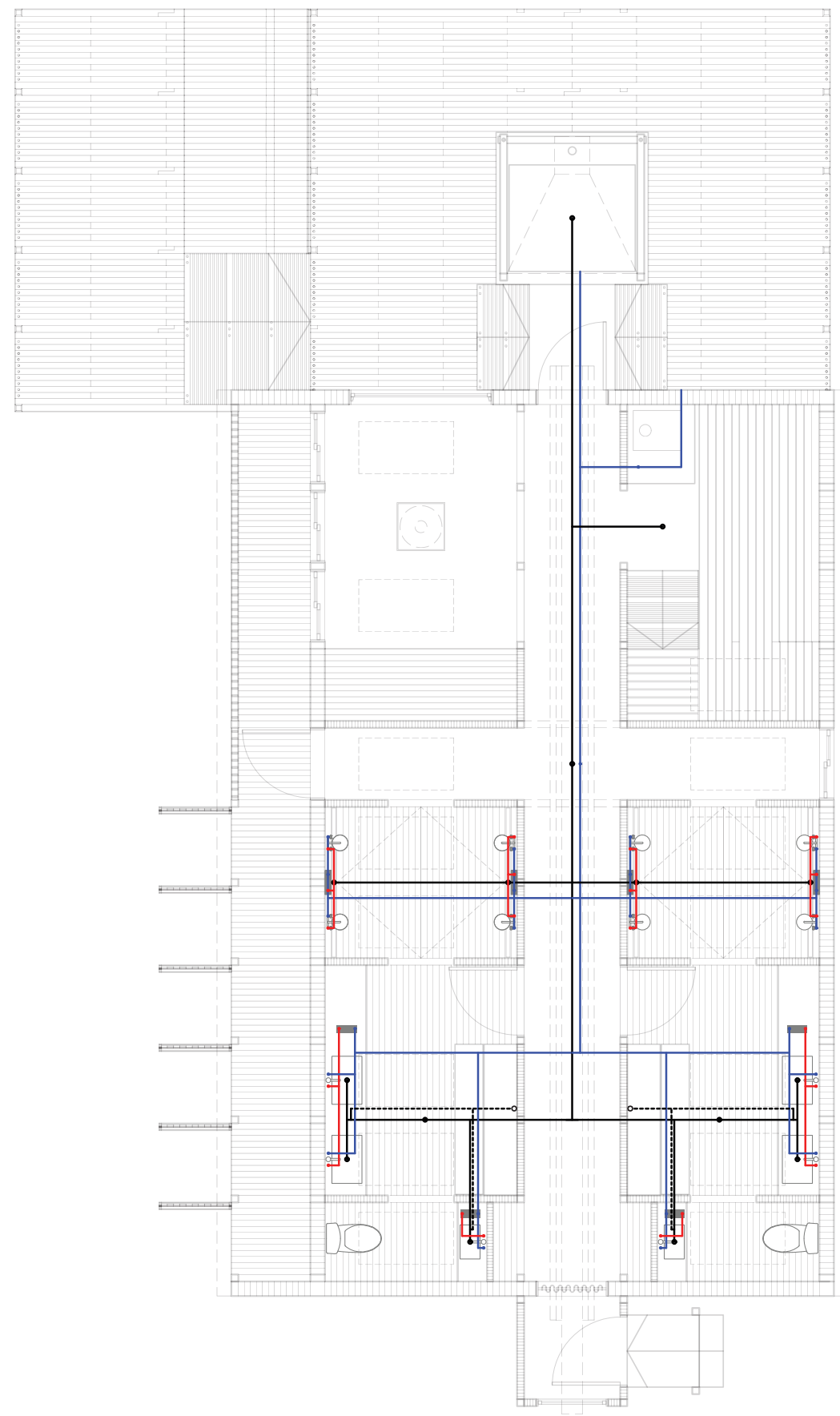

Figure B-5

- Water heater

- Drains \& Vents

- Cold Water Supply

Plumbing diagram

- Hot Water Supply 


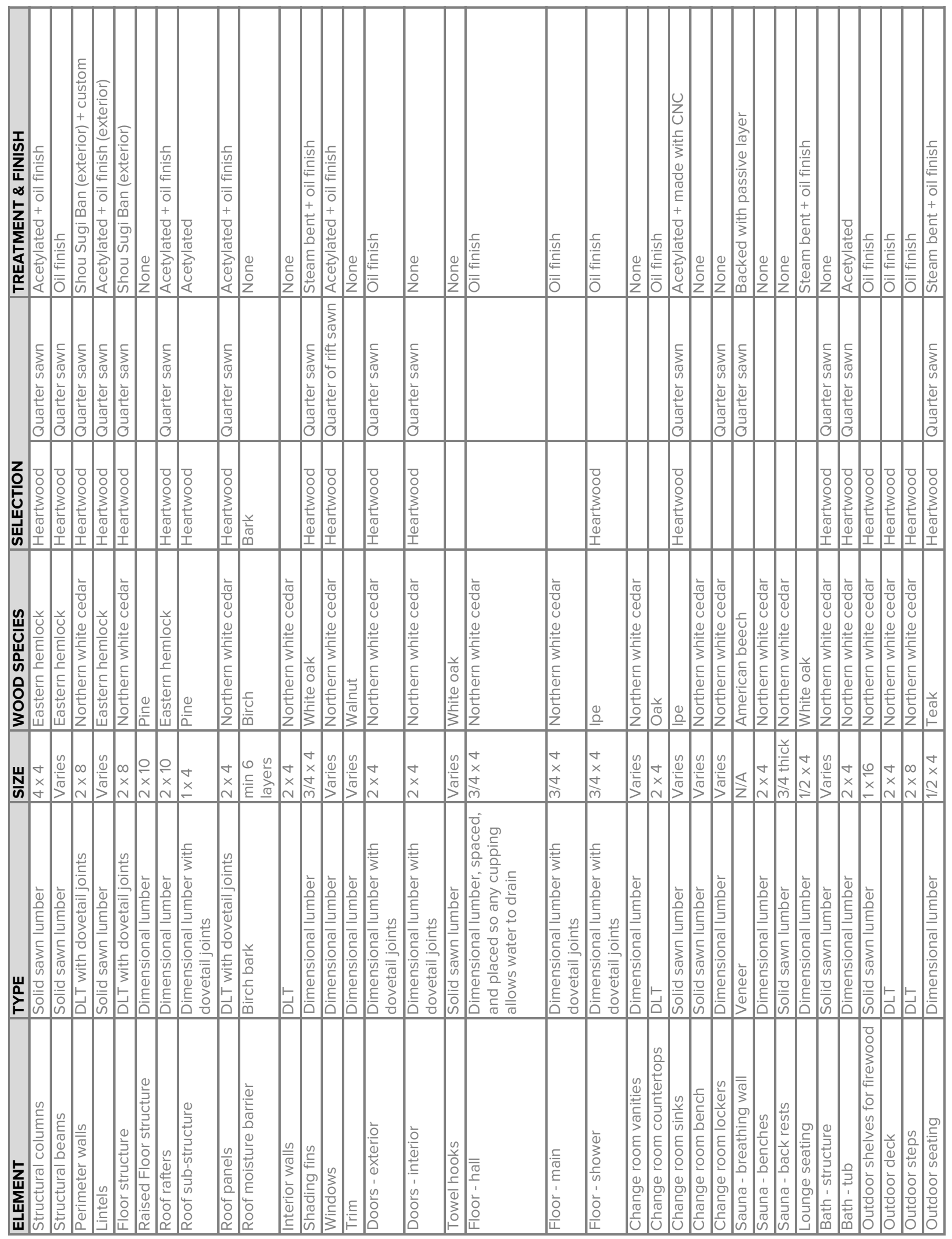

Figure B-6

Wood selection matrix 


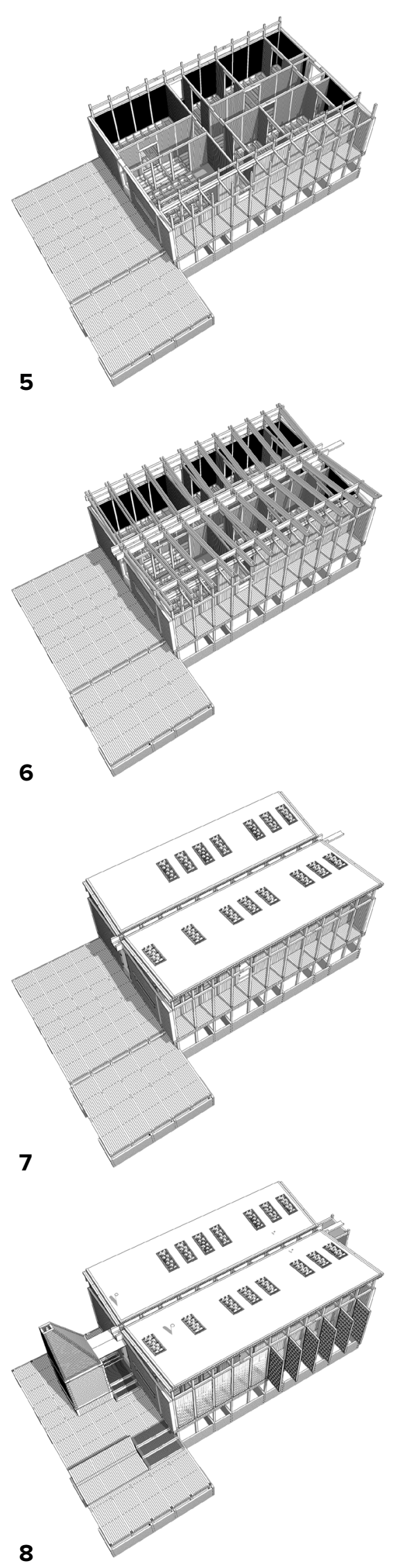


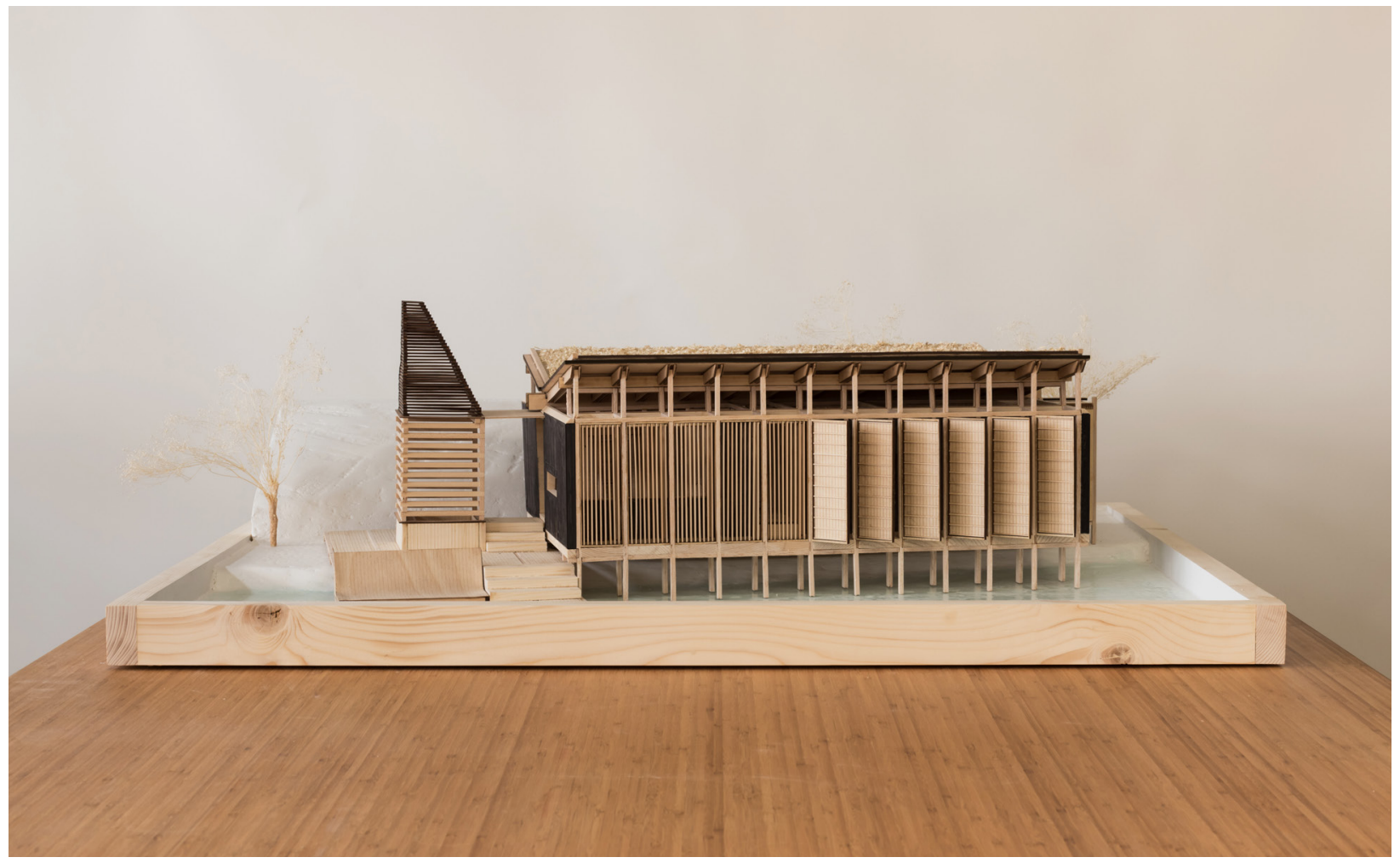

Figure B-8

Model looking east 


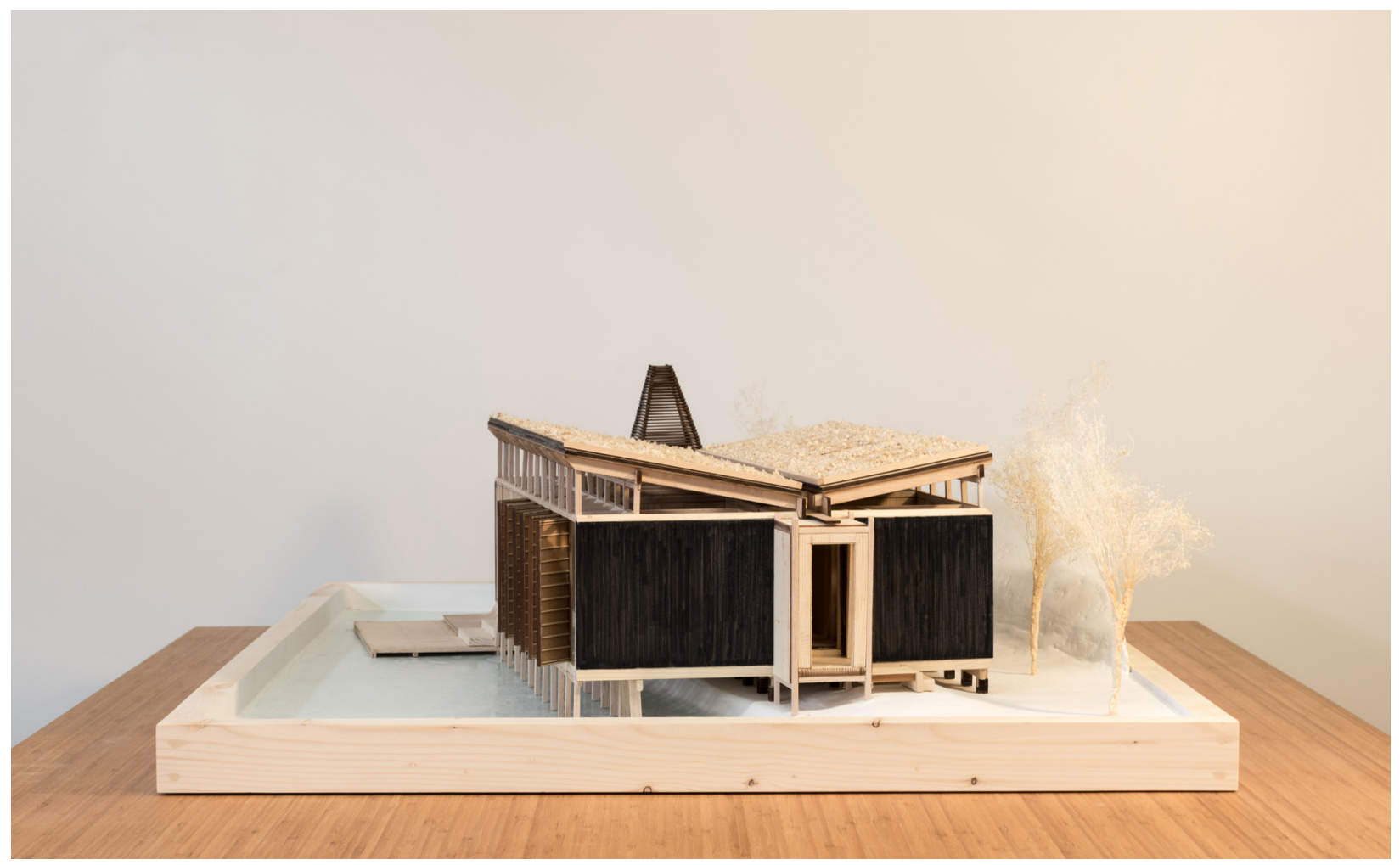

Figure B-9

Model looking north 


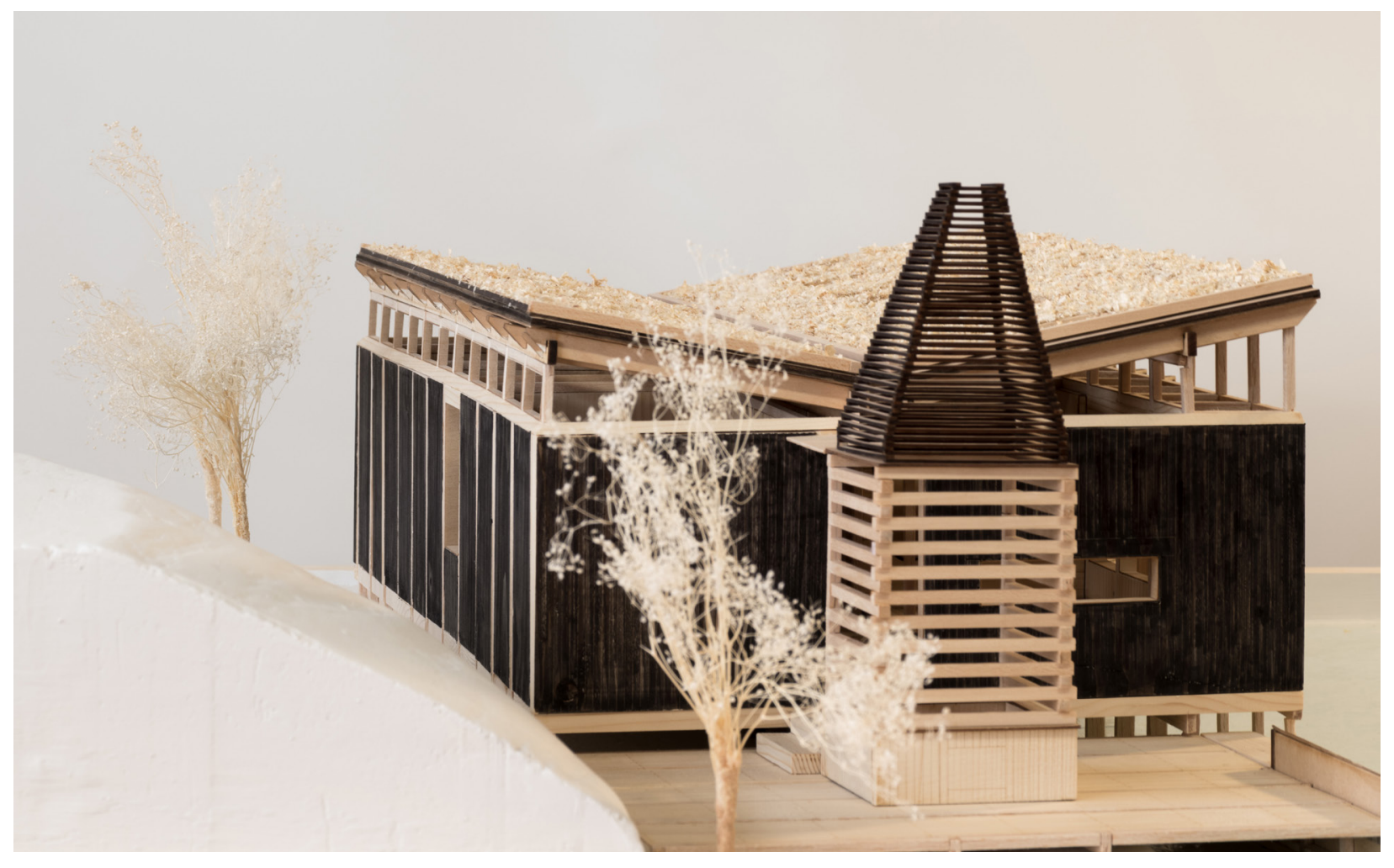

Figure B-10

Model looking south 


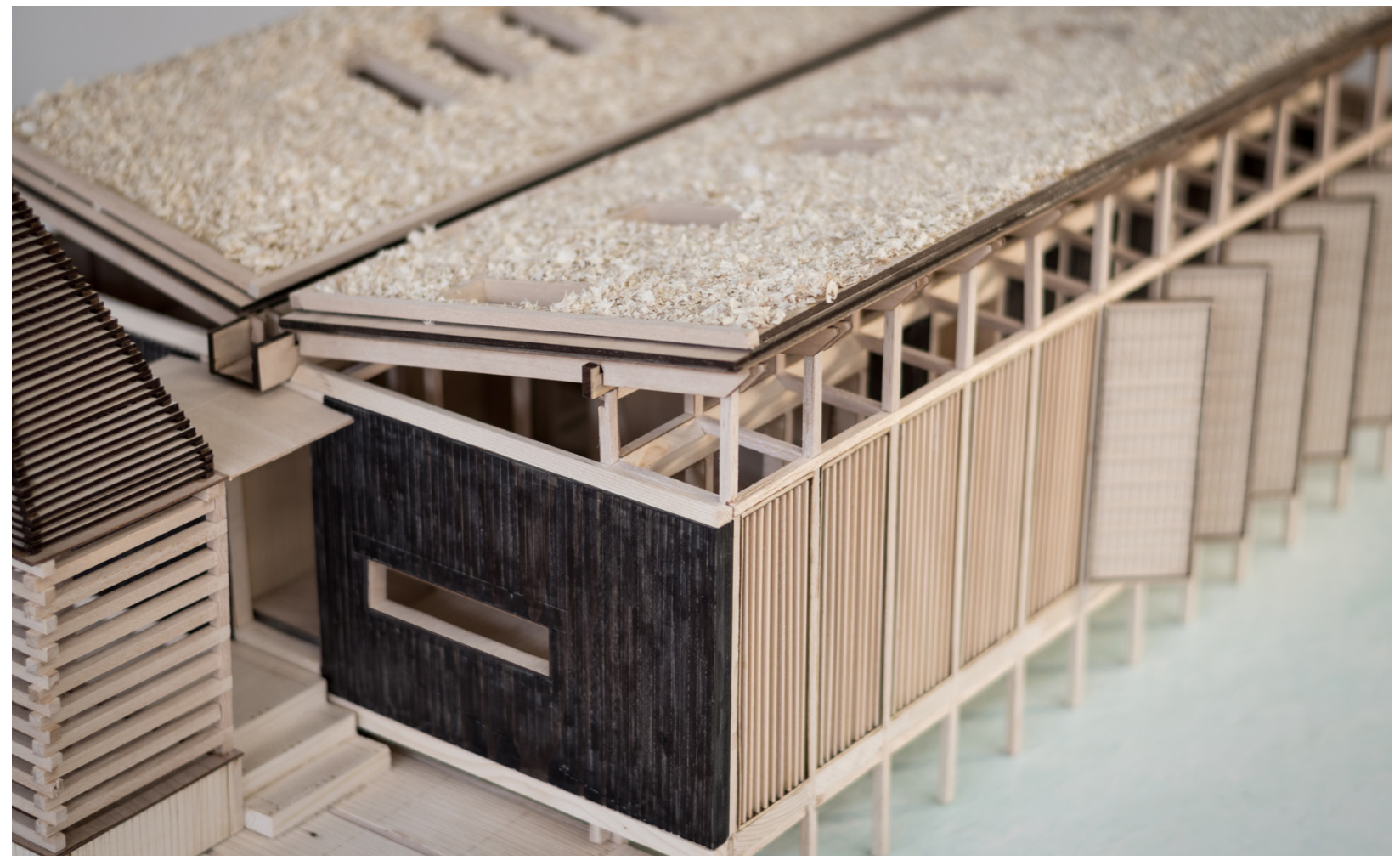

Figure B-11

Aerial model photo 


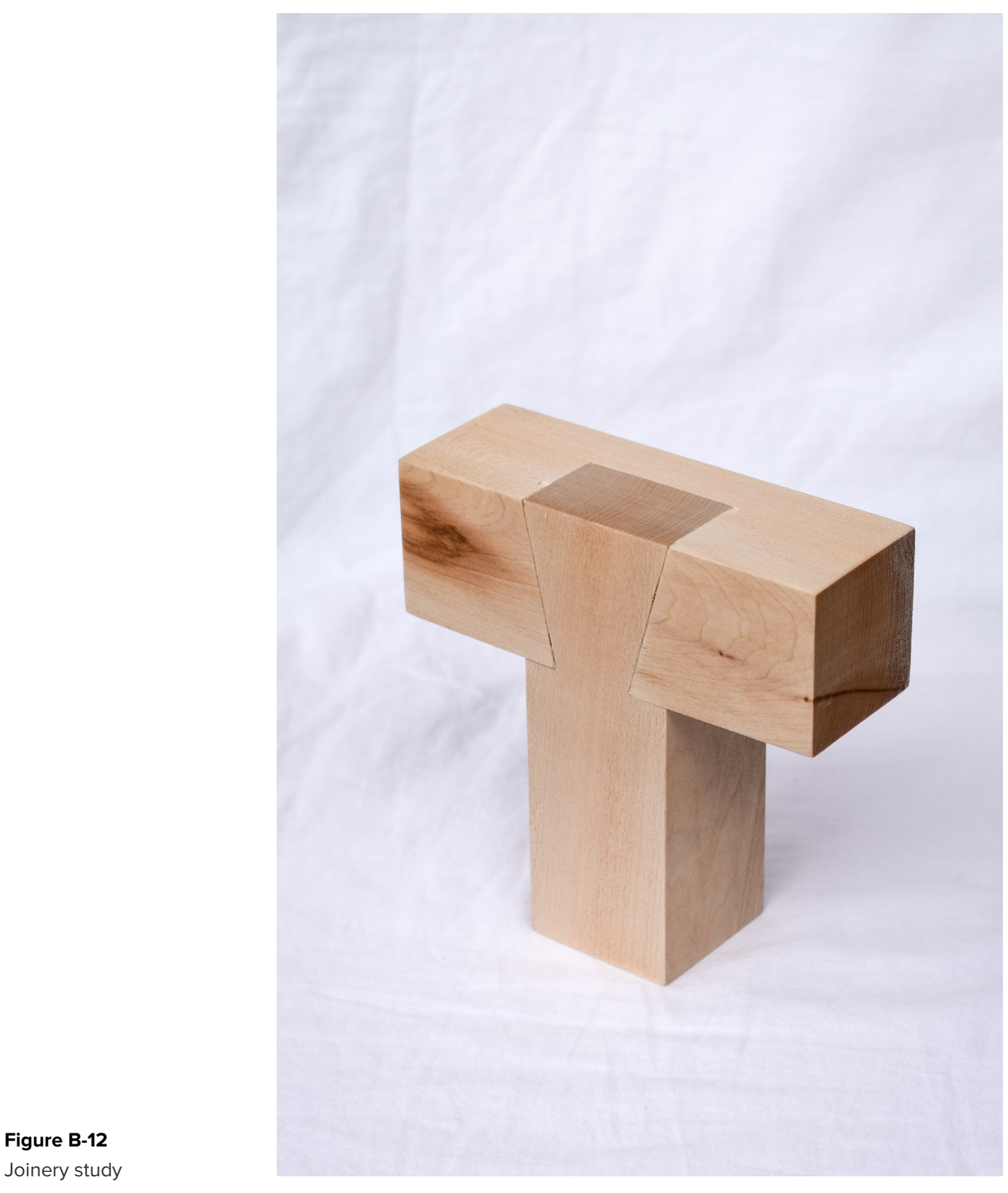





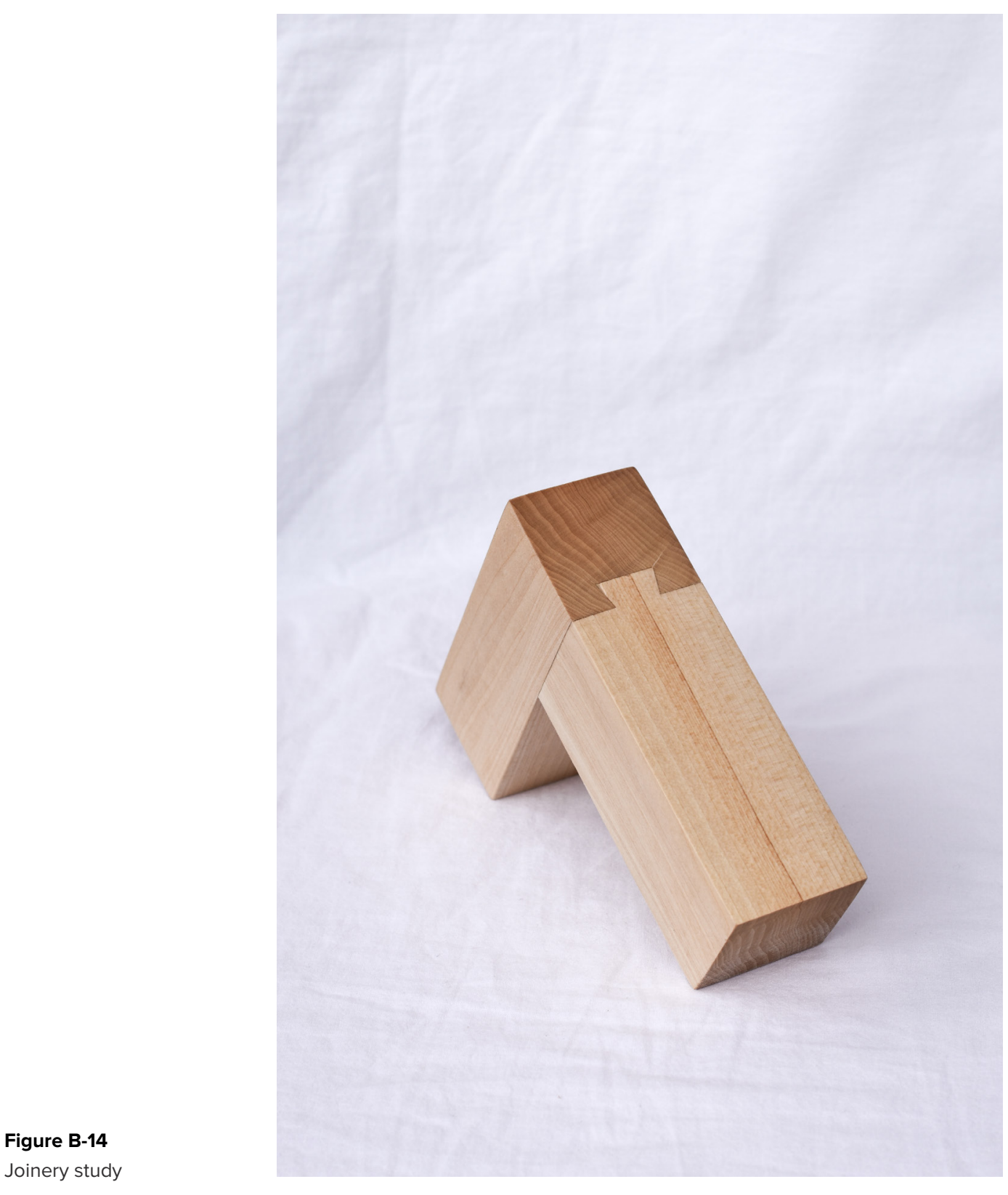




\section{Figure B-15}

Joinery study

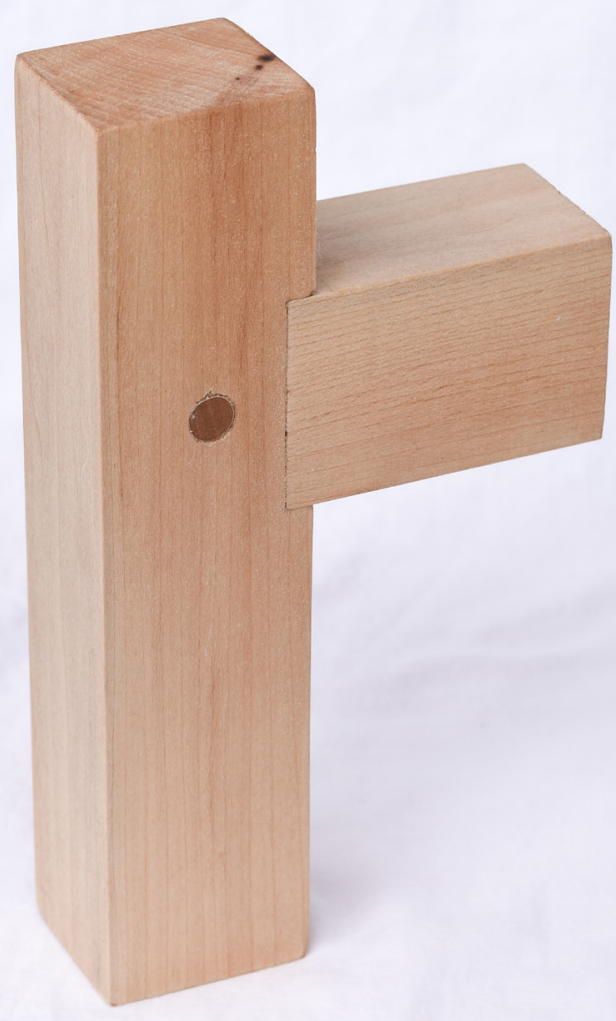




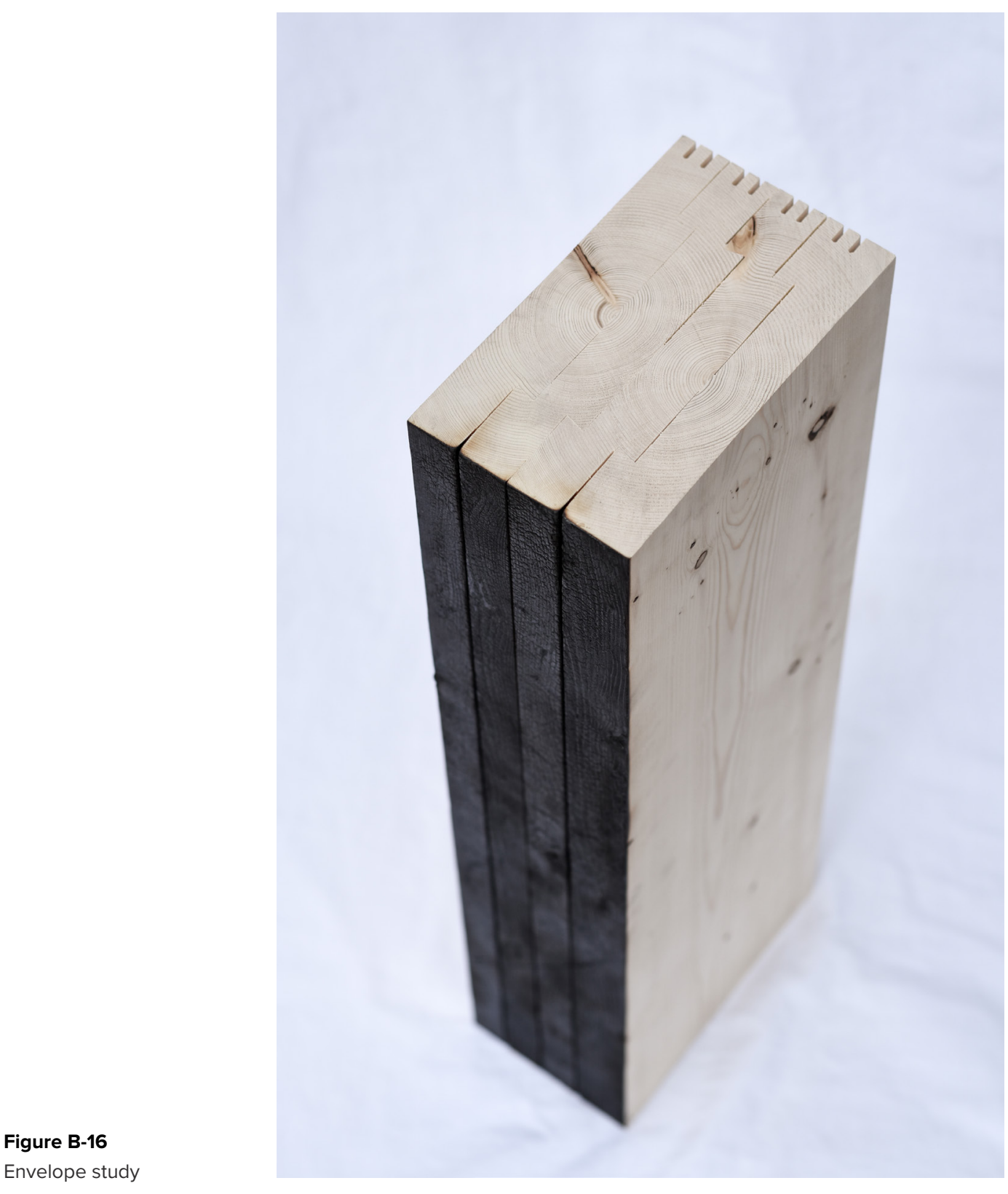




\section{BIBLIOGRAPHY}

Acoustic Performance. n.d. https://goo.gl/Ddm1wr (accessed November 2018).

Aghaei Meibodi, Mania. Generative Design Exploration: Computation and Material Practice. Doctoral Thesis, Stockholm: KTH Royal Institute of Technology, 2016.

AITC. Timber Construction Manual. Hoboken: John Wiley \& Sons, Inc, 2012.

Barker, Oliver. Experimentation, Not Replication. n.d. https://goo.gl/rHmNwB.

DeLanda, Manuel. “The New Materiality.” Architectural Design 85, no. 5 (2015): 16-21.

DeLanda, Manuel. Uniformity and Variation: An Essay in the Philosophy of Matter. 2006.

Deleuze, Gilles, Felix Guattari, and Brian Massumi. A Thousand Plateaus: Capitalism and Schizophrenia. University of Minnesota Press, 1987.

Dickson, Michael, and Dave Parker. Sustainable Timber Design. London \& New York: Routledge, 2015.

“Dowel Laminated Timber Design Guide \& Profile Handbook." StructureCraft. March 2018. https://goo.gl/ e8XgFH (accessed November 2018).

Fathy, Hassan. Natural Energy and Vernacular Architecture: Principles and Examples with Reference to Hot Arid Climates. Chicago: University of Chicago Press, 1986.

Giedion, Sigfried. Mechanization Takes Command. Minnesota: University Of Minnesota Press, 1948.

Green, Michael, and Jim Taggart. Tall Wood Buildings: Design, Construction and Performance. Basel: Birkhäuser, 2017.

Hensel, Michael. Performance-oriented architecture: Rethinking architectural design and the built environment. Wiley, 2013.

Hoadley, R. Bruce. Understanding Wood: A Craftsman's Guide to Wood Technology. Newtown: Taunton Press, 1980.

Holstov, Artem, Ben Bridgens, and Graham Farmer. "Hygromorphic materials for sustainable responsive architecture." Construction and Building Materials 98 (2015): 570-582.

Holstov, Artem, Graham Farmer, and Ben Bridgens. "Sustainable Materialisation of Responsive Architecture." Sustainability 9, no. 3 (2017).

Ikei, Harumi, Chorong Song, and Yoshifumi Miyazaki. "Physiological Effects of Wood on Humans: A Review." Journal of Wood Science 63, no. 1 (2017): 1-23.

IPCC. IPCC Fourth Assessment Report: Climate Change. 2007.

Kettunen, Pentti. Wood: Structure and Properties. Zurich: Trans Tech Publications, Ltd., 2006.

Kim, Yoon Soo, Ryo Funada, and Adya P Singh. Secondary Xylem Biology: Origins, Functions, and Applications. Cambridge: Academic Press, 2016.

Kolarevic, Branko. "Actualising (overlooked) material capacities." Architectural Design 85, no. 5 (2015): 128133. 
Kolarevic, Branko, and Vera Parlac. Building dynamics: Exploring architecture of change. Routledge, Taylor\& Francis Group, 2015.

Kolb, Josef. Systems in timber engineering: Loadbearing structures and component layers. Basel: Birkhäuser, 2008.

Koren, Leonard. Undesigning the Bath. Berkeley: Stone Bridge Press, 1996.

Krieg, Oliver David. "HygroSkin - Meteorosensitive Pavilion." In Advancing Wood Architecture: A Computational Approach, edited by Achim Menges, Tobias Schwinn and Oliver David Krieg, 125-136. London: Routledge Taylor \& Francis Group, 2017.

Künzel, Hartwig M, Andreas Holm, Klaus Sedlbauer, Florian Antretter, and M Ellinger. "Moisture Buffering Effects of Interior Linings Made from Wood or Wood Based Products." IBP Report, 2004.

Laboratory, Building News Inc. \& Forest Products. Wood Engineering Handbook (2nd Edition). BNI Publications Inc, 2000.

Leach, Neil. "Matter Matters: A Philisophical Preface." In Active Matter, edited by Skylar Tibbits, 18-23. Cambridge: The MIT Press, 2017.

Leach, Neil. "New Materialism in Architecture." In De-signing Design: Cartographies of Theory and Practice, edited by Elizabeth Grierson, Harriet Edquist and Hélène Frichot, 213-214. Lanham: Lexington Books, 2016.

Menges, Achim. "Computational material culture." Architectural Design 86, no. 2 (2016): 76-83.

Menges, Achim. "Fusing the computational and the physical: Towards a novel material culture." Architectural Design 85, no. 5 (2015): 8-15.

Menges, Achim. "Material computation: Higher integration in morphogenetic design." Architectural Design 82, no. 2 (2012): 14-21.

Menges, Achim. "Material Resourcefulness: Activating Material Information in Computational Design." Architectural Design 82, no. 2 (2012): 34-43.

Menges, Achim, and Steffen Reichert. "Material capacity: Embedded responsiveness." Architectural Design 82, no. 2 (2012): 52-59.

Menges, Achim, Tobias Schwinn, and Oliver David Krieg, . Advancing Wood Architecture: A Computational Approach. London: Routledge, Taylor \& Francis Group, 2017.

Miller, Hugh. “Japanese Wood Craftsmanship.” Hugh Miller Furniture. 2016. https://goo.gl/XnWutZ (accessed November 2018).

Negroponte, Nicholas. Soft Architecture Machines. Cambridge: MIT Press, 1975.

Osanyintola, F Olalekan, and J Carey Simonson. "Moisture buffering capacity of hygroscopic building materials: Experimental facilities and energy impact." Energy and Buildings 38, no. 10 (2006): 1270-1282.

Oxman, Neri. "Material-based design computation." Doctoral dissertation, Department of Architecture, Massachusetts Institute of Technology, 2010.

Pask, Gordon. “Architectural Relevance of Cybernetics.” Architectural Design, no. 7/6 (1969): 494-496. 
Peck, Edward. Bending Solid Wood to Form. Washington, D.C.: USDA Forest Service, 1957.

Plato. Cratylus. n.d.

Reichert, Steffen, Achim Menges, and David Correa. "Meteorosensitive architecture: Biomimetic building skins based on materially embedded and hygroscopically enabled responsiveness." Computer-Aided Design 60 (2015): 50-69.

Rüggeberg, Markus, and Ingo Burgert. "Bio-inspired wooden actuators for large scale applications." PloS One 10, no. 3 (2015): 1-16.

Sung, Doris. "Smart geometries for smart materials: Taming thermobimetals to behave." Journal of Architectural Education 70, no. 1 (2016b): 96-106.

Taggart, Jim. Toward a culture of wood architecture. Abacus Editions, 2011.

Tibbits, Skylar. Active Matter. Cambridge: The MIT Press, 2017.

Timoshenko, Stephen. “Analysis of bi-metal thermostats." JOSA 11, no. 3 (1925): 233-255.

Urban Strategies Inc. “Villiers Island Precint Plan.” Planning Report, Toronto, 2017.

Vailati, Chiara, Philipp Hass, Ingo Burgert, and Markus Rüggeberg. "Upscaling of wood bilayers: Design principles for controlling shape change and increasing moisture change rate." Materials and Structures 50, no. 6 (2017): 1-12.

Waterfront Toronto. History of the Port Lands. n.d. https://goo.gl/Rk7yyp (accessed January 2019).

-. Project Timeline. n.d. https://goo.gl/nw4jcf (accessed January 2019).

Winstanley, Tim. AD Classics: Institut du Monde Arabe. October 2, 2011. https://goo.gl/VpPriF (accessed November 2018).

Withers, Jane. Curator's Essay by Jane Withers. 2016. https://bit.ly/2LISvRz.

Wood Odour. n.d. https://goo.gl/uu1msR (accessed November 2018).

Wood, Dylan M, David Correa, Oliver David Krieg, and Achim Menges. "Material computation-4D timber construction: Towards building-scale hygroscopic actuated, self-constructing timber surfaces." International Journal of Architectural Computing 14, no. 1 (2016): 49-62.

Wright, Frank Lloyd. "In the Cause of Architecture: Wood." Architectural Record, 1928.

Zumthor, Peter. Thinking Architecture. Basel: Birkhauser, 1998. 